
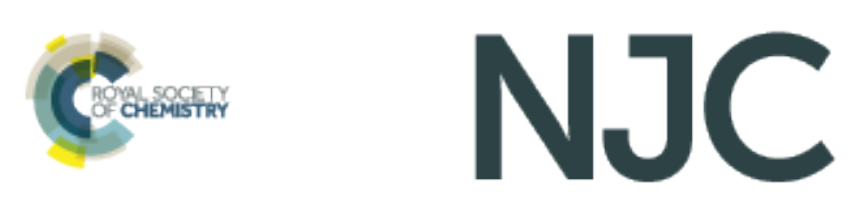

\title{
Type of Complex - BSA Binding Forces Affected by Different Coordination Modes of Alliin in Novel Water-Soluble Ruthenium Complexes
}

\begin{tabular}{|c|c|}
\hline Journal: & New Journal of Chemistry \\
\hline Manuscript ID & NJ-ART-02-2019-000826 \\
\hline Article Type: & Paper \\
\hline $\begin{array}{r}\text { Date Submitted by the } \\
\text { Author: }\end{array}$ & 15-Feb-2019 \\
\hline Complete List of Authors: & $\begin{array}{l}\text { Zahirovic, Adnan; University of Sarajevo Faculty of Science, Chemistry } \\
\text { Žilić, Dijana; Rudjer Boskovic Institute, Department of Physical } \\
\text { Chemistry } \\
\text { Kraljević Pavelić, Sandra; Department of biotehnology, } \\
\text { Hukić, Mirsada; Institute for Biomedical Research and Diagnostics Nalaz } \\
\text { Muratović, Senada; Rudjer Boskovic Institute, Department of Physical } \\
\text { Chemistry } \\
\text { Harej, Anja; Department of biotehnology } \\
\text { Kahrović, Emira; University of Sarajevo Faculty of Science, Chemistry }\end{array}$ \\
\hline
\end{tabular}




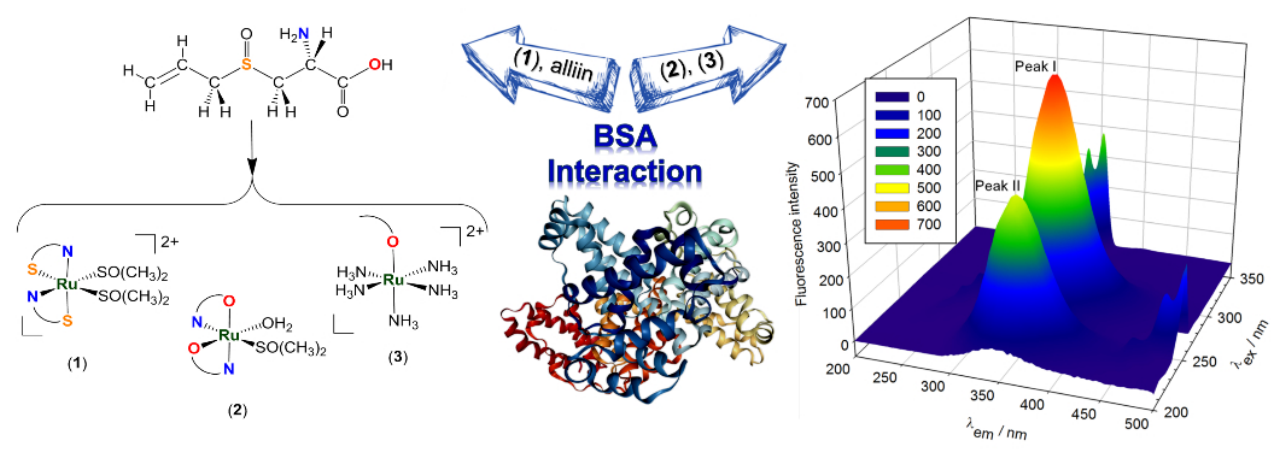

$381 \times 152 \mathrm{~mm}(72 \times 72$ DPI $)$ 


\section{Type of Complex - BSA Binding Forces Affected by Different Coordination Modes of Alliin in Novel Water-Soluble Ruthenium Complexes}

Adnan Zahirović, ${ }^{1}$ Dijana Žilić, ${ }^{2}$ Sandra Kraljević Pavelić, ${ }^{3}$ Mirsada Hukić, ${ }^{4}$ Senada Muratović, ${ }^{2}$ Anja Harej ${ }^{3}$ and Emira Kahrović ${ }^{1 *}$

${ }^{1}$ Department of Chemistry, Faculty of Science, University of Sarajevo, Sarajevo, Bosnia and Herzegovina

${ }^{2}$ Ruđer Bošković Institute, Zagreb, Croatia

${ }^{3}$ Department of Biotechnology, Centre for High-Throughput Technologies, University of Rijeka, Rijeka, Croatia

${ }^{4}$ Institute for Biomedical Research and Diagnostics Nalaz, Sarajevo, Bosnia and Herzegovina

*Corresponding author:

Prof. dr. Emira Kahrović

University of Sarajevo

Faculty of Science

Department of Chemistry

Zmaja od Bosne 35

71000 Sarajevo

Bosnia and Herzegovina

E-mail: emira_kahrovic@yahoo.com

Tel: +38733279910 


\begin{abstract}
Three novel water-soluble ruthenium complexes having differently bound alliin ligand were prepared by solution synthesis and characterized by chemical analysis, infrared, mass, nuclear magnetic resonance and electron paramagnetic resonance spectroscopies. The reaction of (de)protonated alliin with $c i s, f a c-\left[\mathrm{RuCl}_{2}(\mathrm{dmso}-S)_{3}(\mathrm{dmso}-O)\right]$ in the presence of silver triflate afforded cationic $\left[\mathrm{Ru}^{\mathrm{II}}(\mathrm{dmso}-S)_{2}(\text { alliin- } N S)_{2}\right]^{2+}(\mathbf{1})$ and neutral $\left[\mathrm{Ru}^{\mathrm{II}}(\mathrm{dmso}-S)\left(\mathrm{OH}_{2}\right)\right.$ (alliin$\left.N O)_{2}\right](2)$, while $\left[\mathrm{Ru}^{\mathrm{III}}\left(\mathrm{NH}_{3}\right)_{5}(\text { alliin- } O)\right]^{2+}(3)$ was prepared starting from $\left[\mathrm{RuCl}\left(\mathrm{NH}_{3}\right)_{5}\right] \mathrm{Cl}_{2}$. The interaction of the complexes with bovine serum albumin and apo-transferrin was investigated by spectrofluorimetry. Complexes showed higher affinity toward BSA compared to apo-transferrin. Deeper insight into the nature of the binding forces between the complexes and BSA was provided from the thermodynamic measurements, synchronous and 3D emission spectra. Different coordination modes of alliin in complexes (1) - (3) affect the type of the binding forces between the complexes and BSA. Complexes having $O$-bound alliin, (2) and (3), predominantly interact with the BSA through hydrogen bonding and van der Walls interactions, while the hydrophobic forces govern the interaction of (1) with BSA. In vitro antiproliferative and antimicrobial activity of the complexes and alliin was also tested.
\end{abstract}

Key words: ruthenium, alliin, S-Allyl-L-cysteine sulfoxide, coordination modes, BSA. 


\section{Introduction}

Solutions to the challenges posed to inorganic chemists by modern scientific era are often sought in the chemistry of coordination compounds. The predictability of the properties grounded on the chemical portrait of compounds, coupled with the very wide variety of metal centers, donor atoms and versatile stereochemistry of ligands represent an enormous potential in designing the exceedingly specific and highly active coordination compounds toward predefined target or chemo-physical process. In light of this, coordination chemistry offered brilliant solutions in fields ranging from catalysis to medical applications.

Platinum group metals, especially platinum and very attractive alternative ruthenium, are the most extensively studied due to their potential therapeutic applications in treatment of the malignant diseases. ${ }^{1-4}$ Due to the empirically established fact that the coordination of organic molecules to metal ions regularly results in improved activity of the metal complexes, very commonly immanently biologically active ligands are the choice for the coordination to the metal ions in designing the new metal-based therapeutics. ${ }^{5-11}$ A very tempting option is alliin.

Alliin, namely S-Allyl-L-cysteine sulfoxide, is an unsaturated cysteine-derived amino acid naturally occurring in garlic bulbs. ${ }^{12}$ Many health-beneficial properties of garlic are attributed to alliin and allicin, a highly active thiosulfinate compound that is produced by alliinasemediated alliin decomposition. ${ }^{13}$ Allicin is relatively unusable compound and any therapeutic use of allicin should include its generation in situ from more stable alliin. Production rate of allicin and the kinetic control of its release at targeted place could be controlled by complexation. Additionally, alliin's water-solubility, biological recognizability along with predispositions for strong biological activity coupled with diversity of coordination properties inspired the synthesis of palladium(II) ${ }^{14}$ and platinum(II) ${ }^{15}$ complexes. Also, complexes of deoxyalliin and other alliin-like ligands were prepared. ${ }^{16-21}$

As stereochemically flexible ligand, having several potentially donor- atoms, including nitrogen, sulfur and oxygen, alliin can coordinate metal ions in different fashions as mono, bi and tridentate neutral or monobasic ligand. The different coordination modes of the ligand affect chemical and physical properties of corresponding complex. ${ }^{22-25}$ This opens the possibility for controlling the properties of complexes with alliin including those relevant for biological application such as inertness-lability, water-solubility, lipophilicity, charge etc. 
Important targets of alliin - metal complexes might be proteins, the most abundant bimolecular targets in blood. Their importance is a reflection of the fact that alliin is absorbed directly to blood ${ }^{26}$ and that the action mode of allicin is related to $S$-containing proteins. ${ }^{27}$ Also, many biologically active ruthenium complexes bind proteins. ${ }^{28-30}$

Inspired by the above mentioned facts, we prepared and characterized three new heteroleptic water-soluble ruthenium - alliin complexes emphasizing the different coordination abilities of alliin. Also, we investigated their interaction with apo-transferrin and bovine serum albumin and tested their in vitro antiproliferative and antimicrobial activity.

\section{Experimental}

\subsection{Chemicals}

All chemicals were supplied from commercial sources and used as received without further purification unless otherwise indicated. L-Cysteine (p.a.) was obtained from Sigma and allyl bromide from Merck and it was distilled twice prior the use. Cis, fac- $\left[\mathrm{RuCl}_{2}(\mathrm{dmso}-S)_{4}(\mathrm{dmso}-\right.$ $O)]$ and $\left[\mathrm{Ru}\left(\mathrm{NH}_{3}\right)_{5} \mathrm{Cl}\right] \mathrm{Cl}_{2}$ were prepared by published procedures. ${ }^{31,32}$ Lyophilized powder of bovine serum albumin $(\geq 96 \%)$ and human apo-transferrin $(\geq 97 \%)$ were purchased from Sigma.

\subsection{Physical measurements}

Elemental analysis was carried out using Perkin Elmer 2400 Series CHNS/O analyzer. Ruthenium content was determined by published procedure. ${ }^{33}$ Mass spectra were recorded using 4800 Plus MALDI TOF/TOF analyzer in the positive ion reflector mode in $10-2000$ Da region using $\alpha$-cyano-4-hydroxycinnamic acid matrix. ${ }^{1} \mathrm{H}$ and ${ }^{13} \mathrm{C}$ NMR spectra were collected using NMR Bruker Avance 600 instrument from $\mathrm{D}_{2} \mathrm{O}$ or $\mathrm{MeOH}-d_{4}$ solution at 600 and $150 \mathrm{MHz}$, respectively using $\mathrm{Me}_{4} \mathrm{Si}$ as internal standard. Infrared spectra were recorded in $4000-400 \mathrm{~cm}^{-1}$ region as $\mathrm{KBr}$ pallets using Perkin Elmer BX FTIR. Fluorescence measurements were done using Perkin Elmer LS 55 Luminescence. The X-band ESR measurements have been performed on a Bruker Elexsys $580 \mathrm{FT} / \mathrm{CW}$ spectrometer in the range from liquid nitrogen to room temperature. The microwave frequency was around 9.7 $\mathrm{GHz}$, the magnetic field modulation amplitude $0.5 \mathrm{mT}$ and the modulation frequency 100 $\mathrm{kHz}$. 


\subsection{Interaction with proteins}

Interaction with proteins was carried out in $10 \mathrm{mM}$ Tris- $\mathrm{HCl}$ buffer solution at $\mathrm{pH}$ 7.42. In the case of apo-transferrin, solution additionally contained $25 \mathrm{mM} \mathrm{NaHCO}_{3}$. Stock solutions of proteins $(\sim 1 \mu \mathrm{M})$ were prepared prior measurements and were not used longer than 2 days. Protein concentrations were determined spectrophotometrically using extinction coefficient of $43824 \mathrm{M}^{-1} \mathrm{~cm}^{-1}$ for BSA and $83800 \mathrm{M}^{-1} \mathrm{~cm}^{-1}$ for apo-transferrin. Stock solutions of complexes and alliin $(\sim 0.4 \mathrm{mM})$ were prepared in water.

Titration experiments were carried out at controlled temperature $\left( \pm 0.1^{\circ} \mathrm{C}\right)$ by adding the microliters amounts $(10-60 \mu \mathrm{L})$ of stock solution of complex to protein solution $(2.000 \mathrm{~mL})$ with equilibration time of 2 minutes.

Emission spectra were recorded in 290 - $420 \mathrm{~nm}$ range for BSA and $300-400 \mathrm{~nm}$ range for apo-transferrin with excitation wavelength at $278 \mathrm{~nm}$ in both cases. Synchronous fluorescence spectra of BSA in the absence and presence of an increasing concentrations of complexes were recorded in $250-310 \mathrm{~nm}$ range at $\Delta \lambda=15 \mathrm{~nm}$ and $\Delta \lambda=60 \mathrm{~nm}$. Three-dimensional fluorescence spectra were recorded in $200-500 \mathrm{~nm}$ emission range with $200-350 \mathrm{~nm}$ excitation range.

\subsection{In vitro biological activity}

Antiproliferative activities of complexes and ligand were tested at several cell lines including HeLa (cervical carcinoma), SW620 (colorectal adenocarcinoma, metastatic), MCF-7 (breast adenocarcinoma), CFPAC-1 (ductal pancreatic adenocarcinoma) and HFF-1 (foreskin fibroblasts). The cell growth rate was evaluated by performing the MTT assay. ${ }^{34}$ The $\mathrm{IC}_{50}$ values for each compound were calculated from dose-response curves using linear regression analysis. More details is given in Supplement.

Antimicrobial activity was tested on Gram-positive bacteria Staphylococcus aureus, Gramnegative bacteria Pseudomonas aeruginosa, Escherichia coli and fungi Candida albicans. The diameter of the inhibition zone of bacterial growth was measured after applying an aliquot $(50 \mu \mathrm{L})$ of aqueous solution of the tested agent $\left(2 \mathrm{mg} \mathrm{mL}^{-1}\right)$ into the drilled wells and incubating it for $24 \mathrm{~h}$ at $37^{\circ} \mathrm{C}$. Vancomycin, gentamicin, and nystatin were used as positive controls and water as negative control. 


\subsection{Synthesis}

\subsubsection{Synthesis of ligand}

L-Deoxyalliin and $( \pm)$-L-Alliin were prepared by reported procedures with slight modifications. ${ }^{35-37}$

\section{Synthesis of L-Deoxyalliin (S-Allyl-L-cysteine)}

Ethanol-water mixture $(240 \mathrm{~mL} ; 5 / 1, \mathrm{v} / \mathrm{v})$ was placed in a $500 \mathrm{~mL}$ Erlenmeyer flask equipped with gas purging inlet and magnetic stir bar. Potassium hydroxide (18.52 g; $0.33 \mathrm{~mol}$ ) was dissolved in ethanol-water mixture after which a clear solution was deaerated by purging the argon gas. To thus obtained solution L-cysteine (20 g; $0.165 \mathrm{~mol})$ was added portion wise and the mixture was stirred until complete dissolution, after witch allyl bromide (19.96 g; 0.165 mol) was added drop wise. A clear solution was stirred at ambient temperature for next 24 hours after which was acidified by glacial acetic acid to $\mathrm{pH}$ 5.5. A white powder of Ldeoxyalliin was filtered through fritted glass funnel B4, washed with ice-cold ethanol $(40 \mathrm{~mL})$ and dried under reduced pressure. Yield: $20.33 \mathrm{~g}(76 \%)$.

\section{Synthesis of ( \pm )-L-Alliin (S-Allyl-L-cysteine sulfoxide) - HL}

The suspension of deoxyalliin $(6.00 \mathrm{~g}$; $0.037 \mathrm{~mol})$ in water $(40 \mathrm{~mL})$ was magnetically stirred at room temperature for one hour after which hydrogen peroxide $(30 \% \mathrm{w} / \mathrm{v}, 4.22 \mathrm{~g} ; 0.037$ mol) was added drop wise within one hour. The ivory white suspension was stirred for 24 hours at room temperature, after which the volume was reduced by vacuum distillation up to $20 \mathrm{~mL}$. The solution was acidified with few drops of acetic acid and poured to a vigorously stirred acetone $(200 \mathrm{~mL})$. The white bulky product was filtered through fritted glass funnel B2, thoroughly washed with acetone and vacuum dried. Purification was carried out from saturated aqueous solution by addition of acetone. Yield: $4.42 \mathrm{~g}(64 \%)$.

\subsubsection{Synthesis of complexes}

Synthesis of complex $\left[\mathrm{Ru}^{\mathrm{II}}(\mathrm{DMSO}-\mathrm{S})_{2}(\mathrm{HL}-\mathrm{NS})_{2}\right](\mathrm{OTf})_{2}(\mathbf{1})$

To methanol solution (10 mL) of cis-dichloridotetrakis(dimethylsulfoxide)ruthenium(II) (100 $\mathrm{mg}$; $0.206 \mathrm{mmol})$ silver triflate $(106 \mathrm{mg} ; 0.413 \mathrm{mmol})$ dissolved in methanol $(10 \mathrm{~mL})$ was added and the resulting mixture was magnetically stirred for an hour at reflux temperature. 
After cooling to room temperature silver chloride was filtered off. Alliin (77 mg; $0.413 \mathrm{mmol}$ ) was added to the yellow filtrate and resulting mixture was refluxed for five hours changing its color to light brown. After cooling to room temperature reaction mixture was filtered through blue ribbon and yellow filtrate was evaporated till dryness. Thus obtained orange-yellow gluey mass was dissolved in acetone $(10 \mathrm{~mL})$, filtered and product $(\mathbf{1})$ was precipitated by slow addition of diisopropyl ether $(25 \mathrm{~mL})$. The bulky yellow precipitate was filtered off, washed with diethyl ether $(10 \mathrm{~mL})$ and recrystallized from acetone - diisopropyl ether mixture $(1 / 1, \mathrm{v} / \mathrm{v})$.

Bis(2-amino- $\kappa N-3-[(S)$-prop-2-enylsulfinyl- $\kappa S]$ propanoic acid)bis(dimethylsulfoxide- $\kappa S$ ) ruthenium(II) trifluoromethanesulfonate (1). Yield: $50 \mathrm{mg}$ (27\%). Anal. Calc. (\%) for $\mathrm{C}_{18} \mathrm{H}_{34} \mathrm{~F}_{6} \mathrm{~N}_{2} \mathrm{O}_{14} \mathrm{RuS}_{6}\left(M_{\mathrm{r}}=909.92\right): \mathrm{C}, 23.76 ; \mathrm{H}, 3.77 ; \mathrm{N}, 3.08 ; \mathrm{Ru}, 11.11$; Found (\%): $\mathrm{C}$, 23.56; H, 3.67; N, 3.59; Ru, 11.01. IR (KBr) $v\left(\mathrm{~cm}^{-1}\right)$, intensity: $1738 \mathrm{~m} v_{\mathrm{s}}(\mathrm{COOH}), 1640 \mathrm{~s}$ $v_{\mathrm{s}}(\mathrm{C}=\mathrm{C}), 1565 \mathrm{~m} \delta\left(\mathrm{NH}_{2}\right), 1404,1386 \mathrm{w} \delta\left(\mathrm{CH}_{3}\right), 1277 \mathrm{~s} v_{\mathrm{a}}(\mathrm{S}=\mathrm{O}), 1089,1032 \mathrm{~m} \mathrm{v} v_{\mathrm{a}}(\mathrm{S}-\mathrm{O}), 948$ W $v_{s}(C-N)$. HR MALDI-TOF/TOF MS for $\mathrm{C}_{16} \mathrm{H}_{34} \mathrm{~N}_{2} \mathrm{O}_{8} \mathrm{RuS}_{4}$ Found (Calc.): 612.0247 (612.0260) $[\mathrm{M}]^{+} .{ }^{1} \mathrm{H}$ NMR (600 MHz, Methanol- $\left.d_{4}\right) \delta /$ ppm: 5.98 - 5.91 (m, H5), 5.71 - 5.66 (m, H5, 2 H6a), 5.53 - 5.48 (m, 2 H6b), 3.84 - 3.78 (m, H4a), 3.73 - 3.68 (m, H4a, H4b), 3.63 - 3.58 (m, H4b), 3.43 - 3.34 (m, $9 H(\mathrm{DMSO}-S)$ ), 3.24 - 3.19 (m, $4 H 3), 3.02$ - 2.94 (m, $H 2), 2.91-2.84(\mathrm{~m}, H 2), 2.66$ (s, $3 H(\mathrm{DMSO})) .{ }^{13} \mathrm{C} \mathrm{NMR}(151 \mathrm{MHz}, \mathrm{MeOD}) \delta / \mathrm{ppm}$ : 168.36 (s, C1), 125.11 (s, C5), 123.95 (s, C6), 120.33 (q, $J=318.4 \mathrm{~Hz}, C \mathrm{~F}_{3} \mathrm{SO}_{3}$ ), 57.61 (s, C3), 55.76 (s, C4), 55,23 (s, C2), 47.62 (hept, $J=42.8,21.4 \mathrm{~Hz}, C$-DMSO).

Synthesis of $\left[\mathrm{Ru}^{\mathrm{II}}(\mathrm{DMSO}-\mathrm{S})\left(\mathrm{H}_{2} \mathrm{O}\right)(\mathrm{L}-\mathrm{NO})_{2}\right] \times 3 \mathrm{H}_{2} \mathrm{O}(\mathbf{2})$

Acetone solution $(10 \mathrm{~mL})$ of silver triflate $(106 \mathrm{mg} ; 0.413 \mathrm{mmol})$ was added to a stirred solution of cis-dichloridotetrakis(dimethylsulfoxide)ruthenium(II) (100 mg; $0.206 \mathrm{mmol}$ ) in acetone $(15 \mathrm{~mL})$ and the resulting mixture was refluxed for two hours, cooled to room temperature and silver chloride was filtered off. The yellow filtrate was mixed with earlier prepared well-stirred methanol $(25 \mathrm{~mL})$ solution of alliin $(77 \mathrm{mg} ; 0.413 \mathrm{mmol})$ deprotonated by aqueous potassium hydroxide $(23 \mathrm{mg} ; 0.413 \mathrm{mmol}$ in $0.10 \mathrm{~mL}$ ) and the mixture was refluxed for two hours changing its color to light brown. After standing overnight at ambient temperature reaction mixture was filtered through blue ribbon. The volume of the yellow brown filtrate was reduced to $5 \mathrm{~mL}$ under vacuum and diisopropyl ether $(15 \mathrm{~mL})$ was added drop wise. The light brown substance was filtered off, washed with acetone $(5 \mathrm{~mL})$ and 
vacuum dried. Recrystallization was carried out from dimethylsulfoxide-water mixture $(2 \mathrm{~mL}$, $1 / 1, \mathrm{v} / \mathrm{v})$ by slow addition of the acetone $(5 \mathrm{~mL})$.

bis(2-amino- $\kappa N-3-[(S)$-prop-2-enylsulfinyl]propanoato- $\kappa O)$ (aqua )(dimethylsulfoxide- $\kappa S)$ ruthenium(II) trihydrate (3). Yield: $60 \mathrm{mg}(48 \%)$. Anal. Calc. (\%) for $\mathrm{C}_{14} \mathrm{H}_{34} \mathrm{~N}_{2} \mathrm{O}_{11} \mathrm{RuS}_{3}\left(M_{\mathrm{r}}=\right.$ 603.69): C, 27.85; H, 5.68; N, 4.64; Ru, 16.74; Found (\%): C, 27.62; H, 4.49; N, 4.38; Ru, 16.41. IR ( $\mathrm{KBr}) v\left(\mathrm{~cm}^{-1}\right)$, intensity: $1632 \mathrm{~s} \mathrm{v}$ as $\left(\mathrm{COO}^{-}\right)+v_{\mathrm{s}}(\mathrm{C}=\mathrm{C}), 1585 \mathrm{~m} \delta\left(\mathrm{NH}_{2}\right), 1405,1383 \mathrm{w}$ $\delta\left(\mathrm{CH}_{3}\right), 1072,1021 \mathrm{~m} v_{\mathrm{a}}(\mathrm{S}-\mathrm{O}), 943 \mathrm{~m} v_{\mathrm{s}}(\mathrm{C}-\mathrm{N})$. HR MALDI-TOF/TOF MS for $\mathrm{C}_{14} \mathrm{H}_{30} \mathrm{~N}_{2} \mathrm{O}_{8} \mathrm{RuS}_{3}$ Found (Calc.): 553.1760 (553.0300) [M+H] ${ }^{+} .{ }^{1} \mathrm{H}$ NMR (600 MHz, Methanol- $\left.d_{4}\right) \delta$ / ppm: 6.05 - 5.91 (m, H5), 5.72 - 5.65 (m, H5), 5.62 - 5.41 (m, 4 H6a,b), $4.27-4.11$ (m, $2 \mathrm{H} 4 \mathrm{a}), 4.10$ - 3.94 (m, $2 \mathrm{H} 4 \mathrm{~b}), 3.78$ (s, $4 \mathrm{H}\left(\mathrm{N} H_{2}\right)$ ), 3.52 - 3.33 (m, 6 $H(\mathrm{DMSO}-\mathrm{S})$ ), 3.32 - 3.17 (m, 4 H3a,b), 2.68 (s, 1 H(DMSO)), 2.60 - 2.10 (m, $2 H 2$ ).

Synthesis of $\left[\mathrm{Ru}^{\mathrm{III}}\left(\mathrm{NH}_{3}\right)_{5}(\mathrm{~L}-\mathrm{O})\right](\mathrm{OTf})_{2}(\mathbf{3})$

Aqueous solution $(10 \mathrm{~mL})$ of silver triflate $(351 \mathrm{mg} ; 1.367 \mathrm{mmol})$ was added to a suspension of pentamminechloridoruthenium(III) chloride $(200 \mathrm{mg} ; 0.684 \mathrm{mmol})$ in water $(10 \mathrm{~mL})$ and the resulting mixture was magnetically stirred for half an hour after which silver chloride was filtered off. An aqueous solution $(30 \mathrm{~mL})$ of alliin $(127 \mathrm{mg} ; 0.684 \mathrm{mmol})$ deprotonated by potassium hydroxide (38 $\mathrm{mg} ; 0.684 \mathrm{mmol}$ ) was added to the filtrate. The mixture was magnetically stirred and heated in open air flask at $65^{\circ} \mathrm{C}$ for ten hours with concomitant reduction of the volume to $5 \mathrm{~mL}$ changing its color over cyclamen red to brown. Methanol (20 $\mathrm{mL}$ ) was added to the brown solution and mixture was kept in ice for an hour to complete precipitation, after which black substance was filtered off, washed with methanol $(5 \mathrm{~mL})$ and dried under vacuum.

Pentaammine(2-amino-3-[(S)-prop-2-enylsulfinyl]propanoato- $\kappa O)$ ruthenium(III) trifluoromethanesulfonate (3). Yield: $119 \mathrm{mg}$ (26\%). Anal. Calc. (\%) for $\mathrm{C}_{8} \mathrm{H}_{25} \mathrm{~F}_{6} \mathrm{~N}_{6} \mathrm{O}_{9} \mathrm{RuS}_{3}$ $\left(M_{\mathrm{r}}=660.58\right): \mathrm{C}, 14.55 ; \mathrm{H}, 3.81 ; \mathrm{N}, 12.72 ; \mathrm{Ru}, 15.30 ;$ Found $(\%): \mathrm{C}, 14.72 ; \mathrm{H}, 4.27 ; \mathrm{N}$, 12.05; $\mathrm{Ru}, 15.25$. IR ( $\mathrm{KBr}) v\left(\mathrm{~cm}^{-1}\right)$, intensity: $1629 \mathrm{vb} \mathrm{s} v_{\mathrm{as}}\left(\mathrm{COO}^{-}\right)+v_{\mathrm{s}}(\mathrm{C}=\mathrm{C})+\delta_{\mathrm{d}}\left(\mathrm{NH}_{3}\right), 1387$ $v_{\mathrm{s}}\left(\mathrm{COO}^{-}\right), 1287 \mathrm{~m}_{\mathrm{d}}\left(\mathrm{NH}_{3}\right), 1279 \mathrm{~s} v_{\mathrm{a}}(\mathrm{S}=\mathrm{O}),, 1032 \mathrm{~m} v_{\mathrm{a}}(\mathrm{S}-\mathrm{O}), 998 \mathrm{~m} v_{\mathrm{s}}(\mathrm{C}-\mathrm{N})$. HR MALDITOF/TOF MS for $\mathrm{C}_{6} \mathrm{H}_{25} \mathrm{~N}_{6} \mathrm{O}_{3} \mathrm{RuS}$ Found (Calc.): 364.0596 (364.0840) $[\mathrm{M}+\mathrm{H}]^{+}$. ${ }^{1} \mathrm{H}$ NMR $\left(600 \mathrm{MHz}, \mathrm{D}_{2} \mathrm{O}\right) \delta / \mathrm{ppm}: 6.00-5.96$ (m, H5), 5.55 - 5.52 (m, H6a), 5.46 (dt, $J=16.7,8.4$ Hz, H6b), 4.16 - 4.10 (m, H4a), $4.04-3.98$ (m, H4b), 3.80 (dd, $J=13.6,7.7$ Hz, H2), 3.57 3.39 (m, $2 H 3 \mathrm{a}, \mathrm{b}), 3.22$ (s, $\left.2 H\left(\mathrm{NH}_{2}\right)\right), 2.44-2.13$ (m, vb, $\left.15 H\left(\mathrm{NH}_{3}\right)\right) .{ }^{13} \mathrm{C} \mathrm{NMR}(151 \mathrm{MHz}$, 
Deuterium Oxide) $\delta$ / ppm: 175.07 (s, C1), 125.43 (s, C5), 124.84 (s, C6), 119.56 (q, $J=$ $\left.317.4 \mathrm{~Hz}, \mathrm{CF}_{3} \mathrm{SO}_{3}\right), 63.11,62.86(\mathrm{~s}, C 2), 61.25,60.85$ (s, $\left.C 3\right), 56.51,56.08$ (s, $\left.C 4\right)$.

\section{Results and Discussion}

\subsection{Synthesis}

Ligand $( \pm$ )-L-Alliin was prepared by oxidation of deoxyalliin in aqueous solution by hydrogen peroxide and precipitated by acetone (Fig. 1). Deoxyalliin was prepared by the condensation reaction of deprotonated L-cysteine and allyl bromide in ethanol-water mixture under inert atmosphere at room temperature. Precipitation of the product was induced by acidifying the reaction mixture with acetic acid until pH 5.50 was reached.
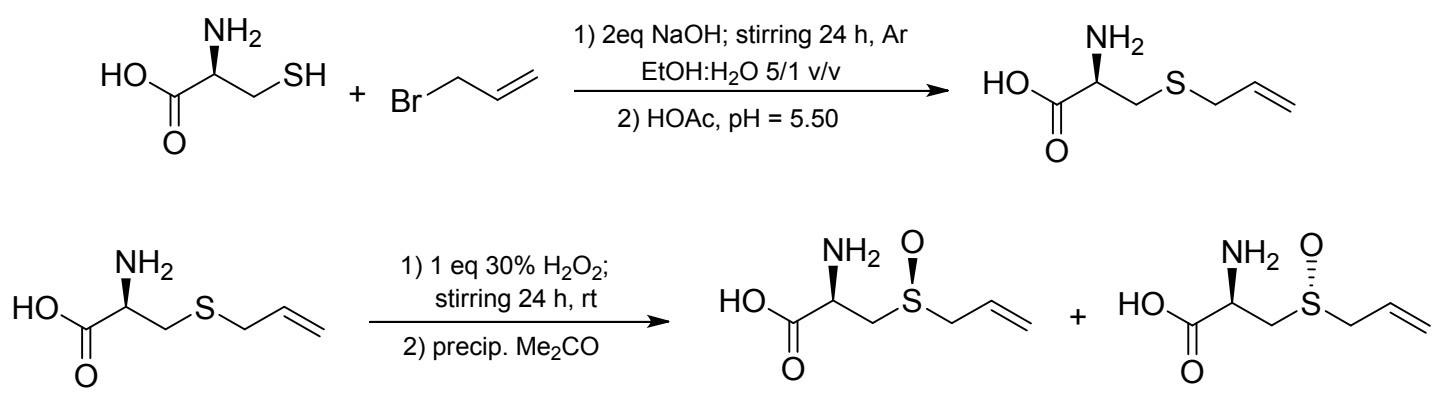

L-Deoxyalliin

( \pm )-L-Alliin

Figure 1. Preparation of deoxyalliin and alliin.

Ruthenium complexes with alliin (1) - (3) were prepared by several step solution synthesis. Complexes (1) and (2) were prepared starting from cis-[ $\left.\mathrm{RuCl}_{2}(\mathrm{dmso})_{4}\right]$, while complex (3) was prepared from $\left[\mathrm{RuCl}\left(\mathrm{NH}_{3}\right)_{5}\right] \mathrm{Cl}_{2}$. Complexes (1) and (2) have diamagnetic octahedrally coordinated $\mathrm{Ru}(\mathrm{II})$ metal center with two bidentate alliin molecules and two monodentate solvent molecules, while complex (3) has paramagnetic octahedrally coordinated $\mathrm{Ru}(\mathrm{III})$ with five ammonia molecules and one monodentate anionic $O$-bonded alliin ligand (Fig. 2).

Complexes (1) and (2) were prepared by silver triflate assisted substitution of chlorido ligands from $c i s-\left[\mathrm{RuCl}_{2}(\mathrm{dmso})_{4}\right]$, after which alliin was added to the reaction mixture in molar ratio 1:2. In the case of complex (2) alliin was deprotonated by aqueous potassium hydroxide prior the addition to tempt complexation of $\mathrm{Ru}(\mathrm{II})$ through carboxylate oxygen. Cationic complex (1), having two alliin molecules bound as bidentate neutral $N, S$-donor ligands and two $S$ bonded dimethyl sulfoxide molecules as coligands, was isolated as triflate salt from methanol by addition of diisopropyl ether. In neutral complex (2) two alliin ligands are bound to $\mathrm{Ru}(\mathrm{II})$ as bidentate anionic $O, N$-donor ligands, while water and one $S$-bonded dimethyl sulfoxide 
molecule occupy fifth and sixth coordination position. Complex (2) was recrystallized from DMSO-water mixture and consequently isolated as hydrate.

Complex (3) was prepared substituting the chlorido ligand from $\left[\mathrm{RuCl}\left(\mathrm{NH}_{3}\right)_{5}\right]^{2+}$ by deprotonated alliin in aqueous solution. Two anionic chlorides from $\left[\mathrm{RuCl}\left(\mathrm{NH}_{3}\right)_{5}\right] \mathrm{Cl}_{2}$ were precipitated as silver salt prior the addition of alliin. Cationic complex (3) was precipitated as triflate salt after addition of methanol and cooling the reaction mixture.

Synthetic procedures for complexes (1) - (3) were carefully design to show that protonation state of alliin and the presence of different coligands bound to ruthenium center can result in different coordination modes of alliin. This is particularly important from the aspect of the possible control of the properties of the complex compounds since it is well documented that different coordination modes of the ligand can affect chemical or physical properties of the complex. ${ }^{22-25}$

All three isolated complexes are highly soluble in water. Complexes (1) and (2) are also soluble in most of the organic polar solvents. Complexes (1) and (2) are yellow to light brown substances, while complex (3) is black powder. All three complexes have distinctive garliclike flavor when grinded.

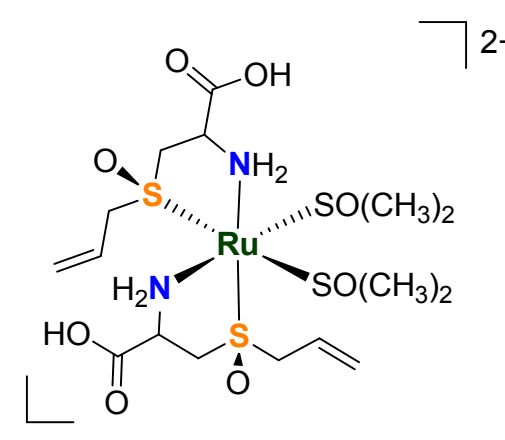

(1)

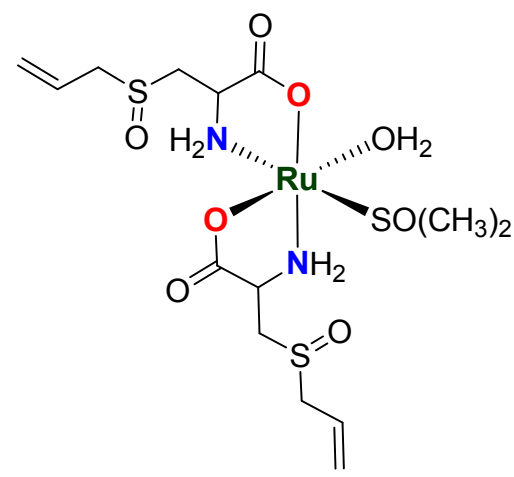

(2)

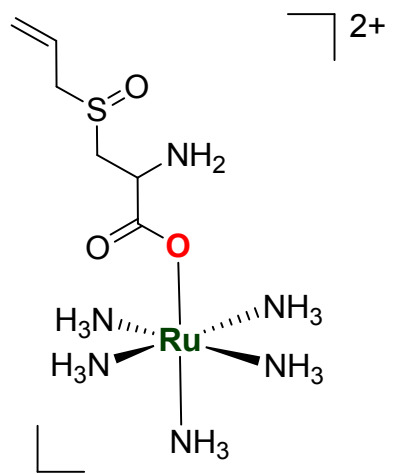

(3)

Figure 2. Different binding modes of alliin in ruthenium complexes (1) - (3).

\subsection{Characterization}

The formulation and characterization of ruthenium - alliin complexes (1) - (3) was made by elemental analysis, mass spectrometry, infrared, ${ }^{1} \mathrm{H}$ and ${ }^{13} \mathrm{C}$ NMR and EPR spectroscopy.

The results of the chemical analysis of $\mathrm{C}, \mathrm{H}, \mathrm{N}$ and $\mathrm{Ru}$ content confirms proposed formulation and good purity of new ruthenium - alliin complexes. The mass spectra of complexes (1) (3) showed typical isotopic ruthenium distribution for anticipated molecular ions. Molecular ions, $[\mathrm{M}]^{+}$for (1) and $[\mathrm{M}+\mathrm{H}]^{+}$for (2) and (3), were observed at 612.03, 553.18 and 364.06 
$\mathrm{Da}$, respectively which is consistent with $\left[\mathrm{Ru}(\mathrm{alliin})_{2}(\mathrm{dmso})_{2}\right]$ entity for (1), $\left[\mathrm{Ru}(\text { alliin })_{2}(\mathrm{dmso})\left(\mathrm{H}_{2} \mathrm{O}\right)\right]$ for $(2)$ and $\left[\mathrm{Ru}\left(\mathrm{NH}_{3}\right)_{5}(\right.$ alliin $\left.)\right]$ entity for (3) (Fig. S1 - S6).

Different coordination modes of alliin in ruthenium complexes (1) - (3) were indicated by infrared spectra. Alliin is a stereochemically flexible ligand having several potentially donor atoms and thus it can coordinate metal ions in several fashions. Due to the presence of nitrogen, sulfur and three oxygen atoms and the fact that carboxylic group can be deprotonated alliin can bind metal ions as neutral or anionic mono-, bi- and tridentate ligand (Inset in Fig. 3).

In the solid state alliin exists as a zwitterion ${ }^{35}$ exhibiting typical vibrations corresponding to asymmetric and symmetric stretching of deprotonated carboxylic group and bending of protonated amine group at 1611,1391 and $1525 \mathrm{~cm}^{-1}$, respectively. Upon coordination to ruthenium through amine or carboxylic group these bands experience shifting. If the coordination occurs through nitrogen band corresponding to bending of ammonium group $\left(1525 \mathrm{~cm}^{-1}\right)$ disappears in spectrum of complexes ${ }^{14}, 15$ while band corresponding to $\mathrm{C}-\mathrm{N}$ stretching $\left(993 \mathrm{~cm}^{-1}\right)$ is shifted toward lower wavenumber $\left(\sim 945 \mathrm{~cm}^{-1}\right)$ due to weakening of $\mathrm{C}-\mathrm{N}$ bond as a consequence of $\mathrm{Ru}-\mathrm{N}$ bond formation. In spectrum of complex (3), where no amine coordination was observed, this band is not significantly affected and it is found at 998 $\mathrm{cm}^{-1}$. Another coordination site of alliin is carboxylate group which coordinates metal ions in unidentate or bidentate fashion. Distinction between these coordination modes can be made by comparing the difference between asymmetric $\left(v_{\text {asym }}\right)$ and symmetric $\left(v_{\text {asym }}\right)$ stretching modes in ligand and complex. ${ }^{38}$ If the difference $\Delta\left(\mathrm{COO}^{-}\right)$in complex is larger compared to pristine ligand than carboxylate is coordinated as unidentate ligand. On the other hand, reduction in $\Delta\left(\mathrm{COO}^{-}\right)$upon coordination indicates bidentate coordination of carboxylate. In case of complexes (2) and (3) the difference $\Delta\left(\mathrm{COO}^{-}\right)$is 249 and $243 \mathrm{~cm}^{-1}$, respectively which is larger compared to $220 \mathrm{~cm}^{-1}$ as observed in spectrum of alliin. This clearly indicates unidentate coordination of carboxylate to ruthenium in complexes (2) and (3). As for the complex (1) a new band at $1738 \mathrm{~cm}^{-1}$ corresponding to protonated carboxylic group was observed, thus confirming that no coordination of alliin through carboxylic oxygen took a place. ${ }^{15}$ This finding is consistent with the fact that the same band is found in the spectrum of alliin hydrochloride at $1740 \mathrm{~cm}^{-1}$.

The third potential coordination site of alliin is sulfoxide group. Sulfoxides are ambidentate ligands that can coordinate metal ions through sulfur or oxygen atom. If the coordination is achieved through oxygen atom this gives rise to higher polarization of S-O bond thus 
wakening $\mathrm{S}=\mathrm{O}$ bond and causing shifting of $v(\mathrm{~S}=\mathrm{O})$ to lower wavenumbers. ${ }^{39}$ Oppositely, coordination through sulfur atom strengthens $\mathrm{S}=\mathrm{O}$ bond shifting the $v(\mathrm{~S}=\mathrm{O})$ to higher wavenumbers upon coordination. Considering ruthenium - alliin complexes (1) - (3) only in complex (1) coordination through sulfoxide group was found. In spectrum of alliin $v(S=O)$ is observed at $1021 \mathrm{~cm}^{-1}$ and upon coordination to $\mathrm{Ru}(\mathrm{II})$ in (1) it is shifted to $1032 \mathrm{~cm}^{-1}$ hence confirming coordination through sulfur atom of sulfoxide group.

Presence of $S$-bonded dimethyl sulfoxide to $\mathrm{Ru}(\mathrm{II})$ in complexes (1) and (2) is confirmed by bands appearing in $1060-1100 \mathrm{~cm}^{-1}$ region, which is consistent with S-bonded DMSO in $\left[\mathrm{RuCl}_{2}(\mathrm{dsmo}-S)_{3}(\mathrm{dmso}-O)\right] \cdot{ }^{31}$ Bands at $1275 \mathrm{~cm}^{-1}$ appearing in spectra of (1) and (3) arise from $\mathrm{S}=\mathrm{O}$ stretching in triflate. ${ }^{40}$

${ }^{1} \mathrm{H}$ and ${ }^{13} \mathrm{C}$ NMR spectra provide useful insights in composition and coordination modes of alliin in ruthenium - alliin complexes (1) - (3). ${ }^{1} \mathrm{H}$ NMR spectrum of complex (1) with atom numbering scheme of alliin is shown in Figure 3. In complexes (1) and (2) two alliin molecules are coordinated to ruthenium metal center. Due to the absence of any symmetry operation that interconverts hydrogen atoms of two alliin molecules all hydrogens are in magnetically nonequivalent environments hence resonating at close but different frequencies. The broad and the most downfield shifted signal in spectrum of complex (1) arises from the carboxylic proton $(-\mathrm{COOH})$ and is found at $8.3 \mathrm{ppm}$. Absence of this signal in spectra of complexes (2) and (3), where coordination of alliin to ruthenium is achieved through carboxylic oxygen, confirms deprotonation of carboxylic group and its involvement in coordination.

Signals of vinyl hydrogens ( $H 5$ and $H 6$ ) are not significantly affected by coordination of alliin to ruthenium due to their relative distance from the coordination sites. The signal of $H 5$ in spectrum of alliin is found at $5.9 \mathrm{ppm}$ and in spectra of complexes (1) - (3) it appears in 5.6 6.0 ppm region. ${ }^{14,37}$ The position of $H 6$ signal in alliin and corresponding complexes $(\mathbf{1})-(\mathbf{3})$ is basically unchanged appearing in all cases in $5.4-5.6 \mathrm{ppm}$ region.

The signals of other alliin hydrogen atoms $(H 2, H 3$ and $H 4)$ experiences shifting upon coordination due to their proximity to metal center. ${ }^{14,} 15$ Coordination of alliin typically cause downfield shifting of these signals as previously observed in metal complexes with alliin and alliin-like ligands. ${ }^{14,15,18,21}$ The largest downfield shifting is found for $H 4$. The signal of $H 4$ in spectrum of alliin is observed in $3.6-3.8 \mathrm{ppm}$ and upon coordination is shifted to $3.6-4.3$ ppm region in spectra of complexes (1) - (3). Multiplets of $H 3$ are found in spectra of (1) (3) in $3.2-3.6 \mathrm{ppm}$ region while appearing in the spectrum of alliin in $3.2-3.4 \mathrm{ppm}$ region. 
The coordination of alliin through nitrogen atom in (1) and (2) causes significant upfield shift of $H 2$ from $4.2 \mathrm{ppm}$ in spectrum of alliin to below $3 \mathrm{ppm}$ in spectra of complexes. On the other hand, in case of (3), where alliin is monodentatly bound to ruthenium through carboxylate oxygen, this shift is significantly smaller and the corresponding signal is found at $3.8 \mathrm{ppm}$.

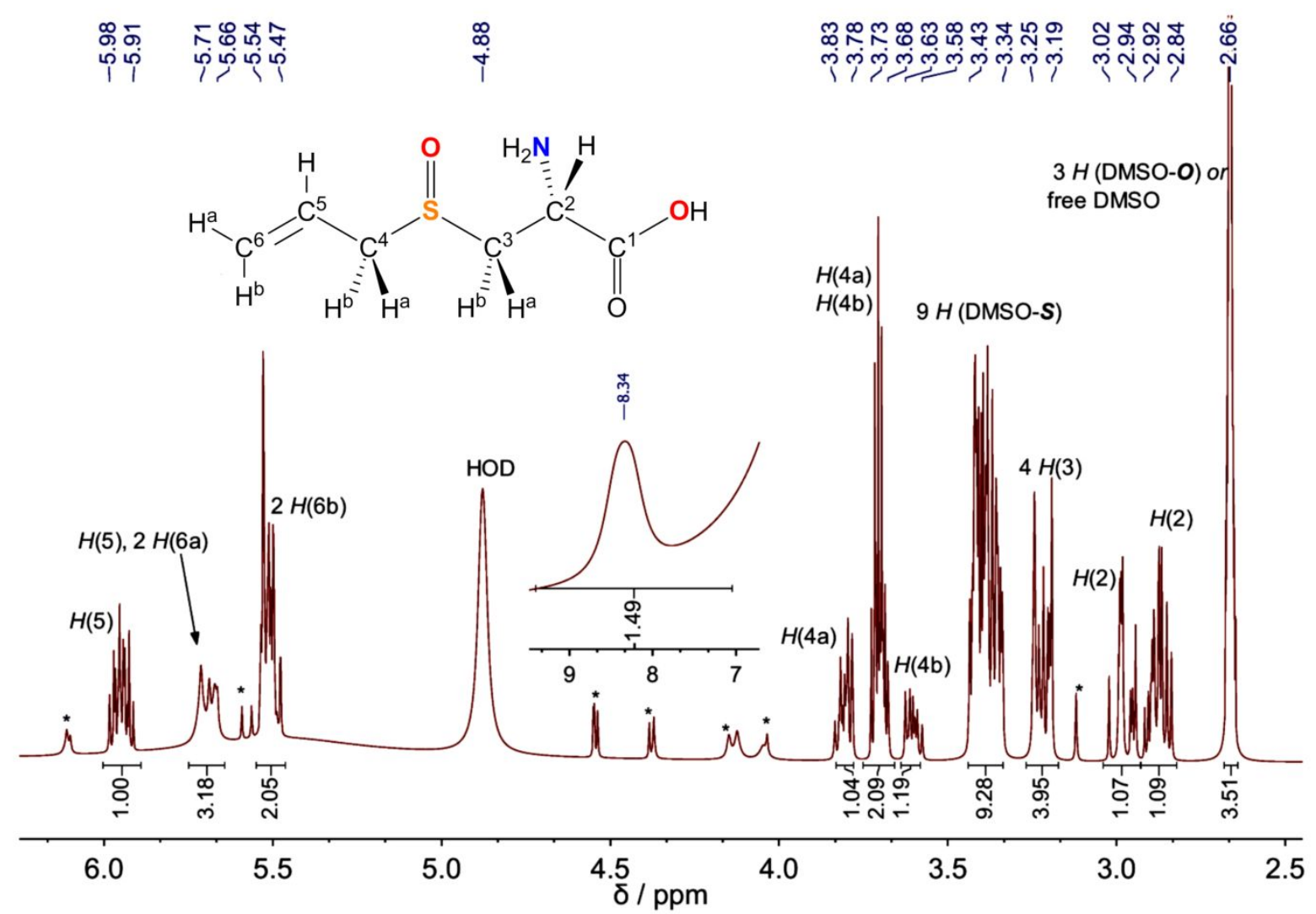

Figure 3. ${ }^{1} \mathrm{H}$ NMR spectrum of complex (1). Inset: Atom numbering scheme for alliin.

Several signals corresponding to dimethyl sulfoxide hydrogen atoms are found in spectra of complexes (1) and (2) where DMSO is bound to ruthenium as coligand. The signals at 3.3 $3.5 \mathrm{ppm}$ arise from $S$-bonded DMSO, as previously observed for other ruthenium - DMSO complexes. ${ }^{41}$ The presence of sharp singlet in spectra of (1) and (2) at $2.7 \mathrm{ppm}$, corresponding to free or $O$-bonded DMSO, indicates that DMSO undergoes substitution or linkage isomerism in solution. The presence of $O$-bonded isomers was not observed in solid state. The sum of the integer values of the DMSO signals (free and $S$-bonded) match the number of the DMSO molecules present per molecular unit of (1) and (2).

${ }^{13} \mathrm{C}$ NMR spectra of alliin and corresponding ruthenium complexes (1) - (3) can be seen as three sets of resonances (Fig. 4). The first set consists of only one resonance around $170 \mathrm{ppm}$ 
corresponding to carboxylic carbon $(C 1)$, the second set (near $125 \mathrm{ppm}$ ) involves two signals of $C 5$ and $C 6$, while three signals participate in the third set comprising the $C 2, C 3$ and $C 4$ atoms and are found in upfield region $(50-65 \mathrm{ppm})$.

Carboxylic carbon $(C 1)$ shows chemical shift at $171.4 \mathrm{ppm}$ in spectrum of alliin and upon coordination it is found at $168.4 \mathrm{ppm}$ in spectrum of (1). However, upfield shifting is not associated with its involvement in coordination. This shifting is also observed in platinum(II) complex with alliin and it is consistent with $N, S$-coordinaiton. ${ }^{15}$ On the other hand, downfield shifted signal of $C 1$ in spectrum of (3), appearing at $175 \mathrm{ppm}$, clearly indicates coordination of alliin through carboxylic oxygen. ${ }^{14}$ Vinyl carbon atoms associated with positions 5 and 6 , do not show any shifting upon coordination which is consistent with their ${ }^{1} \mathrm{H}$ NMR spectra.

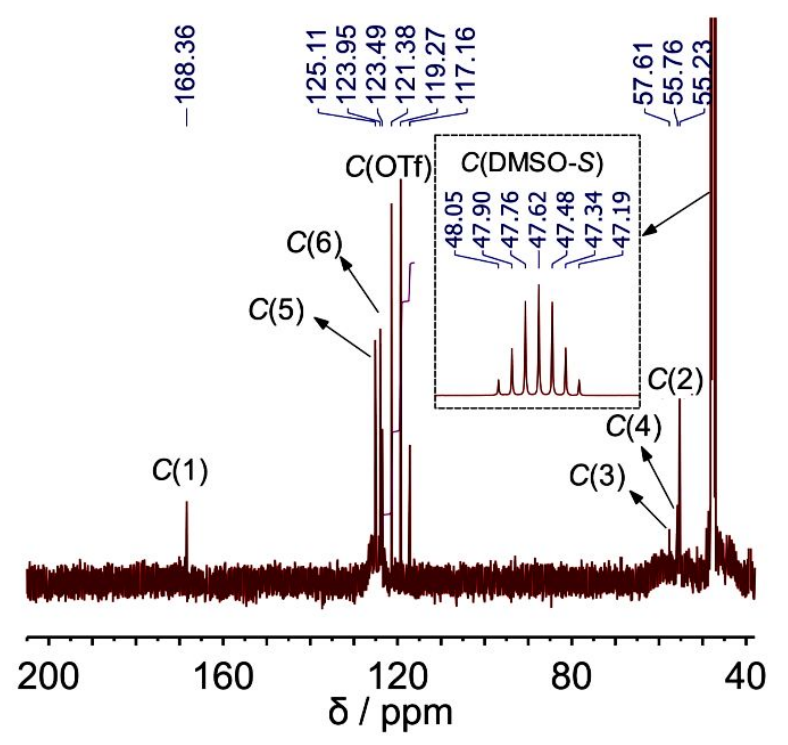

Figure $4 .{ }^{13} \mathrm{C}$ NMR spectrum of complex (2).

Three signals in low frequency region appearing at 54.7, 50.2 and $49.7 \mathrm{ppm}$ in spectrum of alliin arise from $C 4, C 2$ and $C 3$, respectively. ${ }^{14}$ Due to their proximity to the coordination sites of alliin the positions of these signals are the most affected by coordination. Typically, coordination results in their downfield shifting with the chemical shift being dependent on the coordination mode of alliin. ${ }^{14,15}$ In case of complex (1), where NS coordination is found, these signals appear at $57.6(C 3), 55.8(C 4)$ and 55.2 (C2) resembling to $\mathrm{Pt}(\mathrm{II})$-alliin complex. ${ }^{15}$ In the spectrum of the ruthenium-ammine complex (3) these signals are observed at $63.1(C 2), 61.2(C 3)$ and $56.1(C 4)$.

Well defined septet at $47.6 \mathrm{ppm}$ in spectra of complexes (1) and (2) arise from DMSO carbon atoms. Additionally, cationic complexes (1) and (3) exhibit quartet near $120 \mathrm{ppm}$ with coupling constant $J \sim 317 \mathrm{~Hz}$ hence confirming presence of triflate $\left(\mathrm{CF}_{3} \mathrm{SO}_{3}\right)$ as counter ion. ${ }^{42}$ 
Polycrystalline ruthenium - alliin complexes (1) - (3) were investigated by electron spin/paramagnetic resonance (ESR/EPR) spectroscopy. The complex (1) was ESR silent i.e. no ESR signal was detected in the investigated temperature range, as it is expected for diamagnetic $\mathrm{Ru}(\mathrm{II})$ ions. ${ }^{43}, 44$ The complex (3) with paramagnetic $\mathrm{Ru}(\mathrm{III})$ ions exhibits strong ESR signal presented in Fig. 5. The complex (2) with Ru(II) ions shows weak ESR signal with intensity comparable to the background signal of ESR cavity. The comparison of (2) signal with (3) signal could be seen in Fig. S12.

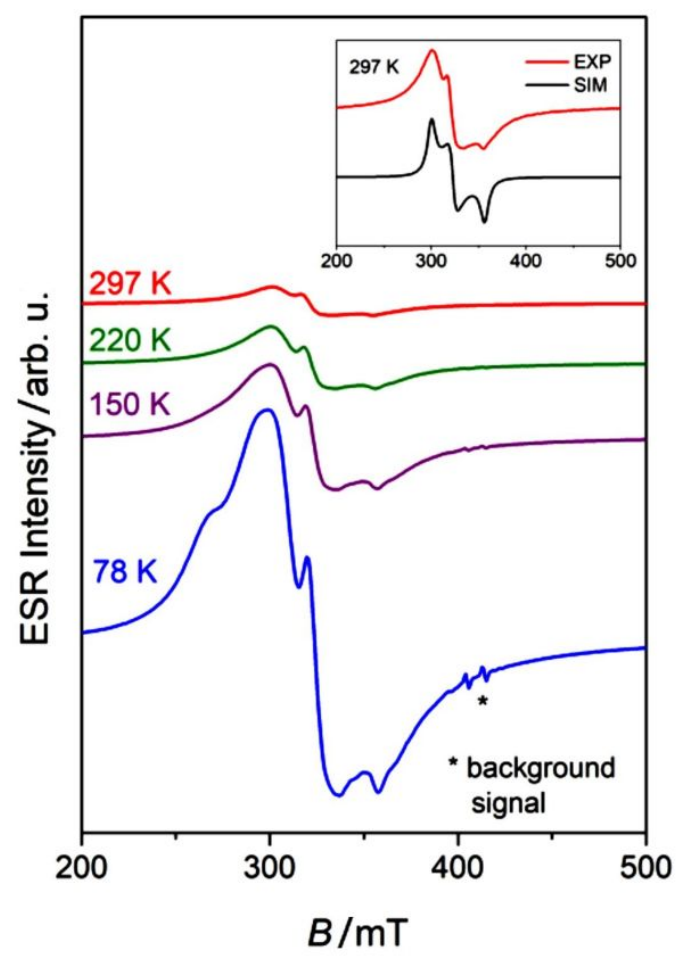

Figure 5. The temperature dependence of ESR spectra of (3). Inset shows experimental (red line) and simulated (black line) spectra of (3) at room temperature.

The spectral simulation was obtained using EasySpin software. ${ }^{45} \mathrm{Ru}(\mathrm{III})$ ions $\left(4 \mathrm{~d}^{5}\right.$ configuration) could be satisfactory described with low-spin states $S=1 / 2$ and reduced form of the spin-Hamiltonian: ${ }^{45}$

$$
H=\mu_{B} \times B \times g \times S
$$

In Eq. (1), the constant $\mu_{\mathrm{B}}$ is Bohr magneton, $\mathrm{g}$ is the g-tensor, $\mathrm{B}$ is the magnetic field vector and $\mathrm{S}$ is the spin operator. Hyperfine interactions between electron spin $S=1 / 2$ and nuclear spin $I=5 / 2$ for two isotopes ${ }^{99} \mathrm{Ru}$ (natural abundance $12.76 \%$ ) and ${ }^{101} \mathrm{Ru}$ (natural abundance $17.06 \%)^{46}$ were not detected i.e. the hyperfine splittings were covered by total spectral linewidth. The spectra were simulated assuming anisotropic g-tensor and Lorentzian 
lineshape. The obtained principal values of g-tensor are [2.29 2.13 1.93]. Here obtained results for $g$-values are in agreement with the $g$-values for $\mathrm{Ru}(\mathrm{III})$ complexes that can be found in the literature. ${ }^{43,44,47}$ The simulated spectrum at room temperature is shown in the inset of Fig. 5.

\subsection{Protein binding studies}

Interaction of small molecules with proteins is of the great importance regarding their biological availability, distribution and transport. ${ }^{48-50}$ One of the important targets of alliin metal complexes might be proteins since it is known that alliin is absorbed directly to blood and the most abundant bimolecular targets in blood are proteins, especially albumin and (apo)transferrin. Taking into account that the mechanism of allicin action is related to its reactivity toward $S$-containing proteins ${ }^{27}$ and the fact that many ruthenium complexes bind proteins, the first reasonable step in evaluating the biological potential of ruthenium - alliin complexes is their interaction with proteins.

The interaction of ruthenium - alliin complexes (1) - (3) and alliin with proteins was investigated by spectrofluorimetry. The intrinsic fluorescence of the most proteins arises from the tryptophan, tyrosine and phenylalanine hindered amino acid residues. ${ }^{51}$ In bovine serum albumin (BSA) two tryptophan residues, Trp-134 in first domain and Trp-212 in the second domain, show strong intrinsic fluorescence that dominates the emission spectrum of BSA. ${ }^{52}$ If the conformation of the protein is changed the microenvironment around these two residues changes hence altering the fluorescence intensity. This allows to investigate interaction of BSA with small molecules simply by measuring the changes of the fluorescence in presence of different complex to BSA ratios.

Typical changes of the BSA fluorescence in the presence of an increasing complex concentrations are shown in Fig. 6a. The linear decrease of the fluorescence with the increase of quencher concentrations was observed for all ruthenium complexes (1) - (3) and alliin. It was found that the decrease obeys to Stern - Volmer equation ${ }^{53}$ (Eq. 2):

$$
\frac{I_{0}}{I}=1+K_{q} \tau_{0}[\text { complex }]=1+K_{S V}[\text { complex }](2)
$$

where $I_{0}$ and $I$ are fluorescence intensities in absence and presence of complex, respectively and $K_{\mathrm{q}}$ is quenching rate constant, $\tau_{0}$ is average lifetime in the absence of the quencher $\left(\tau_{0}=\right.$ 
$10^{-8} \mathrm{~s}$ ) and [complex] is the concentration of complex and $K_{\mathrm{SV}}$ is the quenching constant. Plotting the $I_{0} / I$ versus [complex] gives $K_{\mathrm{SV}}$ values.

The $K_{\mathrm{SV}}$ values are $10^{3}-10^{4} \mathrm{M}^{-1}$ thus suggesting that the noticeable interaction between BSA and complexes occurs (Table 1). More precisely, $K_{\mathrm{SV}}$ values larger than $10^{4} \mathrm{M}^{-1}$ indicate there is a significant conformational change of the protein. ${ }^{54}$ The $K_{\mathrm{SV}}$ values decrease in order (3)> (1) $>$ (2) $>$ alliin, regardless to temperature. The decrease of the $K_{\mathrm{SV}}$ with the increase of the temperature for individual complexes suggest that the quenching occurs through static mechanism. ${ }^{51}$ Two main mechanism by which fluorescence can be quenched are static and dynamic. In case of the static quenching fluorophore and the quencher form adduct in the ground state, while in the case of the dynamic quenching energy transfer occurs in the excited state. ${ }^{55}$ Since the temperature increases the number of the individual collision between BSA and complex the quenching constant also increases. This is typical for dynamic quenching. On contrary, increase in temperature destabilizes the BSA-complex adduct thus decreasing the quenching constant in the case of static quenching ${ }^{56}$. Another valuable evidence that ruthenium complexes with alliin (1) - (3) quench BSA fluorescence through static quenching is quenching rate constant that has values of $10^{11}-10^{12} \mathrm{M}^{-1} \mathrm{~s}^{-1}$ (Table 1). The maximal constant rate for the dynamic quenching is $2 \times 10^{10} \mathrm{M}^{-1} \mathrm{~s}^{-1} .51$
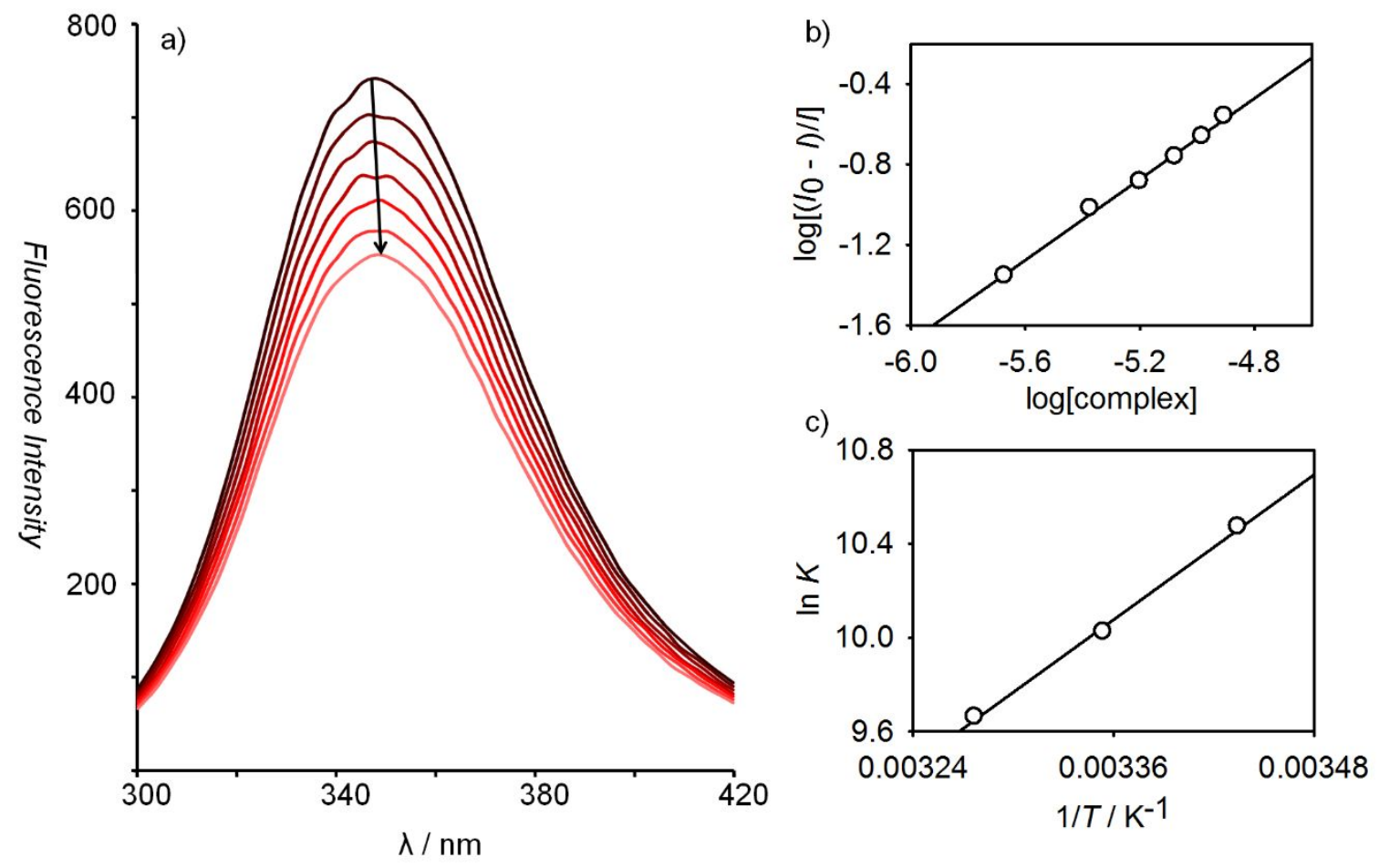

Figure 6. Interaction of (3) with BSA: a) quenching the BSA fluorescence in presence of increasing concentrations of (3), b) graphical determination of the binding constant, c) van't Hoff plot. 
The binding constant $\left(K_{\mathrm{b}}\right)$ and number of the binding sites $(n)$ per albumin molecule can be graphically obtained (Fig. S20 - S23) using Eq 3:54

$$
\log \frac{I_{0}-I}{I}=\log K_{b}+n \log [\text { complex }]
$$

The binding constant were measured at three temperatures (291, 298 and $305 \mathrm{~K}$ ) in order to determine the thermodynamic parameters of the interaction (vide infra). The binding constants for all three complexes are $10^{4} \mathrm{M}^{-1}$ magnitude and are $4-30$ times higher compared to alliin. However the same trend of $K_{\mathrm{b}}$ change with temperature increase was not found for each complex. The $K_{\mathrm{b}}$ value for complexes (2) and (3) decreases with an increase of temperature. On contrary, for complex (1) and pristine alliin the $K_{\mathrm{b}}$ values are greater at higher temperatures. This clearly indicates that the same binding forces do not govern the interaction of ruthenium - alliin complexes in all cases. The number of the binding sites was not affected by the change of the temperature and in all cases is near 1 . The number of binding sites close to 1 often indicates that the complexes are bound to BSA in hydrophobic pocket of IIA or IIIA subdomain. ${ }^{57}$ Substantial evidences on the types of the forces that drive the interaction of complexes with BSA can be provided from thermodynamic data.

Table 1. Interaction of complexes (1) - (3) and alliin with BSA.

\begin{tabular}{|c|c|c|c|c|c|c|c|c|c|}
\hline$\#$ & $\begin{array}{l}T / \\
\mathbf{K}\end{array}$ & $\begin{array}{c}K_{\mathrm{SV}} / \\
10^{4} \mathrm{M}^{-1}\end{array}$ & $\begin{array}{c}{\left[\operatorname{conc}_{50} /\right.} \\
10^{-4} \mathrm{M}\end{array}$ & $\begin{array}{c}k_{\mathrm{q}} / \\
10^{11} \mathrm{M}^{-1} \mathrm{~s}^{-1}\end{array}$ & $\begin{array}{c}K_{\mathrm{b}} / \\
10^{4} \mathrm{M}^{-1}\end{array}$ & $n$ & $\begin{array}{c}\Delta H / \\
\mathrm{kJ} \mathrm{mol}^{-1}\end{array}$ & $\begin{array}{c}\Delta S / \\
\mathrm{J} \mathrm{mol}^{-1} \mathbf{K}^{-1}\end{array}$ & $\begin{array}{c}\Delta G / \\
\mathbf{k J} \mathrm{mol}^{-1}\end{array}$ \\
\hline \multirow{3}{*}{ (1) } & 291 & 1.25 & 0.80 & 12.5 & 1.68 & 1.03 & \multirow{3}{*}{22.03} & \multirow{3}{*}{156.44} & -23.52 \\
\hline & 298 & 0.89 & 1.12 & 8.93 & 1.98 & 1.07 & & & -24.61 \\
\hline & 305 & 0.79 & 1.27 & 7.88 & 2.56 & 1.10 & & & -25.71 \\
\hline \multirow{3}{*}{ (2) } & 291 & 0.99 & 1.01 & 9.94 & 1.77 & 1.05 & \multirow{3}{*}{-33.03} & \multirow{3}{*}{-31.79} & -23.78 \\
\hline & 298 & 0.75 & 1.33 & 7.49 & 1.46 & 1.06 & & & -23.56 \\
\hline & 305 & 0.70 & 1.43 & 6.99 & 0.94 & 1.03 & & & -23.33 \\
\hline \multirow{3}{*}{ (3) } & 291 & 2.73 & 0.37 & 27.3 & 3.53 & 1.03 & \multirow{3}{*}{-42.82} & \multirow{3}{*}{-60.08} & -25.32 \\
\hline & 298 & 2.15 & 0.47 & 21.5 & 2.26 & 1.01 & & & -24.90 \\
\hline & 305 & 2.24 & 0.45 & 22.4 & 1.57 & 0.97 & & & -24.48 \\
\hline \multirow{3}{*}{ HL } & 291 & 0.37 & 2.68 & 3.72 & 0.12 & 0.89 & \multirow{3}{*}{36.92} & \multirow{3}{*}{184.78} & -16.88 \\
\hline & 298 & 0.31 & 3.19 & 3.13 & 0.13 & 0.92 & & & -18.17 \\
\hline & 305 & 0.34 & 2.91 & 3.44 & 0.23 & 0.96 & & & -19.46 \\
\hline
\end{tabular}

Enthalpy change $(\Delta H)$ and entropy change $(\Delta S)$ can be obtained graphically from van't Hoff plot ( $\ln K v s 1 / \mathrm{T})$ using equation (4):

$$
\ln K=-\frac{\Delta H}{R T}+\frac{\Delta S}{R}(4)
$$


where $R$ is the gas constant. Over the small temperature range enthalpy change can be considered constant and Gibbs energy change can be calculated using equation (5):

$$
\Delta G=\Delta H-T \Delta S(5)
$$

Data on thermodynamic parameters are summarized in Table 1. Different types of interactions between BSA and complexes cause different changes of thermodynamic parameters: ${ }^{58,59}$ (i) $\Delta G>0, \Delta S<0, \Delta H<0$ indicate partial immobilization, (ii) $\Delta G<0, \Delta S>0, \Delta H>0$ indicate hydrophobic interactions, (iii) $\Delta G<0, \Delta S>0, \Delta H \sim 0$ indicate electrostatic interaction, (iv) $\Delta G<0, \Delta S<0, \Delta H<0$ indicate van der Walls interactions and hydrogen bonding, (v) $\Delta H>$ $120 \mathrm{~kJ} \mathrm{~mol}^{-1}$ indicate covalent biding.

Results indicate that the interaction of ruthenium - alliin complexes with BSA are spontaneous under investigated conditions i.e. Gibbs energy change is negative. No significant differences in $\Delta G$ value was observed among complexes. On the other side, significant changes were observed in $\Delta H$ and $\Delta S$ values among complexes. Positive values of enthalpy and entropy change were found for interaction of complex (1) and alliin with BSA. This clearly indicates that the same type of binding forces are responsible for interaction of alliin and complex (1) with BSA. Here, the nature of these forces is predominantly hydrophobic. ${ }^{58}$ Negative values of enthalpy and entropy change were found for the interaction of (2) and (3) with BSA hence indicating that van der Waals forces and hydrogen bonding govern the interaction. ${ }^{58}$ From structural point of view these differences in the type of binding forces of complexes (1) - (3) with BSA can be addressed to different coordination modes of alliin. For pristine alliin and complex (1) the most obvious mutual structural feature is free carboxylic group. At pH 7.42 BSA exist in anionic form $(\mathrm{pI} \sim 4.8) .{ }^{60}$ Also, carboxylic group of alliin and complex (1) is susceptible to deprotonation i.e. the $\mathrm{p} K_{\mathrm{a}}$ values of the most amino acids are close to $2 .{ }^{61}$ These negative charges are aggravating factor in interaction of small molecules with bimolecular anions such proteins or DNA. In complexes (2) and (3) coordination of alliin to ruthenium is achieved through deprotonated carboxylate oxygen and in complex (2) additionally through amine nitrogen. Stronger biding to BSA was found for complex (3) which can be attributed not only to van der Waals forces and hydrogen bonding but also to electrostatic interactions since (3) is cationic complex compared to neutral (2). The obvious differences in interaction of (1) and (2) with BSA clearly indicate that the coordination mode of alliin can alert interaction of complex specie with BSA. Different binding forces that drive the interaction of complexes with BSA are obvious in perturbation of 
the order in which the $K_{\mathrm{b}}$ value decreases with temperature. At $291 \mathrm{~K}$ the $K_{\mathrm{b}}$ decreases in order $(\mathbf{3})>(\mathbf{2})>(\mathbf{1})$, while at $305 \mathrm{~K}$ the order changes and $K_{\mathrm{b}}$ decreases as $(\mathbf{1})>(\mathbf{3})>(\mathbf{2})$.

This means that the resulting adduct of complex - BSA interaction is weakened in case of (2) and (3) as the temperature increases. Oppositely, stronger interaction with BSA is observed with temperature increase in case of (1) and alliin. This suggest that the number of collisions between BSA and complex (1) or alliin in excited state is highly competitive and can prevail lower efficiency in energy transfer due to the decreased stability of BSA - complex adduct in ground state.

The distance between fluorophore and complex at which the energy transfer occurs can be determined by Forster's theory. The efficiency of the energy transfer is dimensionless and can be calculated from fluorescence intensities of BSA in presence $(I)$ and absence $\left(I_{0}\right)$ of complex using equation (6): ${ }^{2}$

$$
E=1-\frac{I}{I_{0}}=\frac{R_{0}^{6}}{R_{0}^{6}+r^{6}}(6)
$$

The parameter $r$ is the distance between the donor and acceptor and $R_{0}$ is the critical distance when the transfer efficiency is $50 \%$. The critical distance can be calculated from experimentally determined overlapping integral value $(J)$ by equation $(7):^{62}$

$$
R_{0}^{6}=8.8 \times 10^{-25} K^{2} \Phi J N^{-4}
$$

where $K^{2}=2 / 3, N=1.336$ and $\varphi=0.118$ are constants for BSA. The overlapping integral value was calculated from luminescence intensity of the fluorescent donor $(F(\lambda))$ at the wavelength $\lambda$ and the extinction coefficient $(\varepsilon(\lambda))$ using equation $(8): 63$

$$
J=\frac{\sum F(\lambda) \varepsilon(\lambda) \lambda^{4} \Delta \lambda}{\sum F(\lambda) \Delta \lambda}
$$




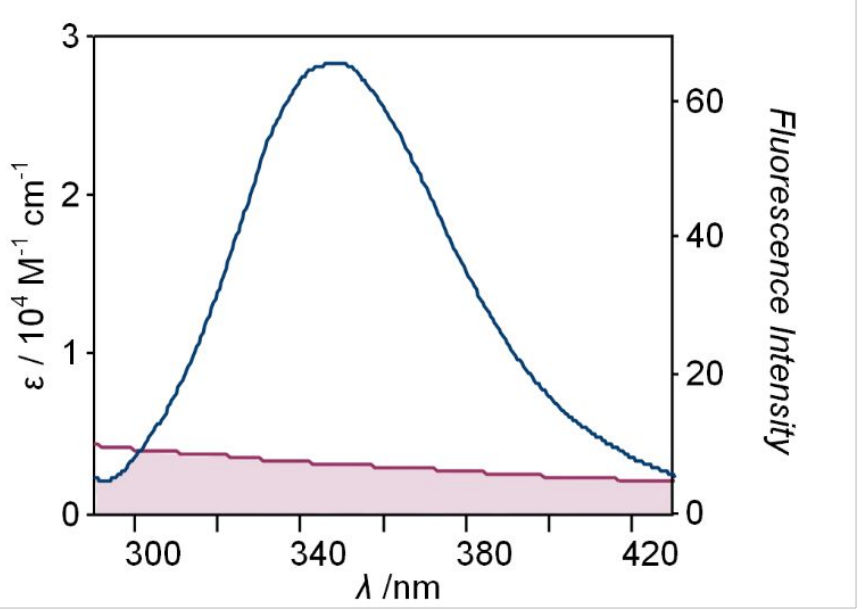

Figure 7. Overlap of the absorption spectrum of (3) and emission spectrum of BSA.

The overlapping between absorption spectrum of (3) and emission spectrum of BSA is given in Figure 7. The distance values $(r)$ lower than $8 \mathrm{~nm}(2.46-2.64 \mathrm{~nm})$ confirm that the nonradiative energy transfer took a place. ${ }^{51}$ The critical distance increases in order aliin $<(\mathbf{1}) \sim$ $(2)<(3)$ (Table 2).

Table 2. Data on energy transfer and synchronous spectra of BSA and ruthenium complexes (1) - (3) and alliin.

\begin{tabular}{|c|c|c|c|c|c|c|}
\hline \multirow{2}{*}{ \# } & \multirow{2}{*}{$J / \mathbf{c m}^{3} \mathbf{L} \mathbf{m o l}^{-1}$} & \multirow{2}{*}{$E$} & \multirow{2}{*}{$R_{0} / \mathrm{nm}$} & \multirow{2}{*}{$r / \mathbf{n m}$} & \multicolumn{2}{|c|}{ Intensity decrease } \\
\hline & & & & & $\Delta \lambda=15 \mathrm{~nm}$ & $\Delta \lambda=60 \mathrm{~nm}$ \\
\hline (1) & $1.00 \times 10^{-15}$ & 0.096 & 1.67 & 2.43 & $8 \%$ & $10 \%$ \\
\hline (2) & $1.06 \times 10^{-15}$ & 0.097 & 1.69 & 2.45 & $5 \%$ & $10 \%$ \\
\hline (3) & $4.74 \times 10^{-15}$ & 0.232 & 2.16 & 2.64 & $18 \%$ & $24 \%$ \\
\hline HL & $5.64 \times 10^{-16}$ & 0.050 & 1.52 & 2.48 & $10 \%$ & $6 \%$ \\
\hline
\end{tabular}

Synchronous spectra can give information on the microenvironment changes of tyrosine and tryptophan, two amino acids that show intrinsic fluorescence in BSA. ${ }^{64}$ Consideration criteria include intensity and position changes of the emission maximum when difference between emission and excitation wavelength is fixed $\left(\Delta \lambda=\lambda_{\mathrm{em}}-\lambda_{\mathrm{ex}}\right)$. The synchronous fluorescence maximum of tyrosine is observed when $\Delta \lambda=15 \mathrm{~nm}$ and tryptophan when $\Delta \lambda=60 \mathrm{~nm}$ (Fig. 8). ${ }^{65}$ No obvious or regular change in the position of the emission maximum of tyrosine or tryptophan was observed in neither the one case when synchronous measurements were done. Yet conformational change of the BSA is evident since the intensity of the synchronous fluorescence of both amino acids is affected (Table 2). Complexes showed stronger quenching of tryptophan fluorescence while alliin rather quench tyrosine fluorescence. This could suggest that alliin and complexes (1) - (3) have different biding sites on BSA. 

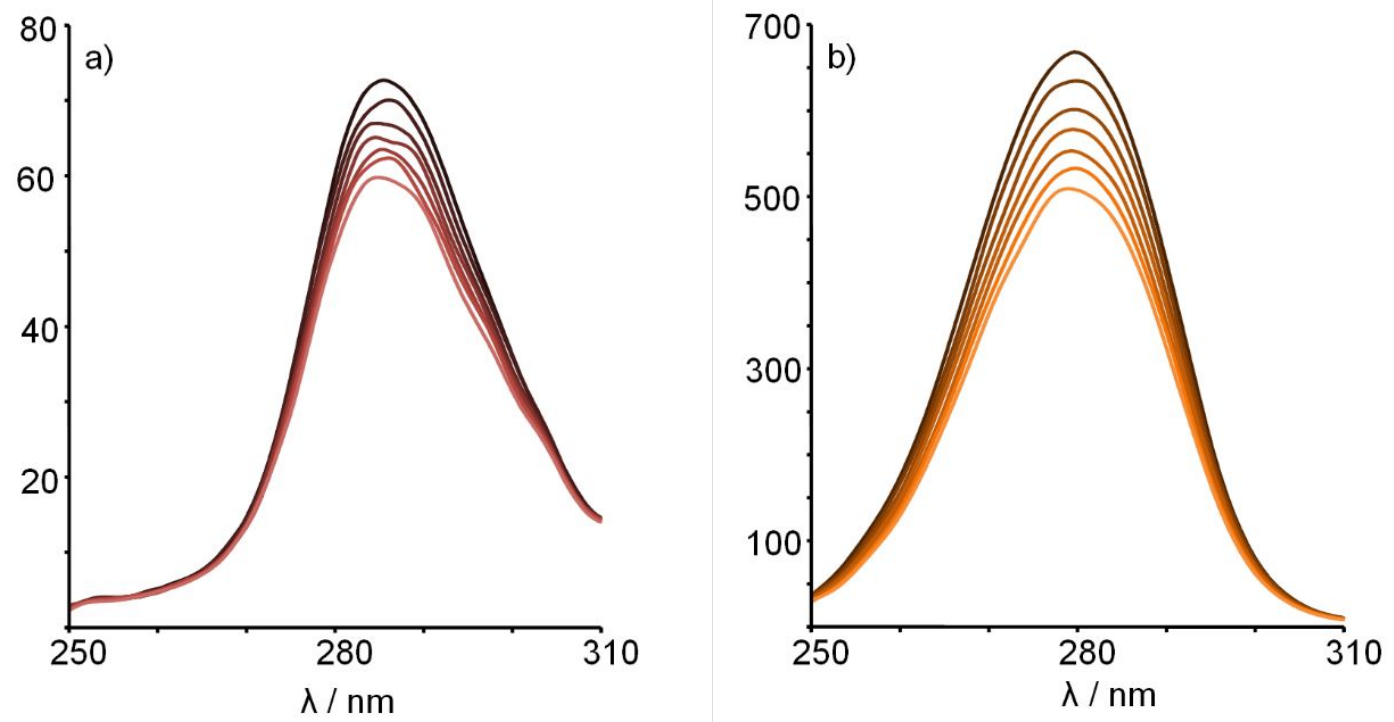

Figure 8. Decrease of the fluorescence in synchronous spectra of BSA in presence of increasing concentration of (3) at: a) $\Delta \lambda=15 \mathrm{~nm}$ and b) $\Delta \lambda=60 \mathrm{~nm}$.

Deeper insight in the conformational change of BSA and changes of the microenvironment around tryptophan and tyrosine in presence of complexes and alliin was provided from 3D fluorescence measurements. Typical three-dimensional fluorescence spectra of BSA in absence and presence of complexes (3) are shown Figure 9 (see also Fig. S18). Two peak are found in $3 \mathrm{D}$ spectra of BSA. Peak I corresponds to intrinsic fluorescence of tyrosine and tryptophan while Peak II is associated with conformational changes of the polypeptide backbone. ${ }^{51}$ The intensity of both peaks decreased in presence of complexes (1) - (3) and alliin. The larger decrease was observed for Peak II (22 - $30 \%)$ compared to Peak I thus suggesting that the conformational change of the BSA polypeptide chain is the prevalent result of its interaction with ruthenium - alliin complexes (1) - (3). The values of the Stokes shift for peak I are lower for BSA - complexes adducts compared to native BSA thus suggesting that the hydrophobicity around tryptophan and/or tyrosine has changed (Table 3 ). Slight increase of Stokes shift was observed for peak II in presence of complexes (1) and (3). Three-dimensional fluorescence spectroscopy confirmed the results acquired by classical fluorescence measurement (vide supra): complexes having alliin bound through carboxylate oxygen to ruthenium show more similarity in interaction with BSA and bind it more tightly compared to species having ionized carboxylate group (alliin and (1)). 

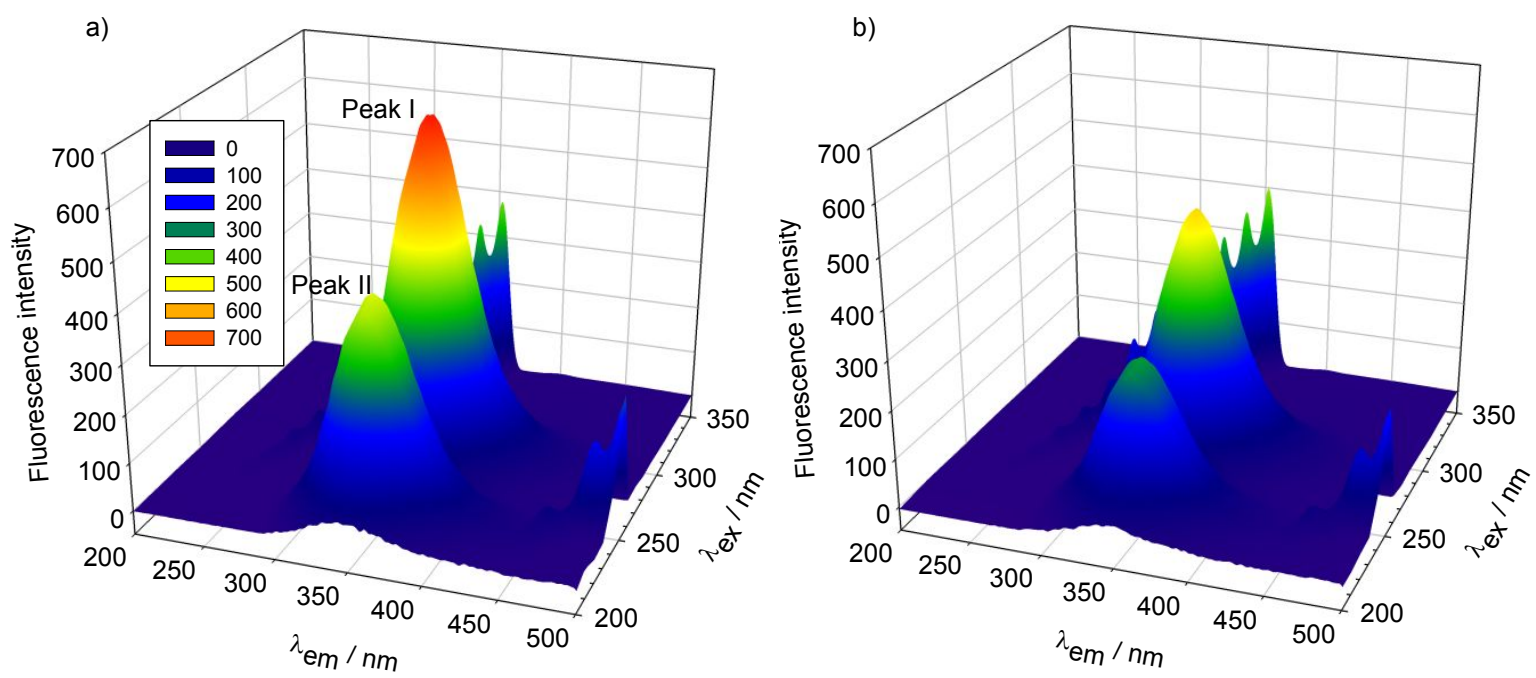

Figure 9. Three-dimensional fluorescence spectrum of BSA (a) and BSA in presence of complex (3) (b) at $[\mathrm{BSA}]=1.71 \mu \mathrm{M}$ and $[$ complex $]=12.5 \mu \mathrm{M}$.

Table 3. Three-dimensional fluorescence spectra data on interaction of complexes (1) - (3) and alliin with BSA.

\begin{tabular}{ccccccccc}
\hline \multirow{2}{*}{} & \multicolumn{9}{c}{ Peak I } & \multicolumn{3}{c}{ Peak II } \\
\cline { 2 - 8 } & $\boldsymbol{\lambda}_{\mathrm{ex}} / \mathbf{n m}$ & $\boldsymbol{\lambda}_{\mathrm{em}} / \mathbf{n m}$ & $\boldsymbol{\Delta} \boldsymbol{\lambda} / \mathbf{n m}$ & Intensity decrease & $\boldsymbol{\lambda}_{\mathrm{ex}} / \mathbf{n m}$ & $\boldsymbol{\lambda}_{\mathrm{em}} / \mathbf{n m}$ & $\boldsymbol{\Delta} \boldsymbol{\lambda} / \mathbf{n m}$ & Intensity decrease \\
\hline BSA & 280 & 350 & 70 & - & 230 & 347 & 117 & - \\
$(\mathbf{1})$ & 280 & 348 & 68 & $16 \%$ & 230 & 349 & 119 & $22 \%$ \\
$(\mathbf{2})$ & 280 & 349 & 69 & $24 \%$ & 230 & 347 & 117 & $30 \%$ \\
$(\mathbf{3})$ & 280 & 348 & 68 & $28 \%$ & 230 & 348 & 118 & $30 \%$ \\
$\mathrm{HL}$ & 280 & 349 & 69 & $15 \%$ & 230 & 346 & 116 & $15 \%$ \\
\hline
\end{tabular}

The interaction of ruthenium - alliin complexes (1) - (3) and alliin with apo-transferrin was investigated by spectrofluorimetry. Apo-transferrin and transferrin are considered as potential natural ruthenium-based drug carriers since there is a hypothesis that ruthenium compounds could be more selectively delivered to target malignant cells by using transferrin receptor overexpression route. ${ }^{66}$

Measurements showed that quenching constants are $10^{3} \mathrm{M}^{-1}$ order except for complex (3) where constant has $10^{4} \mathrm{M}^{-1}$ magnitude (Table 4). Similarly to interaction with BSA, quenching constant rates indicate static mechanism and formation of adduct in ground state. Generally, measurements showed that complexes have lower affinity for apo-transferrin compared to BSA and more detail studies were not undertaken. Lower affinity of ruthenium complexes to apo-transferrin compared to BSA is often encountered. ${ }^{29}$ 
Table 4. Interaction of complexes (1) - (3) and alliin with apo-transferrin.

\begin{tabular}{cccccc}
\hline$\#$ & $\boldsymbol{K}_{\mathbf{S V}} / \mathbf{1 0}^{\mathbf{3}} \mathbf{M}^{-\mathbf{1}}$ & {$[\mathbf{c o n c}]_{\mathbf{5 0}} / \mathbf{1 0}^{\mathbf{- 4}} \mathbf{M}$} & $\boldsymbol{k}_{\mathbf{q}} / \mathbf{1 0}^{\mathbf{1 1}} \mathbf{M}^{-\mathbf{1}} \mathbf{s}^{\mathbf{- 1}}$ & $\boldsymbol{K}_{\mathbf{b}} / \mathbf{1 0}^{\mathbf{3}} \mathbf{M}^{-\mathbf{1}}$ & $\boldsymbol{n}$ \\
\hline$(\mathbf{1})$ & 9.49 & 1.05 & 9.49 & 10.8 & 1.01 \\
$(\mathbf{2})$ & 8.66 & 1.15 & 8.66 & 2.97 & 0.90 \\
$(\mathbf{3})$ & 19.60 & 0.51 & 19.6 & 62.9 & 1.10 \\
HL & 2.97 & 3.36 & 2.97 & 0.23 & 0.77 \\
\hline
\end{tabular}

\subsection{In vitro biological activity}

The antiproliferative testing was aimed to screen the effects of complexes (1) - (3) and alliin on human tumor cell lines, as well as on normal (diploid) human fibroblasts (control cell line) in order to find potential candidates for further pre-clinical evaluation. Substances showing a differential anti-proliferative effect at micromole concentrations are suited for further biological studies and optimization.

Results of antiproliferative testing are summarized in Table S2. All compounds exerted high cytotoxicity on HFF-1 (fibroblast cells) and no antiproliferative effects on tumor cells ( $\mathrm{IC}_{50}$ $>100 \mu \mathrm{M}$ ). Compound (3) has showed strange effect on HeLa, SW620 and HFF-1 cells. Its effects on cells were particularly difficult to evaluate as it acted antiproliferatively (20-40\%) on CFPAC-1 and in SW620 (33-64\%) in all tested concentrations. The growth-response curves for (3) were unusual and did not follow the rule of dose-response. Ruthenium - alliin complexes (1) - (3) did not show significant in vitro anticancer activity, however their in vivo activity can be substantially different as previously observed with ruthenium complexes having antimetastatic activity. ${ }^{67,68}$ Similarly, palladium(II) and platinum(II) complexes with alliin did not show significant anticancer activity except moderate activity toward HeLa. ${ }^{14,15}$ Antimicrobial activity of complexes and alliin was evaluated on strains of Gram-positive Staphylococcus aureus, Gram-negative Pseudomonas aeruginosa, Escherichia coli and fungi Candida albicans. Complexes (1) - (3) and alliin did not show any antimicrobial activity at tested concentrations. Although some papers report antibacterial activity of complexes with alliin-like ligands at high concentrations ${ }^{20}($ e.g. $0.1 \% \mathrm{w} / \mathrm{v})$ we did not took experiments to test it at such high doses since they do not have practical applicability. Further testing will focus on the antimicrobial activity of complexes in presence of alliinase, an enzyme that catalyzes the conversion of alliin to allicin, unsaturated thiosulfinate compound that showed high potency as antimicrobial agent. 


\section{Conclusion}

Solution synthesis afforded three novel heteroleptic water-soluble ruthenium complexes featuring alliin structural moiety bound to metal center in different manners. All three complexes are low-spin having octahedrally coordinated ruthenium with: (1) two $S$-bonded DMSO molecules and two bidentate neutral $N, S$-donor alliin ligands, (2) one water, one $S$ bonded DMSO and two bidentate monobasic $O, N$-donor alliin ligands and (3) five ammine ligands and one monodentate monobasic $O$-donor alliin ligand. Complexes (1) and (2) have diamagnetic ESR silent $4 d^{6} \mathrm{Ru}(\mathrm{II})$ center while complex (3) is ESR active showing paramagnetism corresponding to one unpaired electron of $4 d^{5} \mathrm{Ru}(\mathrm{III})$ metal center.

Complexes showed considerable affinity to bind apo-transferrin and BSA with slightly higher preferences for albumin. Complexes quench fluorescence of both proteins by static mechanism hence forming complex - protein adduct in ground state. It appears that the nature of the binding forces between complexes and BSA is related to the coordination mode of alliin. Complexes having $O$-bound alliin predominantly interact with BSA through hydrogen bonding and van der Waals interactions, while the hydrophobic forces govern the interaction of species having ionized carboxylate group. Synchronous and three-dimensional fluorescence spectra revealed that complexes alter polypeptide chain conformation in BSA without substantial change in the polarity around tryptophan or tyrosine. Complexes did not show any notable in vitro anticancer or antimicrobial activity at tested concentrations and will be subjected to further testing under different experimental conditions. Nevertheless, results provide evidences that by controlling the coordination mode of the ligand, the desired reactivity of the complex toward specific target, such as proteins, can be addressed.

\section{Disclosure statement}

Authors declare no potential conflict of interest.

\section{Funding}

This work is supported by the Federal Ministry of Education and Science of Bosnia and Herzegovina (grant no. 05-39-2619-1/18) and Croatian Science Foundation (grant no. IP2018-01-3168). 


\section{References}

1. B. W. Harper, A. M. Krause-Heuer, M. P. Grant, M. Manohar, K. B. Garbutcheon-Singh and J. R. Aldrich-Wright, Chem. Eur. J., 2010, 16, 7064-7077.

2. N. J. Wheate, S. Walker, G. E. Craig and R. Oun, Dalton Trans., 2010, 39, 8113-8127.

3. A. Bergamo, C. Gaiddon, J. Schellens, J. Beijnen and G. Sava, J. Inorg. Biochem., 2012, 106, 90-99.

4. A. Bergamo and G. Sava, Dalton Trans., 2011, 40, 7817-7823.

5. Y. Zhang, L. Zhang, L. Liu, J. Guo, D. Wu, G. Xu, X. Wang and D. Jia, Inorg. Chim. Acta, 2010, 363, 289-293.

6. S. Rafique, M. Idrees, A. Nasim, H. Akbar and A. Athar, Biotech. Mol. Biol. Rev., 2010, 5, 38-45.

7. Z. H. Chohan, H. A. Shad, M. H. Youssoufi and T. B. Hadda, Eur. J. Med. Chem., 2010, 45, 2893-2901.

8. N. Farrell, Transition metal complexes as drugs and chemotherapeutic agents, Springer Science \& Business Media, 2012.

9. C. G. Hartinger, N. Metzler-Nolte and P. J. Dyson, Organometallics, 2012, 31, 56775685.

10. P. Horcajada, R. Gref, T. Baati, P. K. Allan, G. Maurin, P. Couvreur, G. Ferey, R. E. Morris and C. Serre, Chem. Rev., 2011, 112, 1232-1268.

11. J. H. B. Nunes, F. R. Bergamini, W. R. Lustri, P. P. de Paiva, A. L. T. Ruiz, J. E. de Carvalho and P. P. Corbi, J. Fluor. Chem., 2017, 195, 93-101.

12. S. Ankri and D. Mirelman, Microbes Infec., 1999, 1, 125-129.

13. J. Borlinghaus, F. Albrecht, M. C. Gruhlke, I. D. Nwachukwu and A. J. Slusarenko, Molecules, 2014, 19, 12591-12618.

14. C. Abbehausen, S. F. Sucena, M. Lancellotti, T. A. Heinrich, E. P. Abrao, C. M. Costa-Neto, A. L. Formiga and P. P. Corbi, J. Mol. Struct., 2013, 1035, 421-426.

15. P. Corbi, A. C. Massabni, L. Sabeh and C. Costa-Neto, J. Coord. Chem., 2008, 61, 2470-2477.

16. M. B. Spera, F. A. Quintão, D. K. Ferraresi, W. R. Lustri, A. Magalhães, A. L. Formiga and P. P. Corbi, Spectrochim. Acta A, 2011, 78, 313-318.

17. W. Castello, M. Spera, A. Gomes, F. Gozzo, W. Lustri, A. Formiga and P. Corbi, J. Coord. Chem., 2011, 64, 272-280.

18. P. P. Corbi, A. C. Massabni, A. G. Moreira, F. J. Medrano, M. G. Jasiulionis and C. M. Costa-Neto, Canad. J. Chem., 2005, 83, 104-109.

19. P. P. Corbi and A. C. Massabni, Spectrochim. Acta A, 2006, 64, 418-419.

20. S. Nazir, J. Anwar, M. A. Munawar, J. I. Qazi, S. P. Best, M. Cheah and M. Yaseen, Inorg. Chim. Acta, 2018, 478, 166-175.

21. P. P. Corbi, A. C. Massabni and C. M. Costa-Neto, J. Coord. Chem., 2006, 59, 1101 1106.

22. S. H. Wadman, M. Lutz, D. M. Tooke, A. L. Spek, F. e. Hartl, R. W. Havenith, G. P. van Klink and G. van Koten, Inorg. Chem., 2009, 48, 1887-1900.

23. A. Bencini, A. Caneschi, C. Carbonera, A. Dei, D. Gatteschi, R. Righini, C. Sangregorio and J. Van Slageren, J. Mol. Struct., 2003, 656, 141-154.

24. S. C. Yoon, B.-J. Bae, I.-H. Suh and J. T. Park, Organometallics, 1999, 18, 20492051.

25. Y. Tsukahara, T. Kamatani, T. Suzuki and S. Kaizaki, Dalton Trans., 2003, 12761279.

26. A. C. Massabni, P. P. Corbi, P. Melnikov, M. A. Zacharias and H. R. Rechenberg, J. Braz. Chem. Soc., 2005, 16, 718-722. 
27. A. Rabinkov, T. Miron, L. Konstantinovski, M. Wilchek, D. Mirelman and L. Weiner, Biochim. Biophys. Acta, 1998, 1379, 233-244.

28. F. Piccioli, S. Sabatini, L. Messori, P. Orioli, C. G. Hartinger and B. K. Keppler, J. Inorg. Biochem., 2004, 98, 1135-1142.

29. S. Thota, D. A. Rodrigues, D. C. Crans and E. J. Barreiro, J. Medi. Chem., 2018, 61, 5805-5821.

30. M. Pongratz, P. Schluga, M. A. Jakupec, V. B. Arion, C. G. Hartinger, G. Allmaier and B. K. Keppler, J. Anal. Atom. Spectrom., 2004, 19, 46-51.

31. I. Bratsos and E. Alessio, Inorg. Synth., 2010, 35, 148-152.

32. A. D. Allen, F. Bottomley, R. O. Harris, V. Reinsalu and C. Senoff, J. Am. Chem. Soc., 1967, 89, 5595-5599.

33. A. Zahirović, I. Osmanković, E. Turkušić and E. Kahrović, Anal. Methods, 2018, 10, 5078-5083.

34. T. Gazivoda, S. Raić-Malić, V. Krištafor, D. Makuc, J. Plavec, S. Bratulić, S. Kraljević-Pavelić, K. Pavelić, L. Naesens and G. Andrei, Bioorg. Med. Chem., 2008, 16, 5624-5634.

35. V. D. Nikolić, D. P. Ilić, L. B. Nikolić, M. Z. Stanković, L. P. Stanojević, I. M. Savić and I. M. Savić, Advan. Technol., 2012, 1, 38-46.

36. T. Miron, T. Bercovici, A. Rabinkov, M. Wilchek and D. Mirelman, Anal. Biochem., 2004, 331, 364-369.

37. M. C. Aversa, A. Barattucci, P. Bonaccorsi and P. Giannetto, J. Org. Chem., 2005, 70, 1986-1992.

38. G. Deacon and R. Phillips, Coord. Chem. Rev., 1980, 33, 227-250.

39. K. Nakamoto, Handbook of Vibrational Spectroscopy, 2006.

40. A. Zahirović, E. Kahrović, M. Cindrić, S. Kraljević Pavelić, M. Hukić, A. Harej and E. Turkušić, J. Coord. Chem., 2017, 70, 4030-4053.

41. V. Mahalingam, N. Chitrapriya, F. R. Fronczek and K. Natarajan, Polyhedron, 2008, 27, 2743-2750.

42. C. L. Macdonald, A. M. Corrente, C. G. Andrews, A. Taylor and B. D. Ellis, Chem. Comm., 2004, 250-251.

43. P. Munshi, R. Samanta and G. K. Lahiri, J. Organometallic Chem., 1999, 586, 176183.

44. M. I. Webb and C. J. Walsby, Metallomics, 2013, 5, 1624-1633.

45. S. Stoll and A. Schweiger, J. Mag. Res., 2006, 178, 42-55.

46. J. Poppe, W. Kaim, A. B. Altabef and N. E. Katz, J. Chem. Soc., Perkin Trans. 2, 1993, 2105-2108.

47. C. Canevali, N. Chiodini, F. Morazzoni and R. Scotti, J. Mat. Chem., 2000, 10, 773778.

48. C. X. Zhang and S. J. Lippard, Curr. Op. Chem. Biol., 2003, 7, 481-489.

49. I. Kostova, Curr. Med. Chem., 2006, 13, 1085-1107.

50. C. S. Allardyce and P. J. Dyson, Platin. Met. Rev., 2001, 45, 62-69.

51. D. İnci, R. Aydın, Ö. Vatan, T. Sevgi, D. Yılmaz, Y. Zorlu, Y. Yerli, B. Çoşut, E. Demirkan and N. Çinkılıç, J. Biol. Inorg. Chem., 2017, 22, 61-85.

52. M. E. Pacheco and L. Bruzzone, J. Lumin., 2012, 132, 2730-2735.

53. F. W. J. Teale, Principles of Fluorescence Spectroscopy, 1984.

54. J. R. Lakowicz, Principles of Fluorescence Spectroscopy, Springer, 2008.

55. Y.-J. Hu, Y. Liu, L.-X. Zhang, R.-M. Zhao and S.-S. Qu, J. Mol. Struct., 2005, 750, 174-178.

56. U. Mote, S. Bhattar, S. Patil and G. Kolekar, Lumin., 2010, 25, 1-8. 
57. J. Xiao, J. Shi, H. Cao, S. Wu, F. Ren and M. Xu, J. Pharm. Biomed. Anal., 2007, 45, 609-615.

58. J. M. Mollerup, Chem. Eng. Technol., 2008, 31, 864-874.

59. P. D. Ross and S. Subramanian, Biochem., 1981, 20, 3096-3102.

60. U. K. Aravind, J. Mathew and C. Aravindakumar, J. Memb. Sci., 2007, 299, 146-155.

61. K. Včeláková, I. Zusková, E. Kenndler and B. Gaš, Electrophoresis, 2004, 25, 309317.

62. F. Wang, W. Huang and Z. Dai, J. Mol. Struct., 2008, 875, 509-514.

63. P. Naik, S. Chimatadar and S. Nandibewoor, Spectrochim. Acta A, 2009, 73, 841-845.

64. C.-Q. Jiang, M.-X. Gao and J.-X. He, Anal. Chim. Acta, 2002, 452, 185-189.

65. Y. Z. Zhang, X. X. Chen, J. Dai, X. P. Zhang, Y. X. Liu and Y. Liu, Lumin., 2008, 23, 150-156.

66. O. Mazuryk, K. Kurpiewska, K. Lewiński, G. Stochel and M. Brindell, J. Inorg. Biochem., 2012, 116, 11-18.

67. M. J. Clarke, Coord. Chem. Rev., 2002, 232, 69-93.

68. S. Zorzet, A. Bergamo, M. Cocchietto, A. Sorc, B. Gava, E. Alessio, E. Iengo and G. Sava, J. Pharmacol. Exp. Ther., 2000, 295, 927-933. 


\title{
Supplementary information on
}

\section{Type of Complex - BSA Binding Forces Affected by Different Coordination Modes of Alliin in Novel Water-Soluble Ruthenium Complexes}

\author{
Adnan Zahirović, ${ }^{1}$ Dijana Žilić, ${ }^{2}$ Sandra Kraljević Pavelić, ${ }^{3}$ Mirsada Hukić, ${ }^{4}$ Senada Muratović, ${ }^{2}$ \\ Anja Harej ${ }^{3}$ and Emira Kahrović ${ }^{*}$ \\ ${ }^{1}$ Department of Chemistry, Faculty of Science, University of Sarajevo, Sarajevo, Bosnia and Herzegovina \\ ${ }^{2}$ Ruđer Bošković Institute, Zagreb, Croatia \\ ${ }^{3}$ Department of Biotechnology, Centre for High-Throughput Technologies, University of Rijeka, Rijeka, Croatia \\ ${ }^{4}$ Institute for Biomedical Research and Diagnostics Nalaz, Sarajevo, Bosnia and Herzegovina
}

\section{Contents}

Figure S1. Theoretical isotopic distribution for molecular ion of complex (1). .3

Figure S2. Measured isotopic distribution for molecular ion of complex (1) ......................................

Figure S3. Theoretical isotopic distribution for molecular ion of complex (2). ......................................4

Figure S4. Measured isotopic distribution for molecular ion of complex (2) ......................................4

Figure S5. Theoretical isotopic distribution for molecular ion of complex (3) . ...................................5

Figure S6. Measured isotopic distribution for molecular ion of complex (3) .......................................5

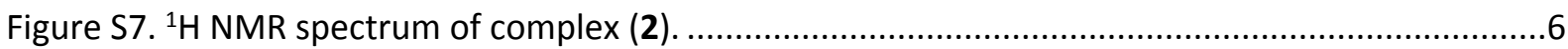

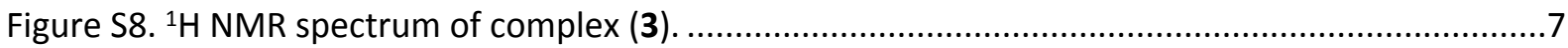

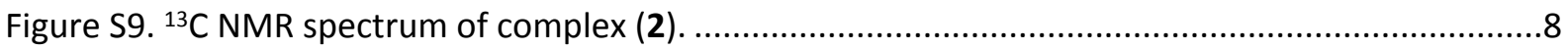

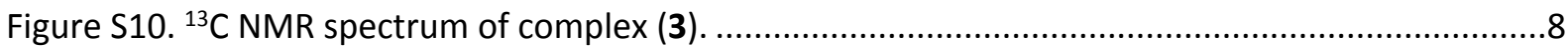

Figure S11. Infrared spectra of alliin at different protonation of amine nitrogen and carboxylate oxygen, ruthenium - alliin complexes $(\mathbf{1})$ - (3) and starting ruthenium compounds. ..........................9

Table S1. Positions of the bands in infrared spectra of complexes (1) - (3), starting Ru compounds and alliin.

Figure S12. The comparison of ESR signals of (2) and (3).

Figure S13. Quenching of the apotransferrin fluorescence in the absence and presence of an increasing concentrations of $(\mathbf{1})-(\mathbf{3})(\mathrm{a}-\mathrm{c})$ and alliin $(\mathrm{d})$ at $298 \mathrm{~K}$.

Figure S14. Quenching of BSA fluorescence in the absence and presence of an increasing concentrations of $(\mathbf{1})-(\mathbf{3})(\mathrm{a}-\mathrm{c})$ and alliin $(\mathrm{d})$ at $291 \mathrm{~K}$.

Figure S15. Quenching of BSA fluorescence in the absence and presence of an increasing concentrations of $(\mathbf{1})-(\mathbf{3})(\mathrm{a}-\mathrm{c})$ and alliin (d) at $298 \mathrm{~K}$.

Figure S16. Quenching of BSA fluorescence in the absence and presence of an increasing concentrations of $(\mathbf{1})-(\mathbf{3})(\mathrm{a}-\mathrm{c})$ and alliin $(\mathrm{d})$ at $298 \mathrm{~K}$. 
Figure S18. 3D fluorescence spectra of BSA in absence (a) and presence of complex (1) - (3) $(b-d)$ and alliin (e). [BSA] = $1.71 \mu \mathrm{M}$ and [complex] $=12.5 \mu \mathrm{M}$.

Figure S19. Overlap of fluorescence emission spectrum of BSA and absorption spectrum of: a) (1), b) (2), c) (3) and d) alliin...

Figure S20. Graphical determination of the binding constant $\left(K_{b}\right)$ and number of binding sites $(n)$ of complex (1) to BSA at three temperatures: a) $291 \mathrm{~K}$, b) $298 \mathrm{~K}$, c) $305 \mathrm{~K}$ and d) van't Hoff plot.

Figure S21. Graphical determination of the binding constant $\left(K_{b}\right)$ and number of binding sites $(n)$ of complex (2) to BSA at three temperatures: a) $291 \mathrm{~K}$, b) $298 \mathrm{~K}$, c) $305 \mathrm{~K}$ and d) van't Hoff plot.

Figure S22. Graphical determination of the binding constant $\left(K_{b}\right)$ and number of binding sites $(n)$ of complex (3) to BSA at three temperatures: a) $291 \mathrm{~K}$, b) $298 \mathrm{~K}$, c) $305 \mathrm{~K}$ and d) van't Hoff plot.

Figure S23. Graphical determination of the binding constant $\left(\mathrm{K}_{\mathrm{b}}\right)$ and number of binding sites $(\mathrm{n})$ of alliin to BSA at three temperatures: a) $291 \mathrm{~K}$, b) $298 \mathrm{~K}$, c) $305 \mathrm{~K}$ and d) van't Hoff plot.

Figure S24. Graphical determination of the binding constant $\left(\mathrm{K}_{\mathrm{b}}\right)$ and number of binding sites $(\mathrm{n})$ of complexes $(\mathbf{1})-(\mathbf{3})(\mathrm{a}-\mathrm{c})$ and alliin (d) with apotransferrin.

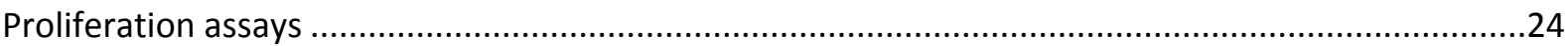

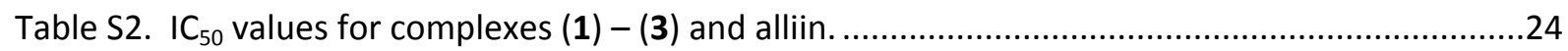




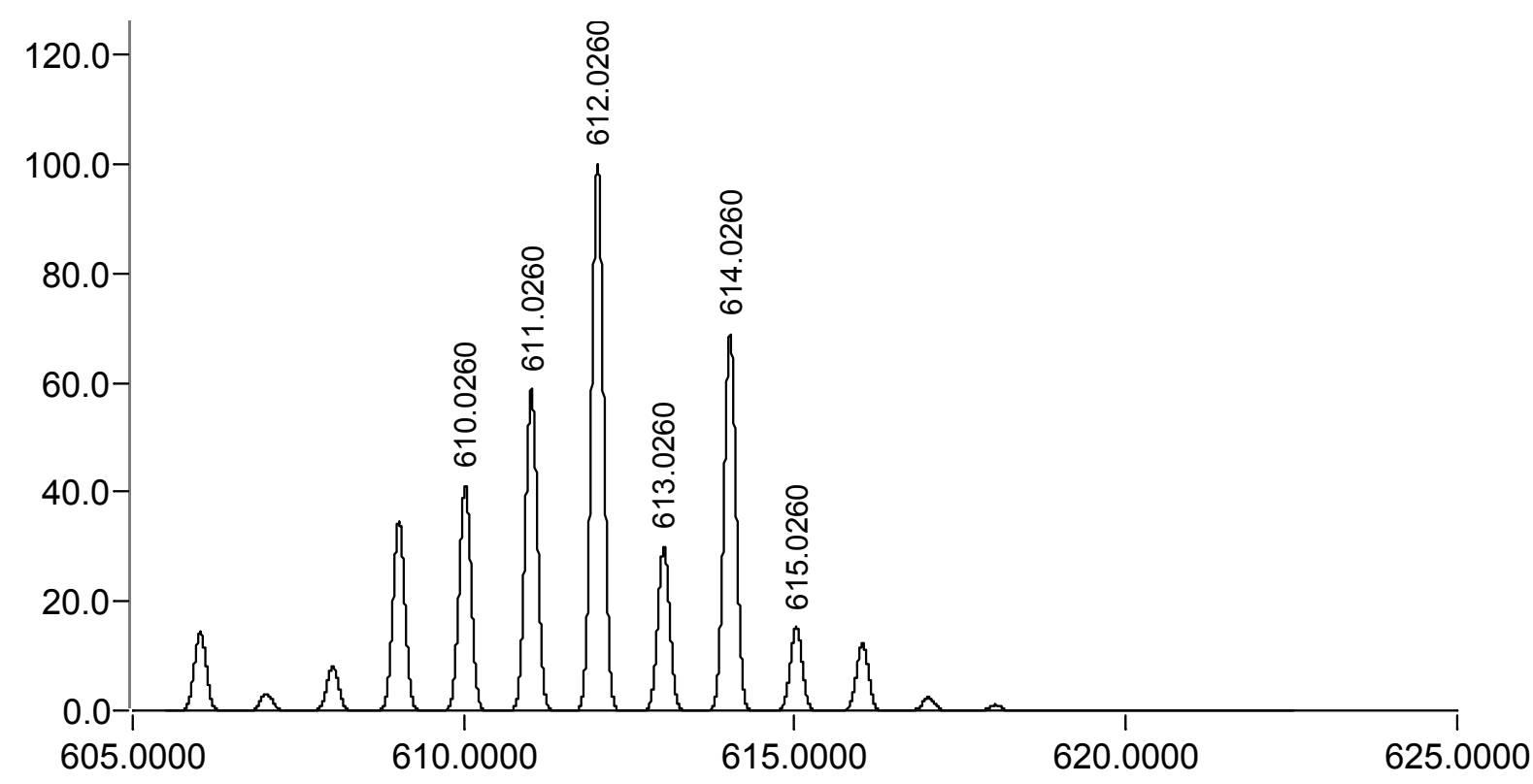

Figure S1. Theoretical isotopic distribution for molecular ion of complex (1).

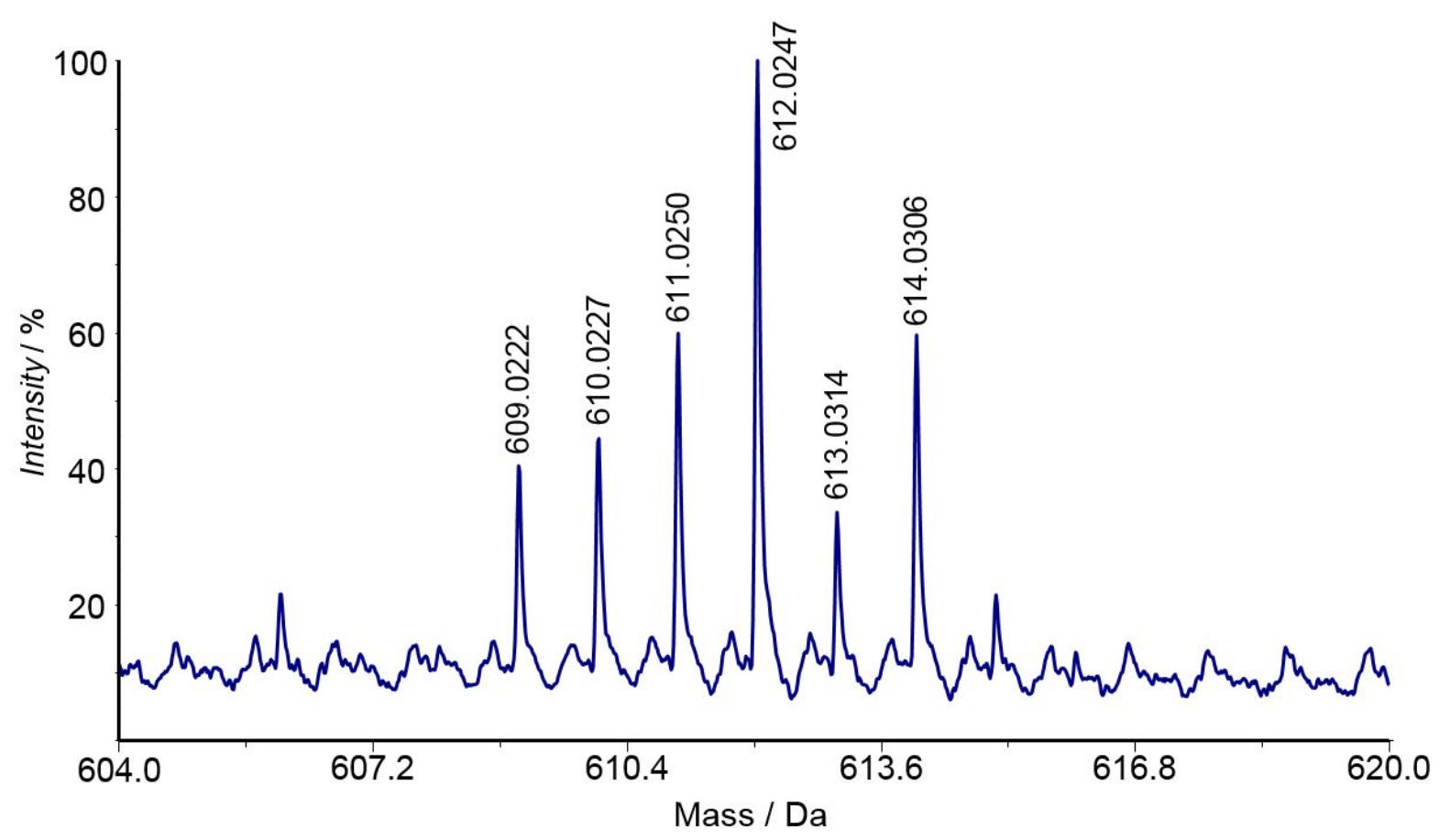

Figure S2. Measured isotopic distribution for molecular ion of complex (1). 


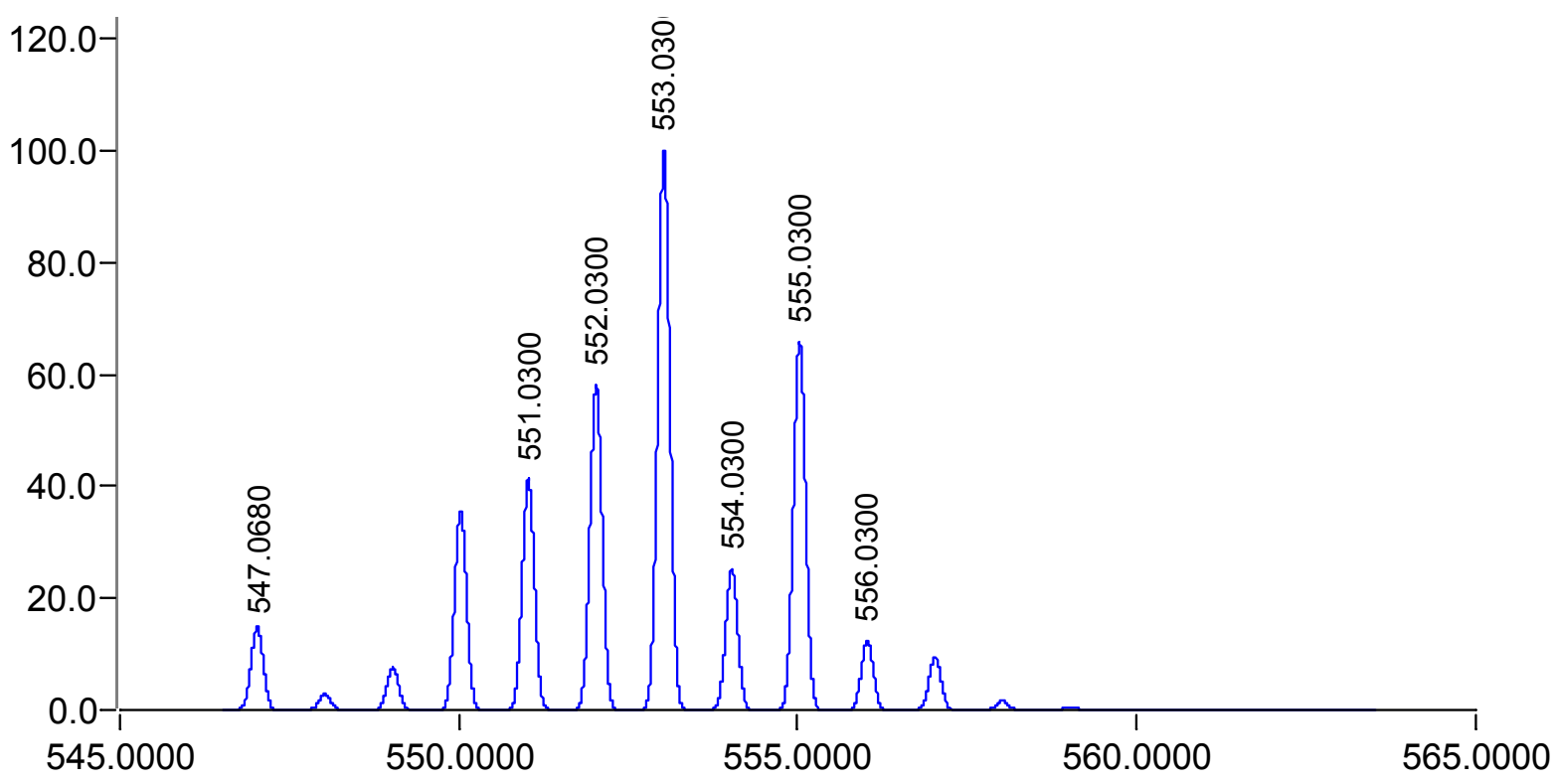

Figure S3. Theoretical isotopic distribution for molecular ion of complex (2).

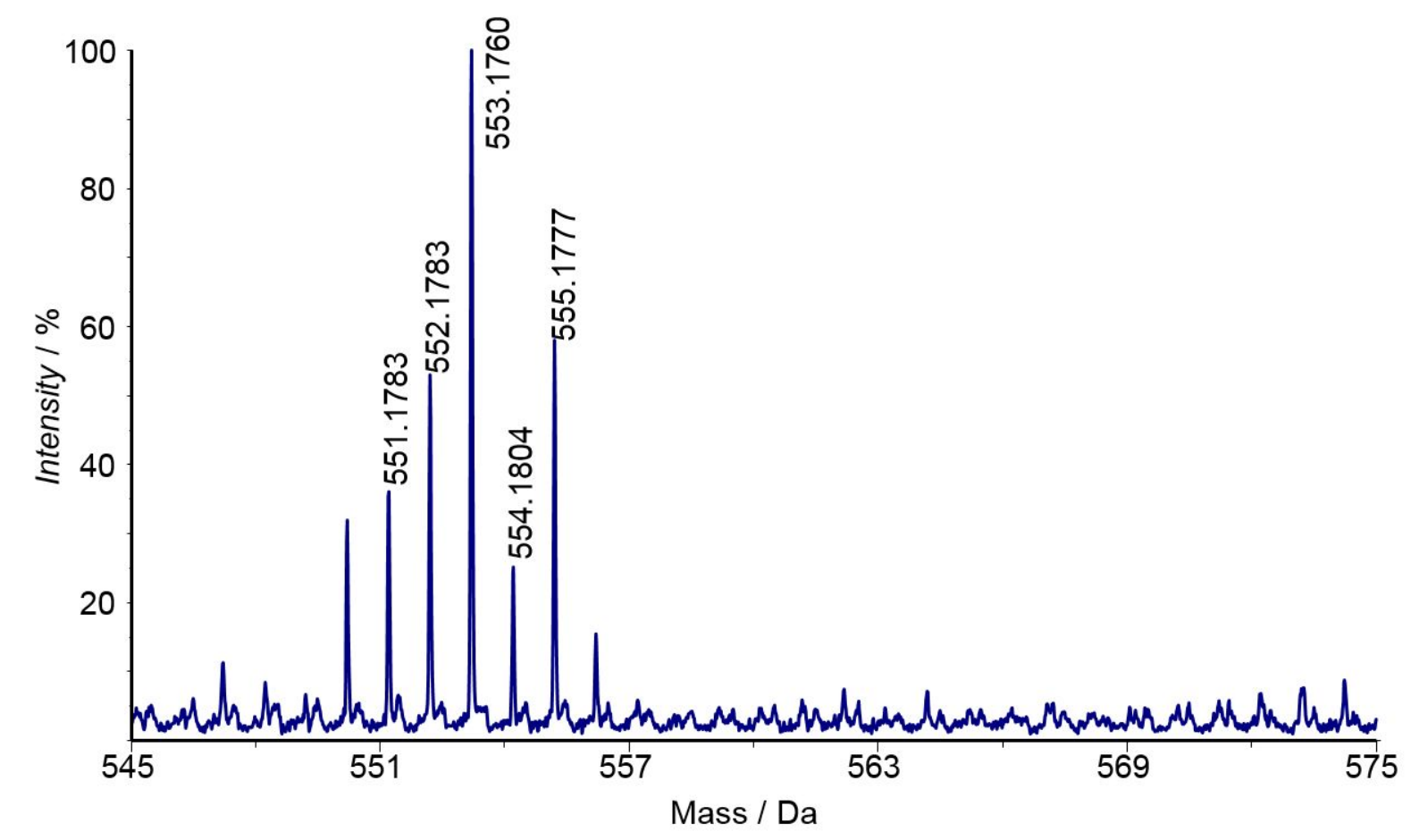

Figure S4. Measured isotopic distribution for molecular ion of complex (2). 


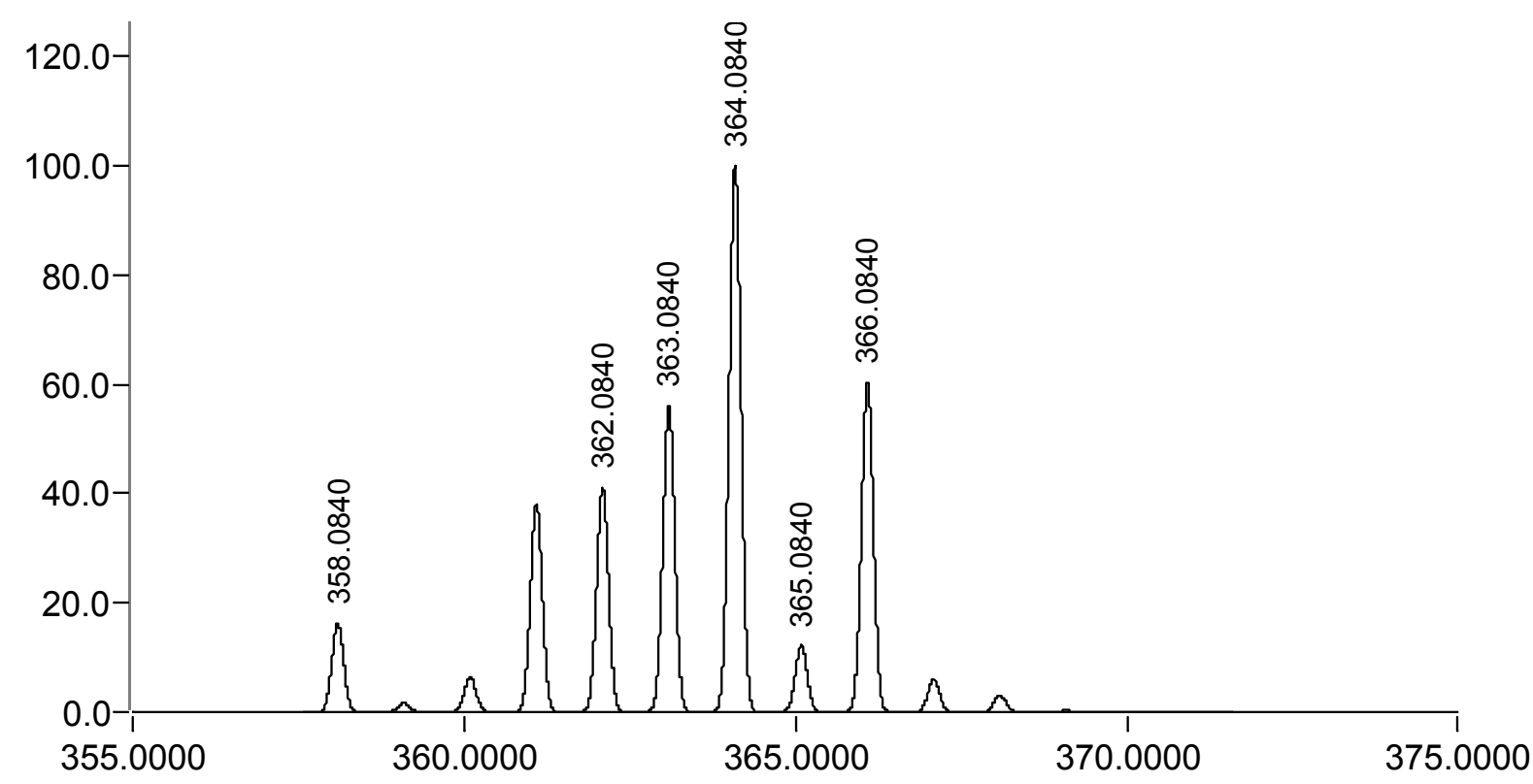

Figure S5. Theoretical isotopic distribution for molecular ion of complex (3).

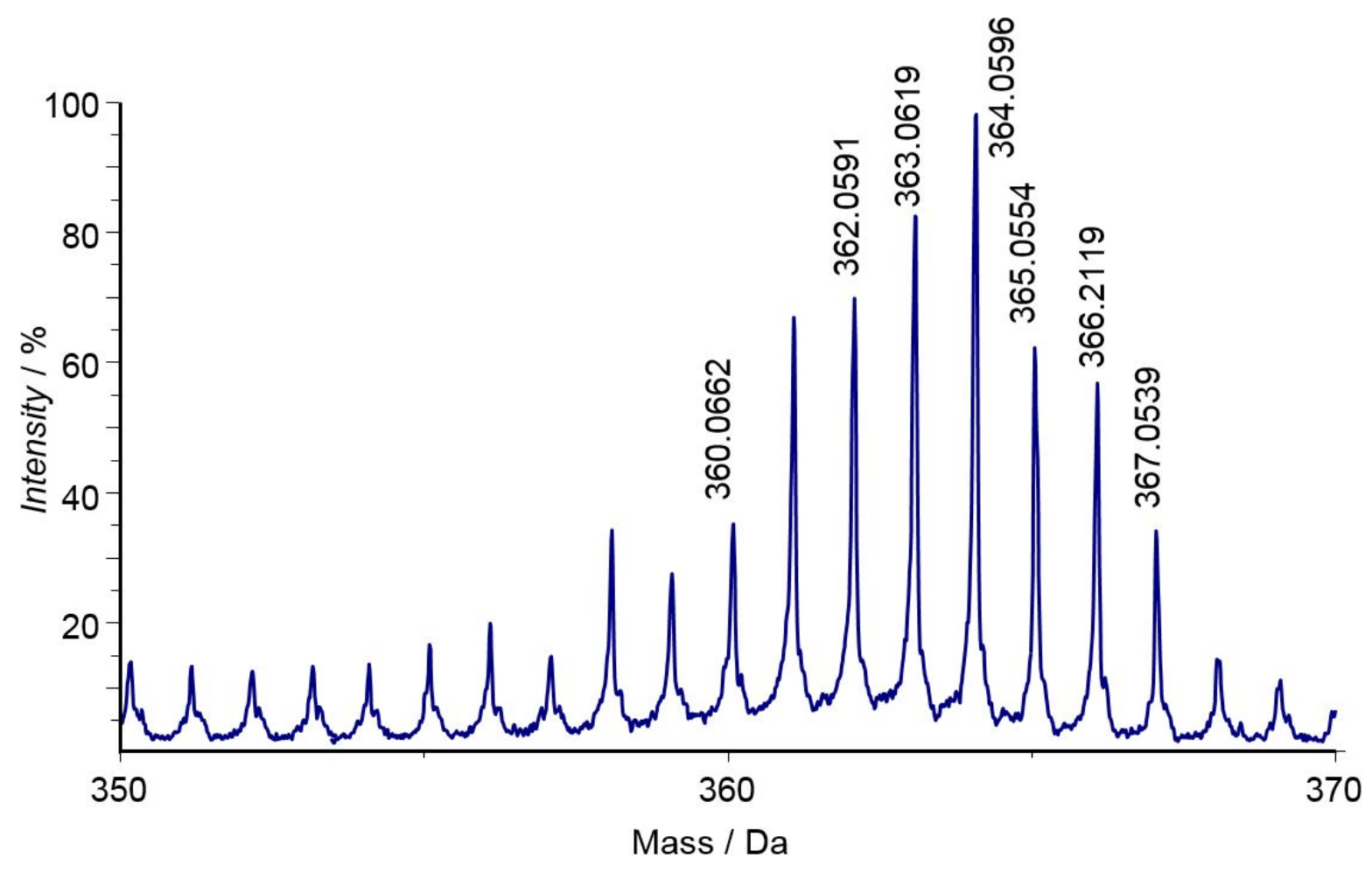

Figure S6. Measured isotopic distribution for molecular ion of complex (3). 


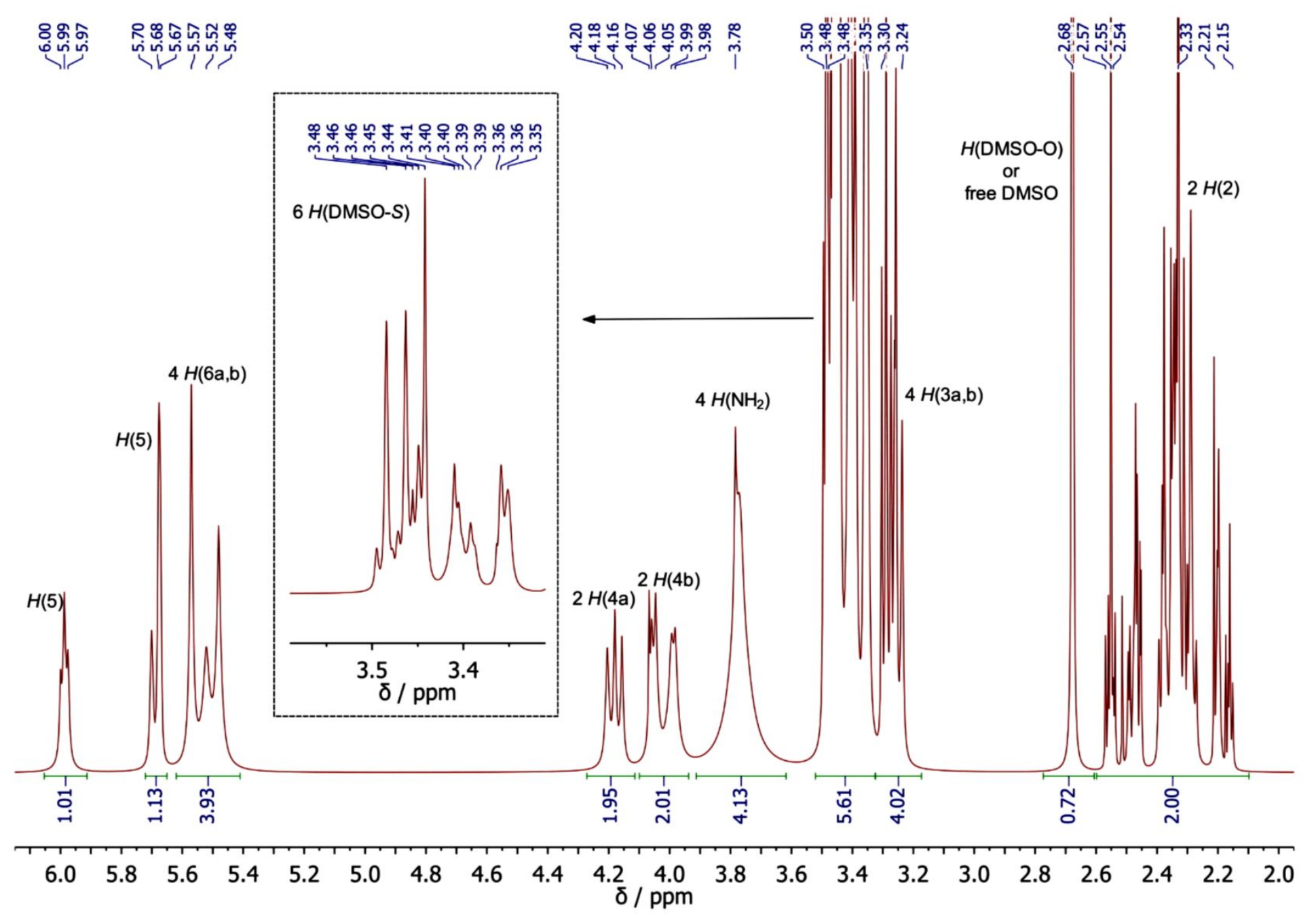

Figure S7. ${ }^{1} \mathrm{H}$ NMR spectrum of complex (2). 


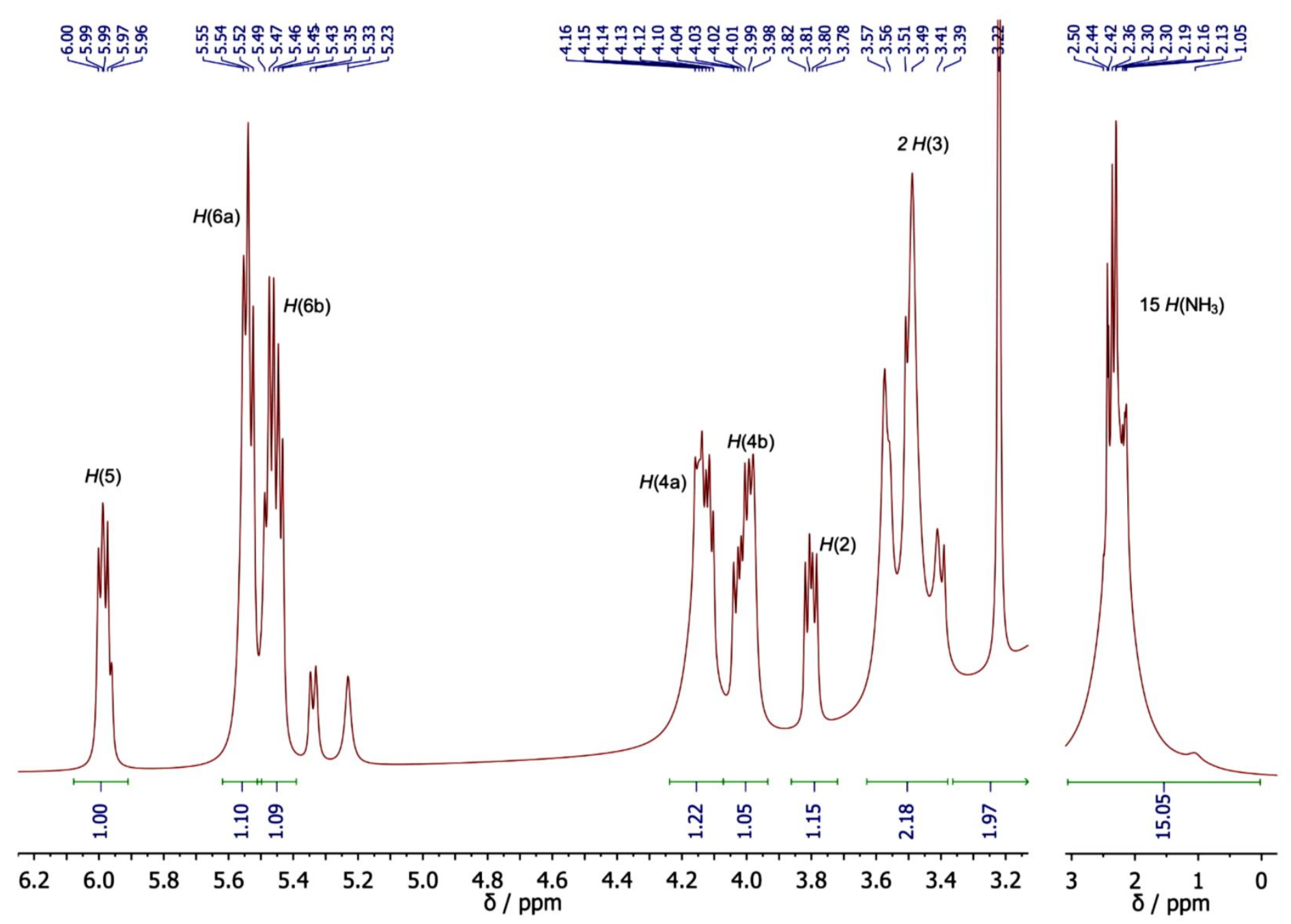

Figure S8. ${ }^{1} \mathrm{H}$ NMR spectrum of complex (3). 


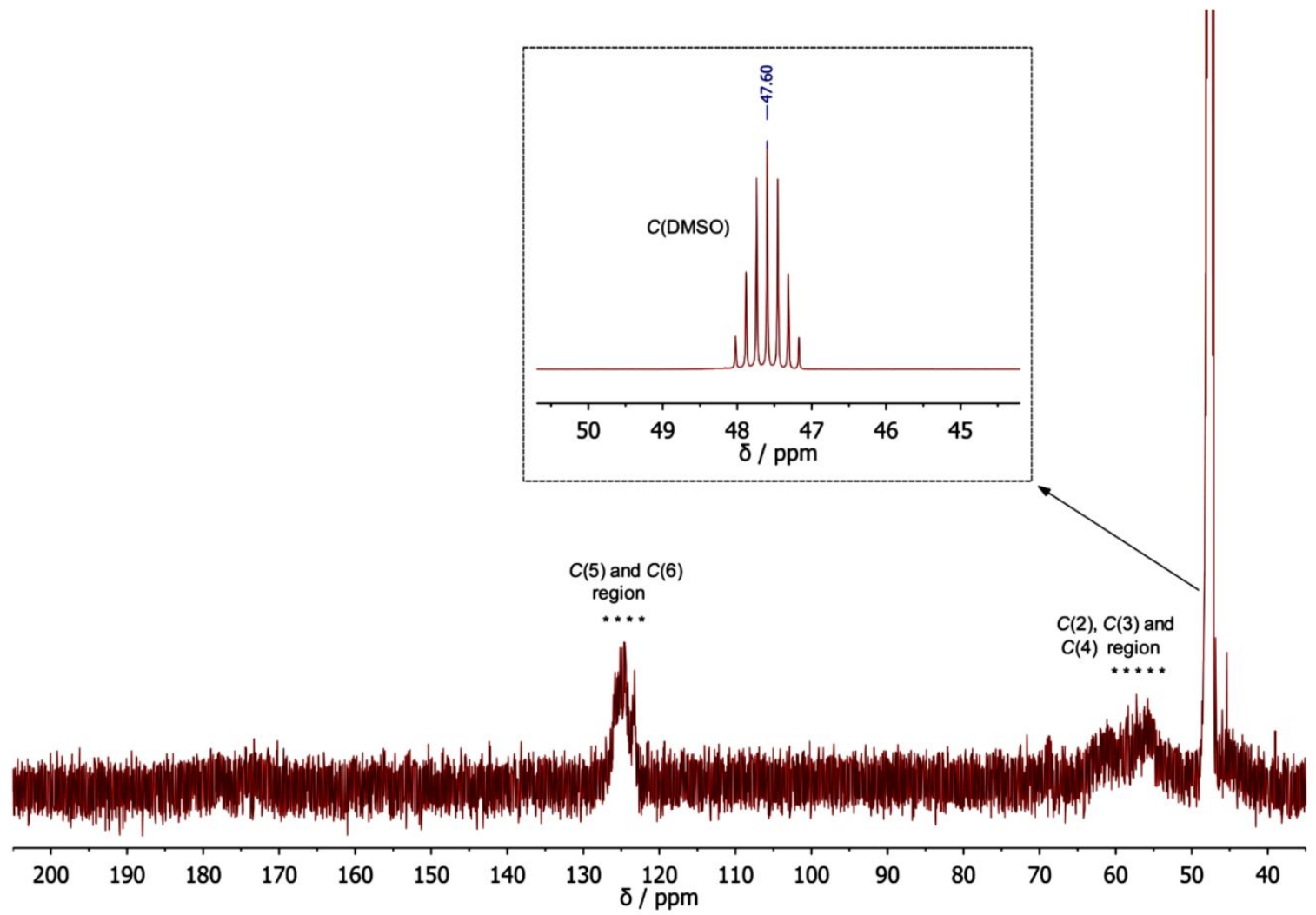

Figure S9. ${ }^{13} \mathrm{C}$ NMR spectrum of complex (2).
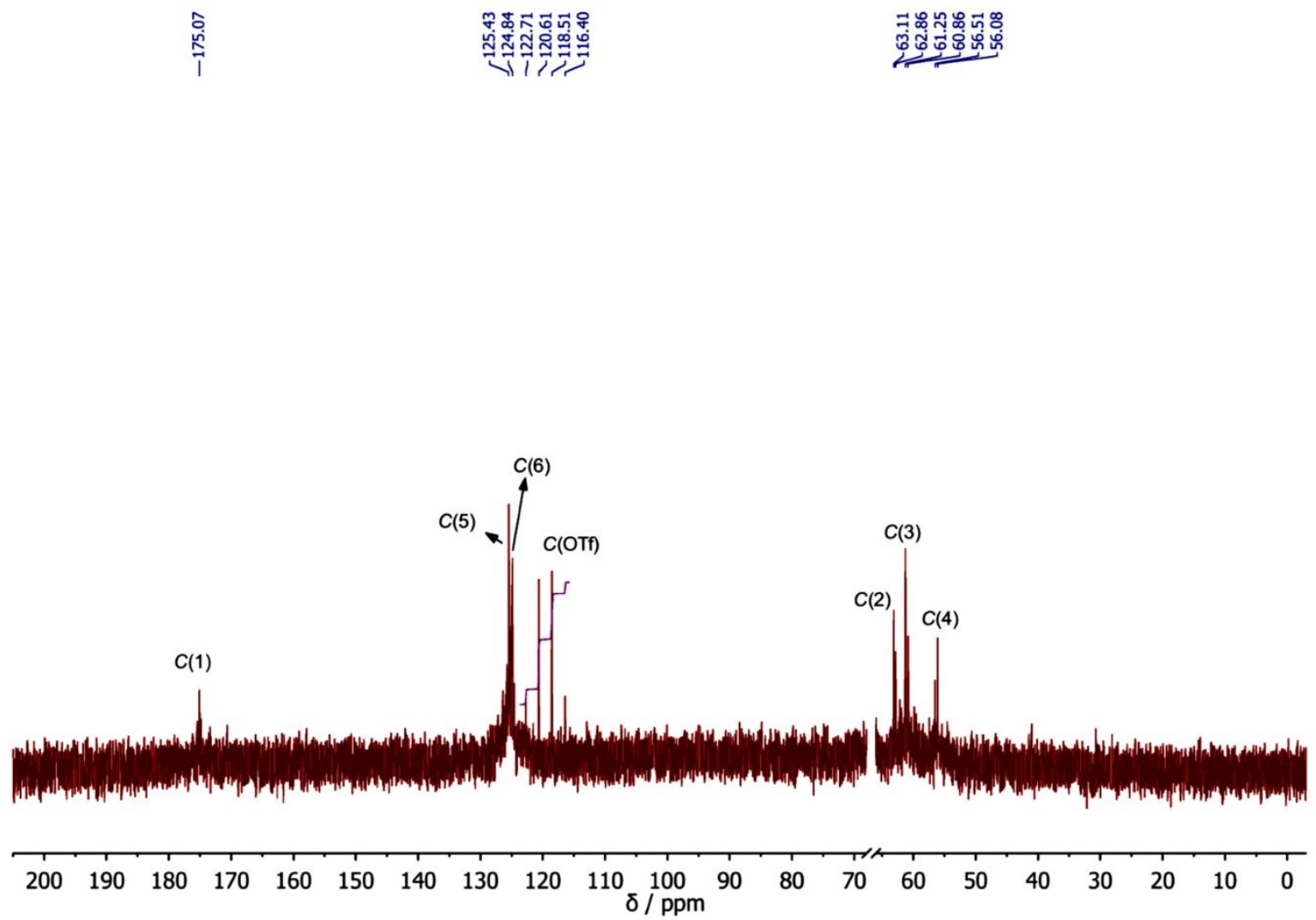

Figure S10. ${ }^{13} \mathrm{C}$ NMR spectrum of complex (3). 

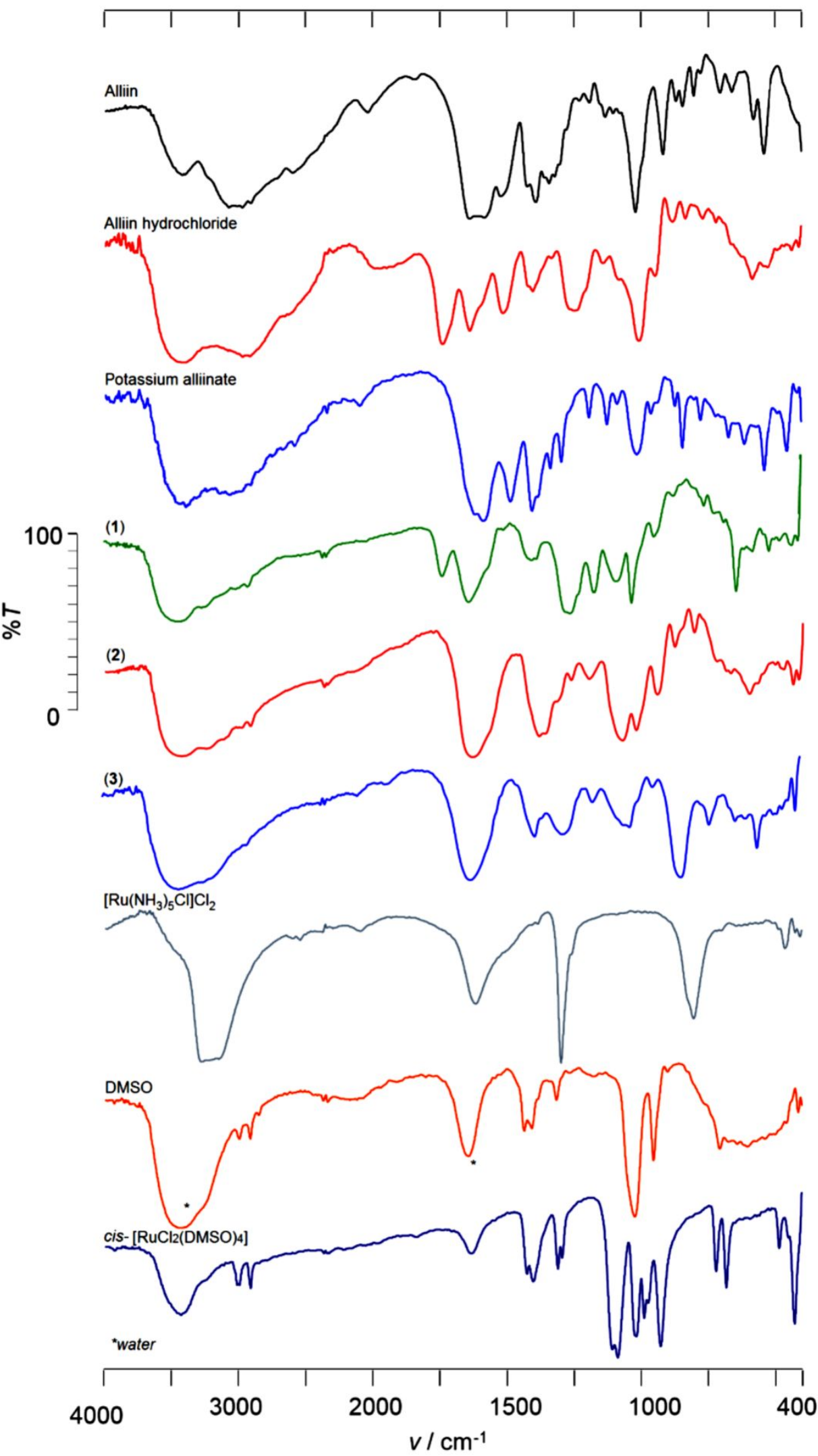

Figure S11. Infrared spectra of alliin at different protonation of amine nitrogen and carboxylate oxygen, ruthenium - alliin complexes (1) - (3) and starting ruthenium compounds. 
Table S1. Positions of the bands in infrared spectra of complexes (1) - (3), starting Ru compounds and alliin.

\begin{tabular}{|c|c|c|c|c|c|c|c|c|c|c|c|c|c|c|c|c|c|c|c|}
\hline \multirow{2}{*}{ 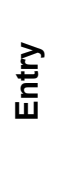 } & \multirow{2}{*}{ Compound } & \multirow{2}{*}{ 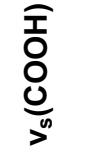 } & \multirow{2}{*}{$\begin{array}{l}\text { J } \\
\underset{>}{0}\end{array}$} & \multirow{2}{*}{$\begin{array}{l}\widehat{\delta} \\
\stackrel{0}{0} \\
>^{n}\end{array}$} & \multirow{2}{*}{ 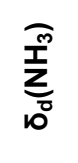 } & \multirow{2}{*}{$\frac{\widehat{T}}{\sum_{10}}$} & \multirow{2}{*}{ 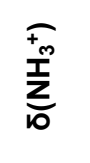 } & \multirow{2}{*}{$\begin{array}{l}\hat{\delta} \\
\hat{0} \\
\frac{0}{n} \\
>^{n}\end{array}$} & \multirow{2}{*}{\multicolumn{2}{|c|}{ 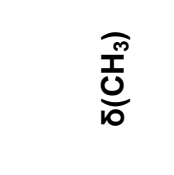 }} & \multirow{2}{*}{\multicolumn{2}{|c|}{$\frac{\widehat{m}}{\sum_{10}^{\frac{m}{2}}}$}} & \multirow{2}{*}{ 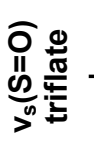 } & \multicolumn{4}{|c|}{$v_{s}(S=0)$} & \multirow{2}{*}{$\begin{array}{l}\widehat{\overline{\mathbf{z}}} \\
\underline{\underline{j}} \\
>^{n}\end{array}$} & \multirow{2}{*}{$\underset{\frac{1}{2}}{\frac{\widehat{m}}{0}}$} \\
\hline & & & & & & & & & & & & & & $S$-bo & ided & $\stackrel{\Xi}{\varrho}$ & ó & & \\
\hline 1. & Alliin & & $\begin{array}{c}164 \\
1\end{array}$ & $\begin{array}{c}161 \\
1\end{array}$ & & $\begin{array}{c}158 \\
5\end{array}$ & $\begin{array}{c}152 \\
5\end{array}$ & $\begin{array}{c}139 \\
1\end{array}$ & & & & & & & & $\begin{array}{c}102 \\
1\end{array}$ & & $\begin{array}{c}99 \\
3\end{array}$ & \\
\hline 2. & $\begin{array}{l}\text { Alliin } \\
\text { hydrochloride }\end{array}$ & $\begin{array}{c}174 \\
0\end{array}$ & $\begin{array}{c}164 \\
0\end{array}$ & & & & $\begin{array}{c}151 \\
4\end{array}$ & & & & & & & & & $\begin{array}{c}100 \\
8\end{array}$ & & & \\
\hline 3. & $\begin{array}{l}\text { Potassium } \\
\text { alliinate }\end{array}$ & & $\begin{array}{c}162 \\
0\end{array}$ & $\begin{array}{c}162 \\
0\end{array}$ & & $\begin{array}{c}158 \\
7\end{array}$ & $\begin{array}{c}148 \\
8\end{array}$ & $\begin{array}{c}140 \\
8\end{array}$ & & & & & & & & $\begin{array}{c}101 \\
5\end{array}$ & & & \\
\hline 4. & (1) & $\begin{array}{c}173 \\
8\end{array}$ & $\begin{array}{c}164 \\
0\end{array}$ & & & $\begin{array}{c}156 \\
5\end{array}$ & - & & & $\begin{array}{c}140 \\
4\end{array}$ & $\begin{array}{c}138 \\
6\end{array}$ & & $\begin{array}{c}127 \\
7\end{array}$ & $\begin{array}{c}108 \\
9\end{array}$ & $\begin{array}{c}103 \\
2\end{array}$ & & & $\begin{array}{c}94 \\
8\end{array}$ & \\
\hline 5. & (2) & & $\begin{array}{c}163 \\
2\end{array}$ & $\begin{array}{c}163 \\
2\end{array}$ & & $\begin{array}{c}158 \\
5\end{array}$ & - & $\begin{array}{c}138 \\
3\end{array}$ & & $\begin{array}{c}140 \\
5\end{array}$ & $\begin{array}{c}138 \\
3\end{array}$ & & & $\begin{array}{c}107 \\
2\end{array}$ & & $\begin{array}{c}102 \\
1\end{array}$ & & $\begin{array}{c}94 \\
3\end{array}$ & \\
\hline 6. & (3) & & $\begin{array}{c}162 \\
9\end{array}$ & $\begin{array}{c}162 \\
9\end{array}$ & & & - & $\begin{array}{c}138 \\
7\end{array}$ & & & & $\begin{array}{c}128 \\
7\end{array}$ & $\begin{array}{c}127 \\
9\end{array}$ & & & $\begin{array}{c}103 \\
2\end{array}$ & & $\begin{array}{c}99 \\
8\end{array}$ & $\begin{array}{c}84 \\
3\end{array}$ \\
\hline 7. & {$\left[\mathrm{Ru}\left(\mathrm{NH}_{3}\right)_{5} \mathrm{Cl}\right] \mathrm{Cl}_{2}$} & & & & $\begin{array}{c}163 \\
0\end{array}$ & & & & & & & $\begin{array}{c}130 \\
0\end{array}$ & & & & & & & $\begin{array}{c}80 \\
4\end{array}$ \\
\hline 8. & Dimethyl sulfoxide & & & & & & & & $\begin{array}{c}143 \\
6\end{array}$ & $\begin{array}{c}140 \\
7\end{array}$ & & & & & & $\begin{array}{c}102 \\
3\end{array}$ & & & \\
\hline 9. & $\begin{array}{l}\text { cis- } \\
{\left[\mathrm{RuCl}_{2}(\mathrm{DMSO})_{4}\right]}\end{array}$ & & & & & & & & $\begin{array}{c}142 \\
6\end{array}$ & $\begin{array}{c}140 \\
1\end{array}$ & & & & $\begin{array}{c}108 \\
7\end{array}$ & & & $\begin{array}{c}92 \\
6\end{array}$ & & \\
\hline
\end{tabular}




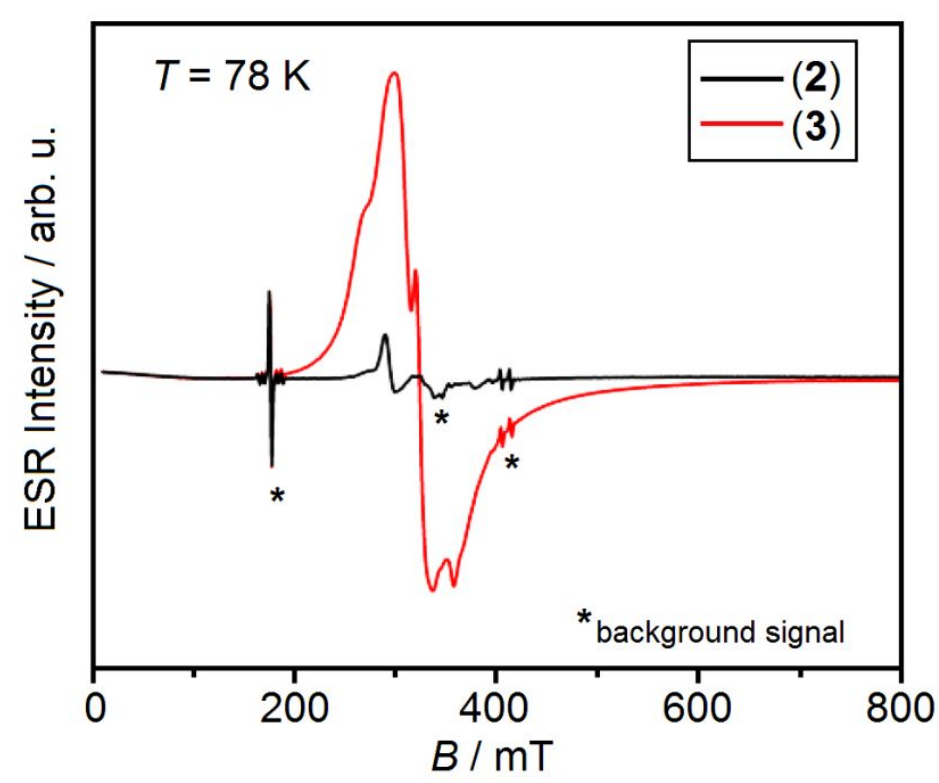

Figure S12. The comparison of ESR signals of (2) and (3). 

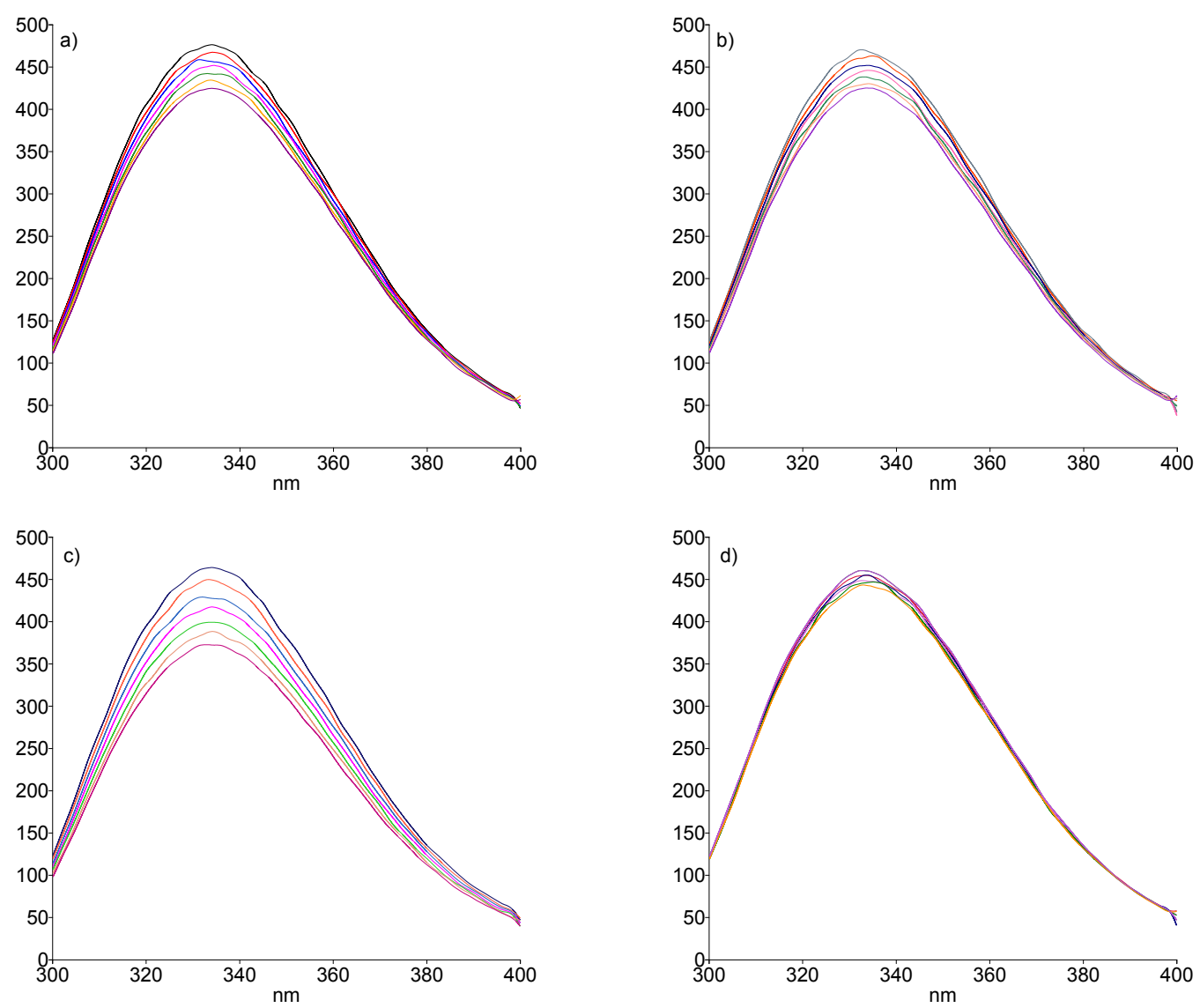

Figure S13. Quenching of the apotransferrin fluorescence in the absence and presence of an increasing concentrations of $(\mathbf{1})-(\mathbf{3})(\mathrm{a}-\mathrm{c})$ and alliin (d) at $298 \mathrm{~K}$. 

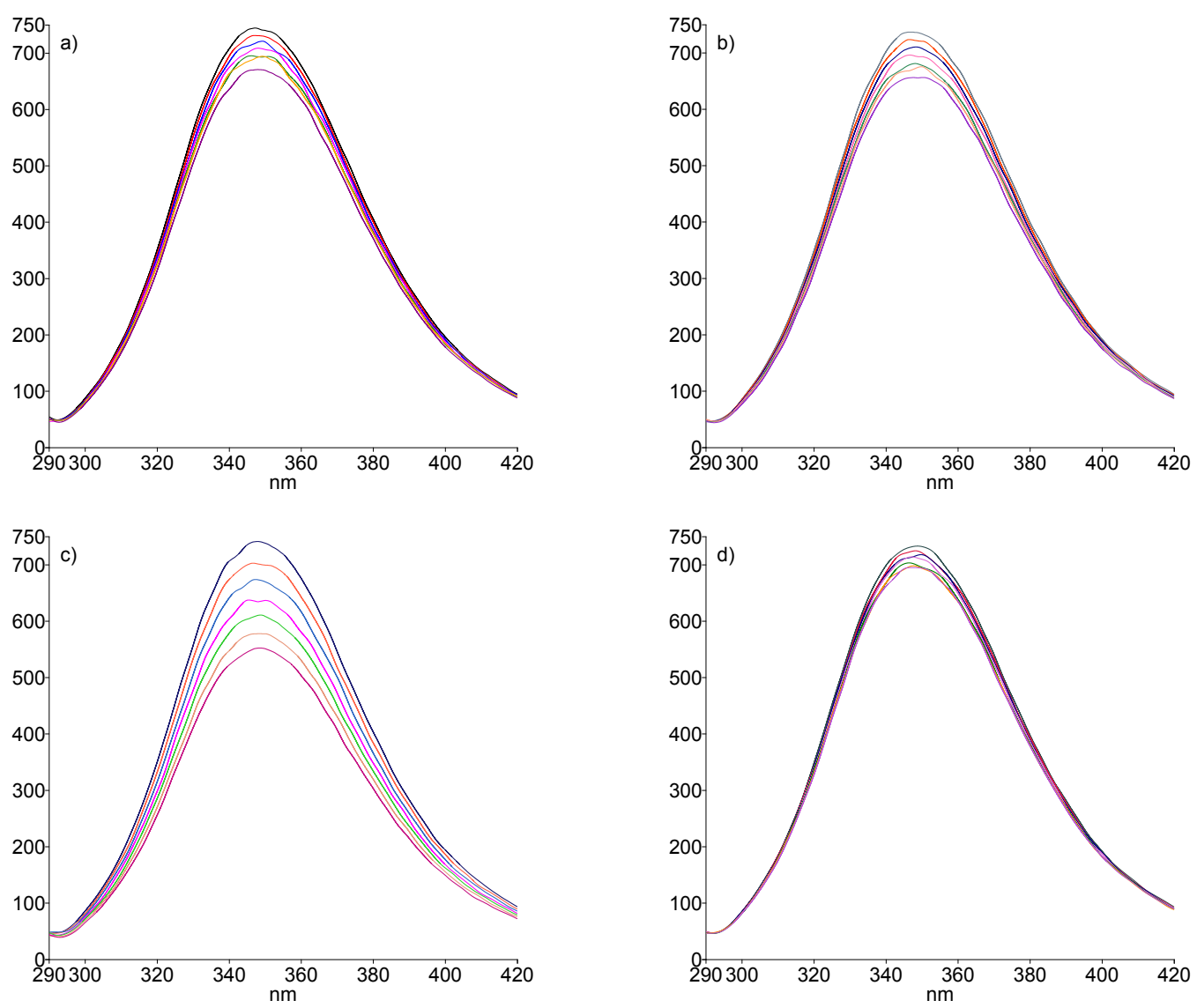

Figure S14. Quenching of BSA fluorescence in the absence and presence of an increasing concentrations of $(\mathbf{1})-(\mathbf{3})(\mathrm{a}-\mathrm{c})$ and alliin (d) at $291 \mathrm{~K}$. 

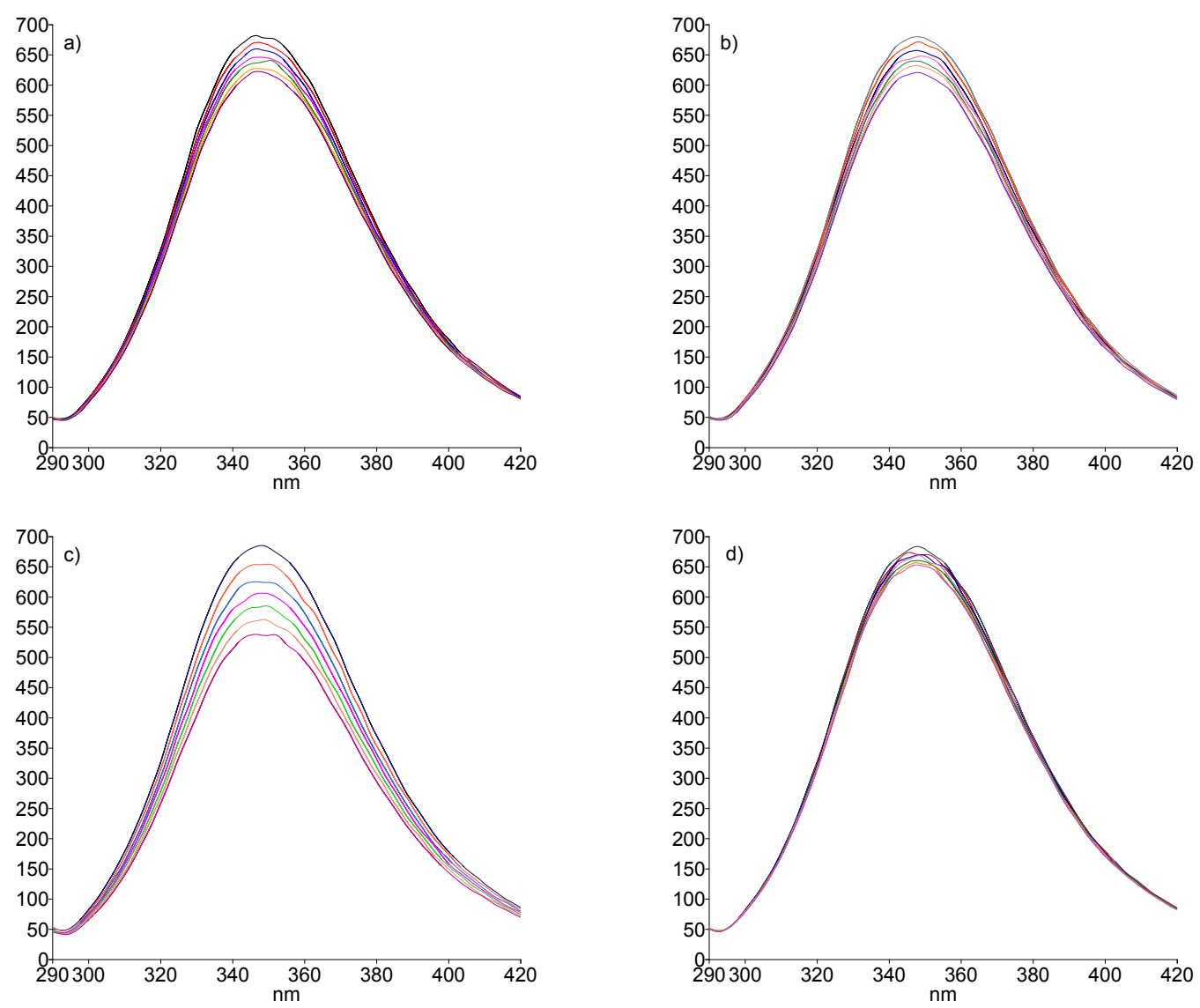

Figure S15. Quenching of BSA fluorescence in the absence and presence of an increasing concentrations of $(\mathbf{1})-(\mathbf{3})(\mathrm{a}-\mathrm{c})$ and alliin (d) at $298 \mathrm{~K}$. 

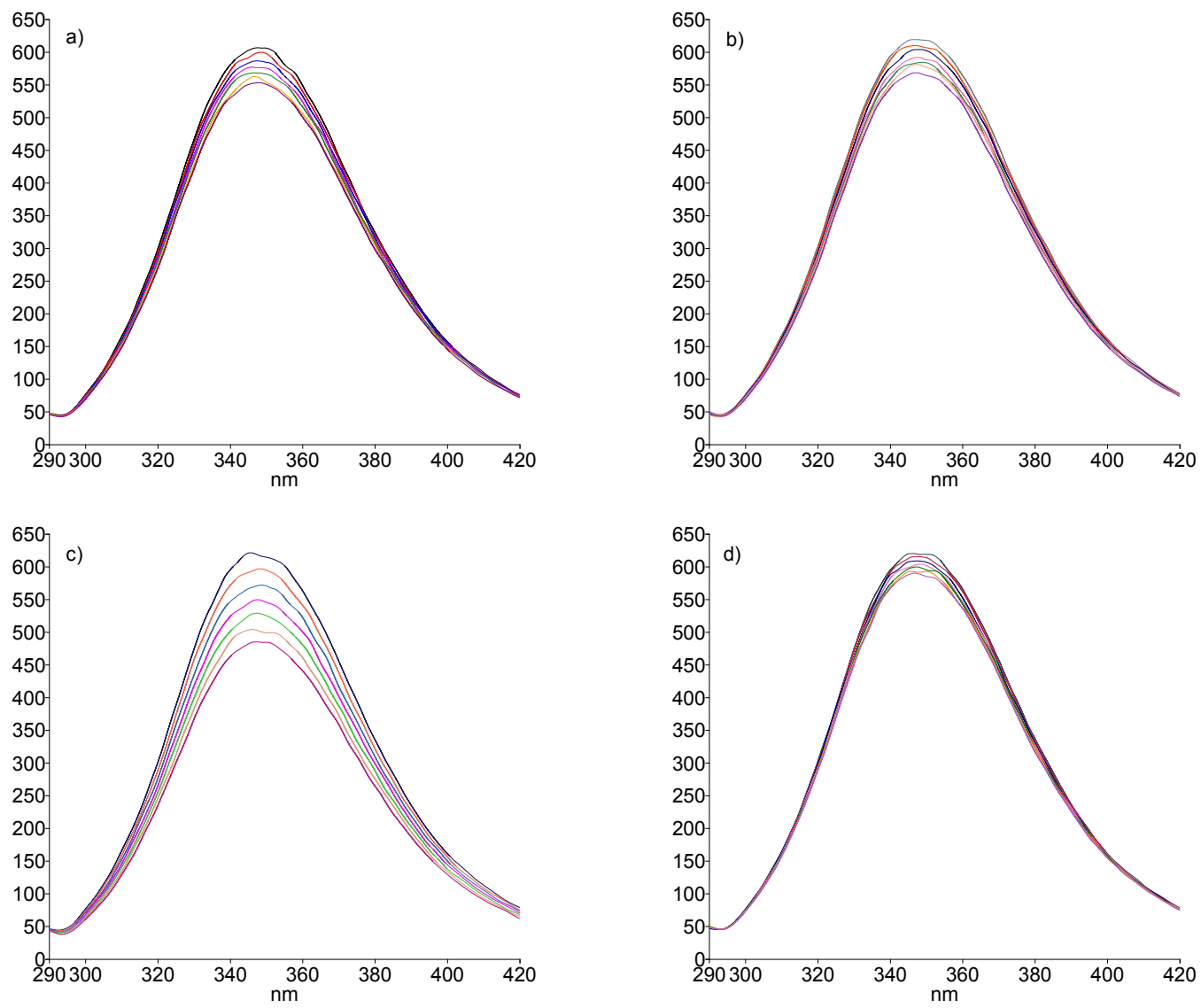

Figure S16. Quenching of BSA fluorescence in the absence and presence of an increasing concentrations of $(\mathbf{1})-(\mathbf{3})(\mathrm{a}-\mathrm{c})$ and alliin (d) at $298 \mathrm{~K}$. 

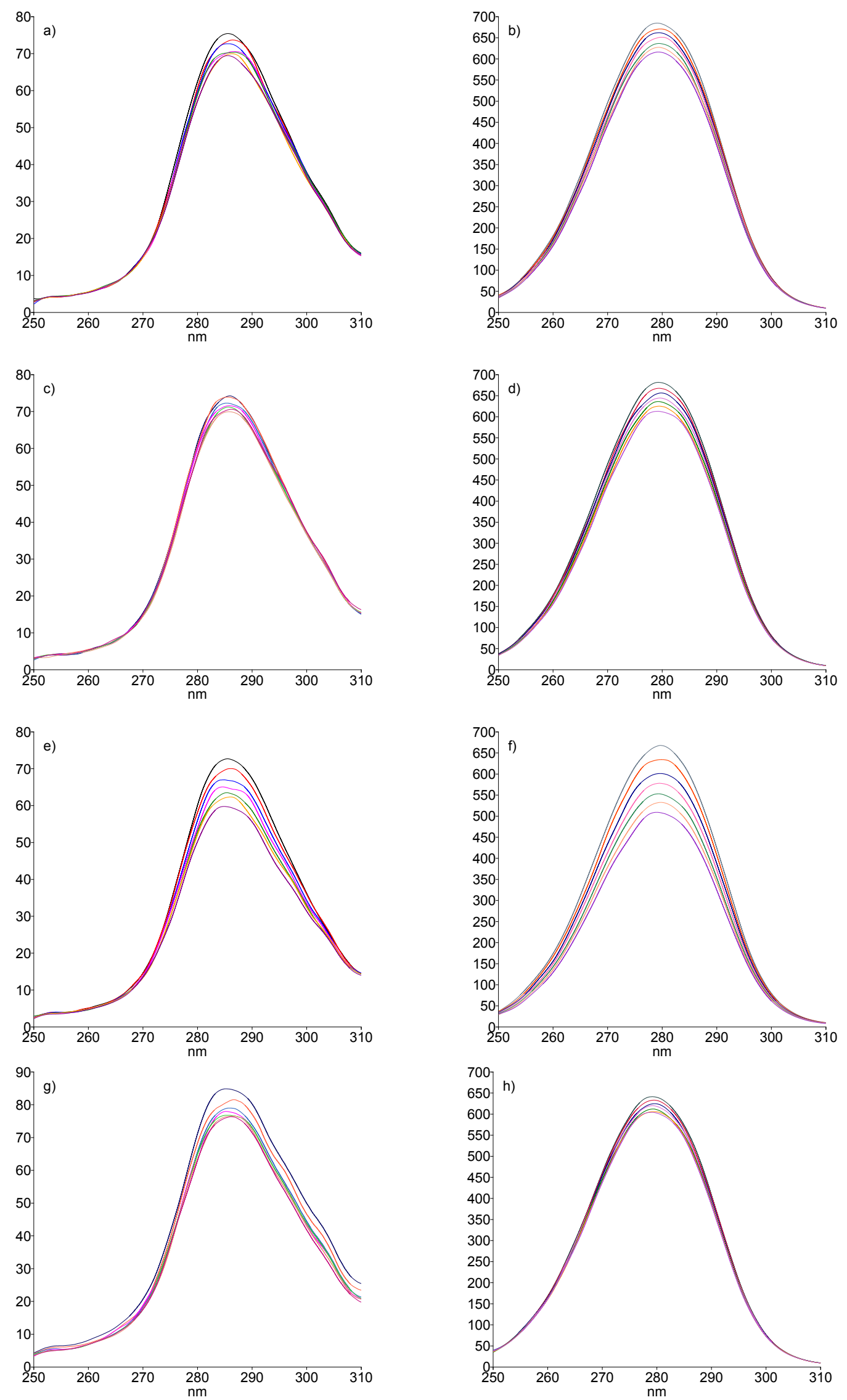

Figure S17. Synchronous fluorescence spectra of BSA in the absence and presence of increasing concentrations of complexes (1) (a, b), (2) (c, d), (3) (e, f) and alliin (g, h); $\Delta \lambda=15 \mathrm{~nm}$ (left column) and $\Delta \lambda=60 \mathrm{~nm}$ (right column). 


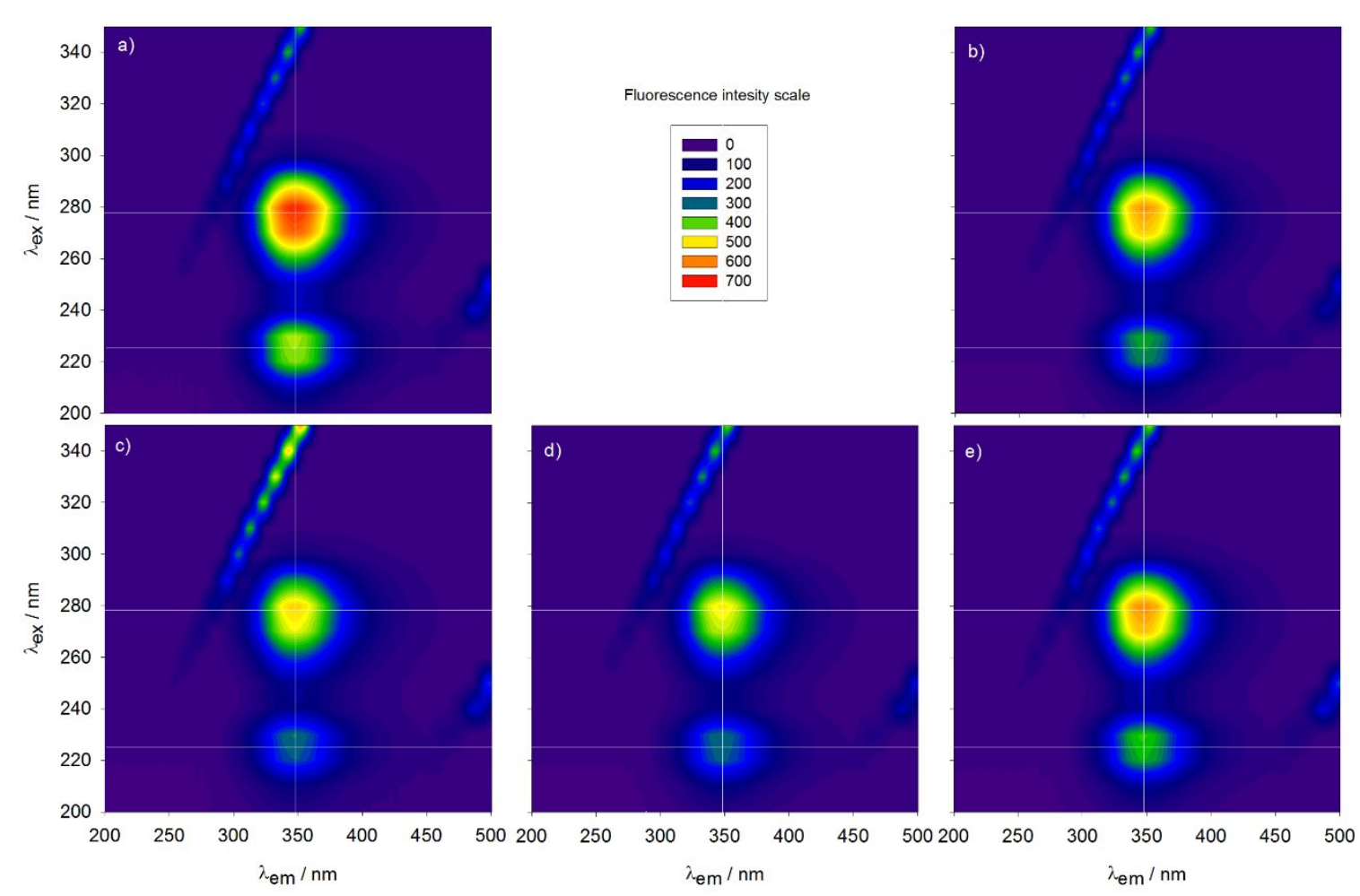

Figure S18. 3D fluorescence spectra of BSA in absence (a) and presence of complex (1) - (3) $(b-d)$ and alliin (e). $[\mathrm{BSA}]=1.71 \mu \mathrm{M}$ and [complex] $=12.5 \mu \mathrm{M}$. 

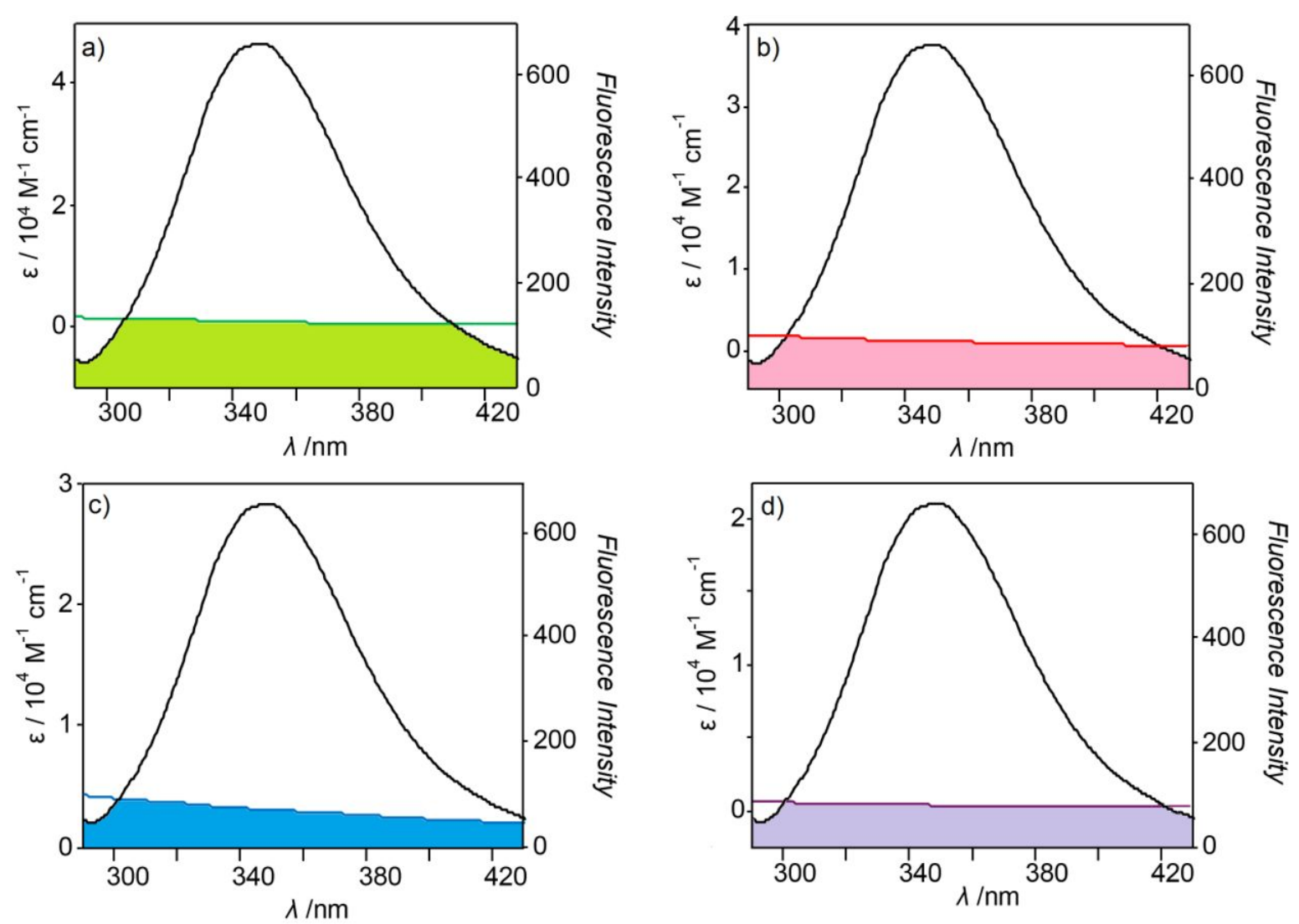

Figure S19. Overlap of fluorescence emission spectrum of BSA and absorption spectrum of: a) (1), b) (2), c) (3) and d) alliin. 

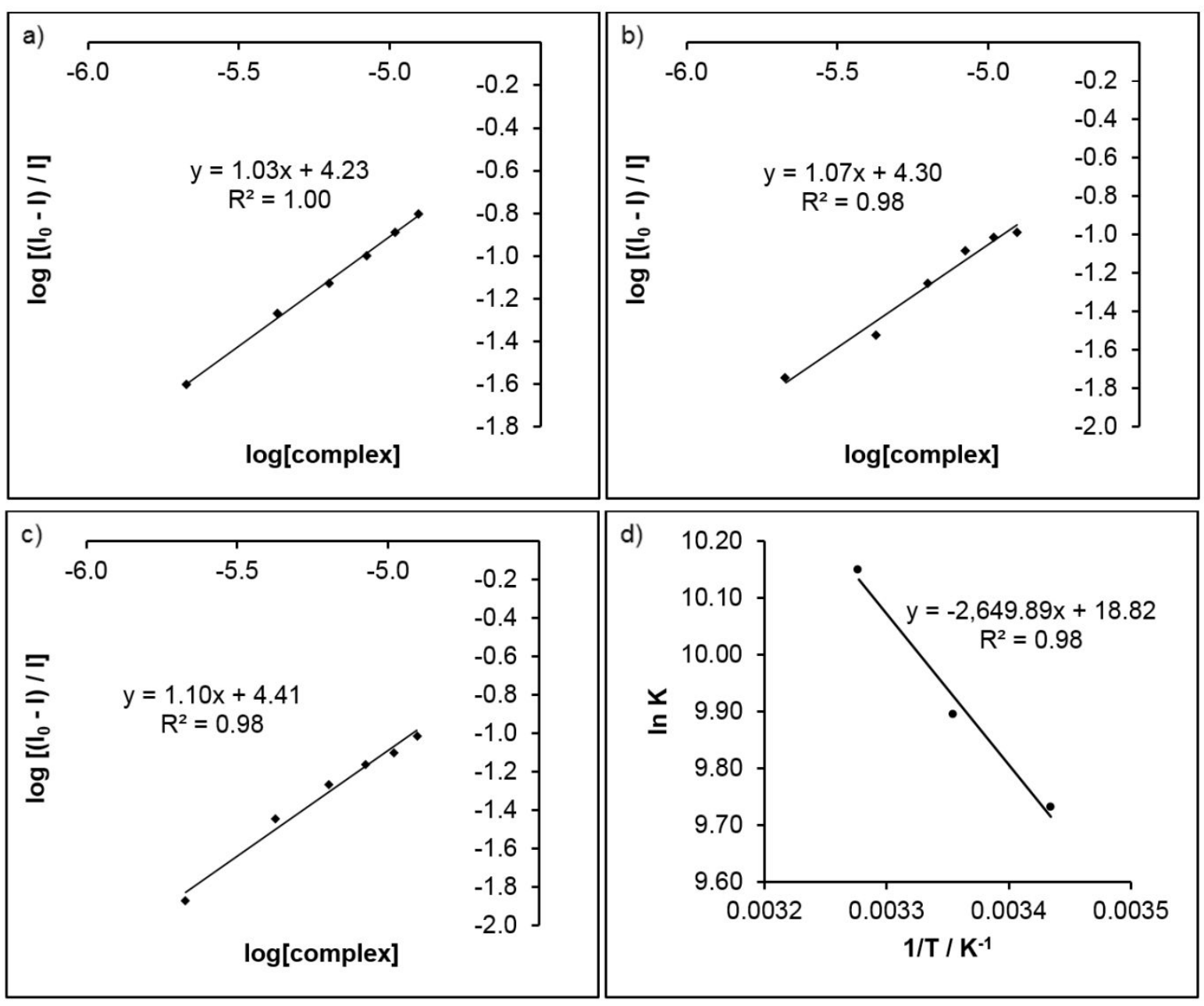

Figure S20. Graphical determination of the binding constant $\left(K_{b}\right)$ and number of binding sites $(n)$ of complex (1) to BSA at three temperatures: a) $291 \mathrm{~K}$, b) $298 \mathrm{~K}$, c) $305 \mathrm{~K}$ and d) van't Hoff plot. 

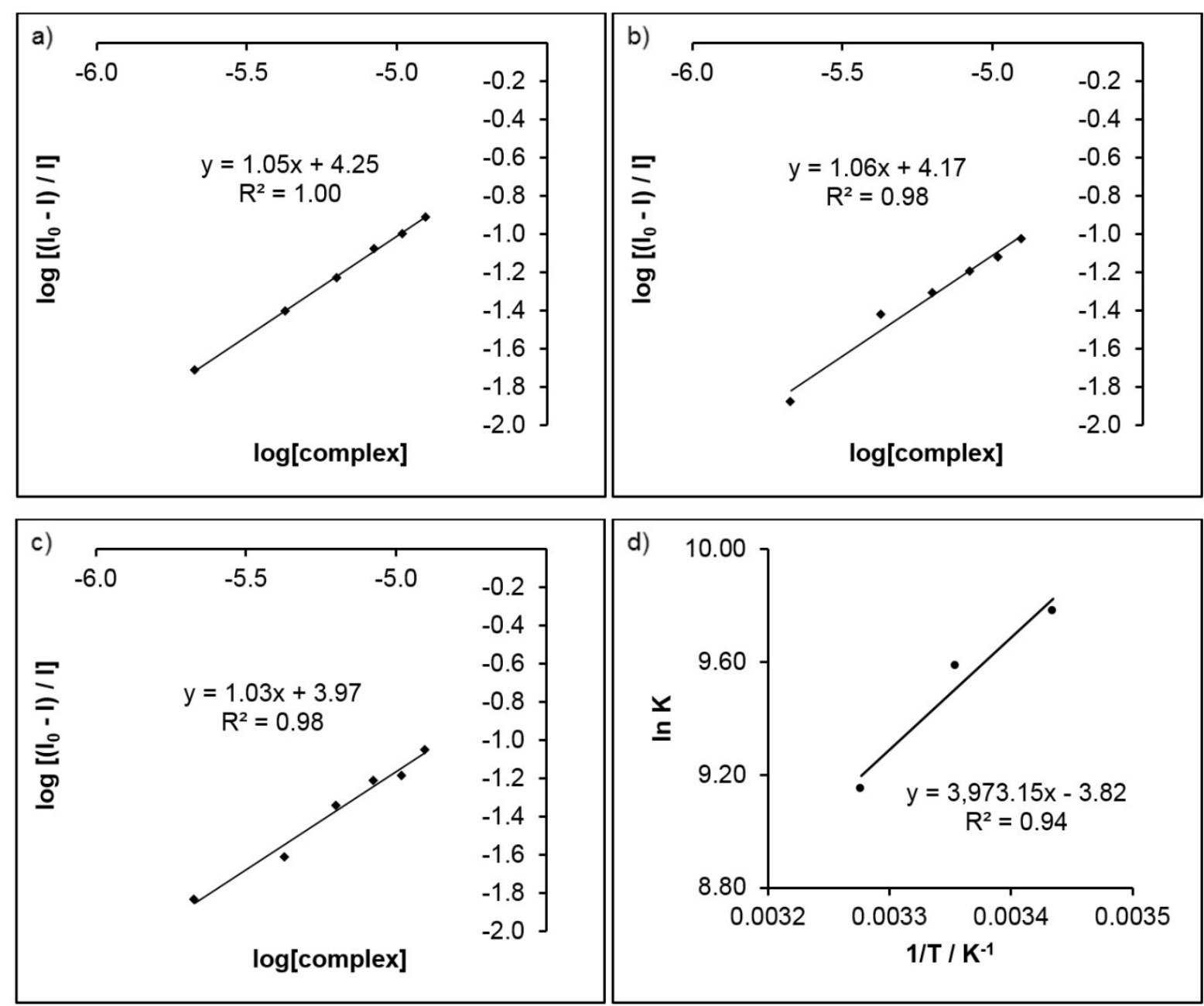

Figure S21. Graphical determination of the binding constant $\left(\mathrm{K}_{\mathrm{b}}\right)$ and number of binding sites $(\mathrm{n})$ of complex (2) to BSA at three temperatures: a) $291 \mathrm{~K}$, b) $298 \mathrm{~K}$, c) $305 \mathrm{~K}$ and d) van't Hoff plot. 

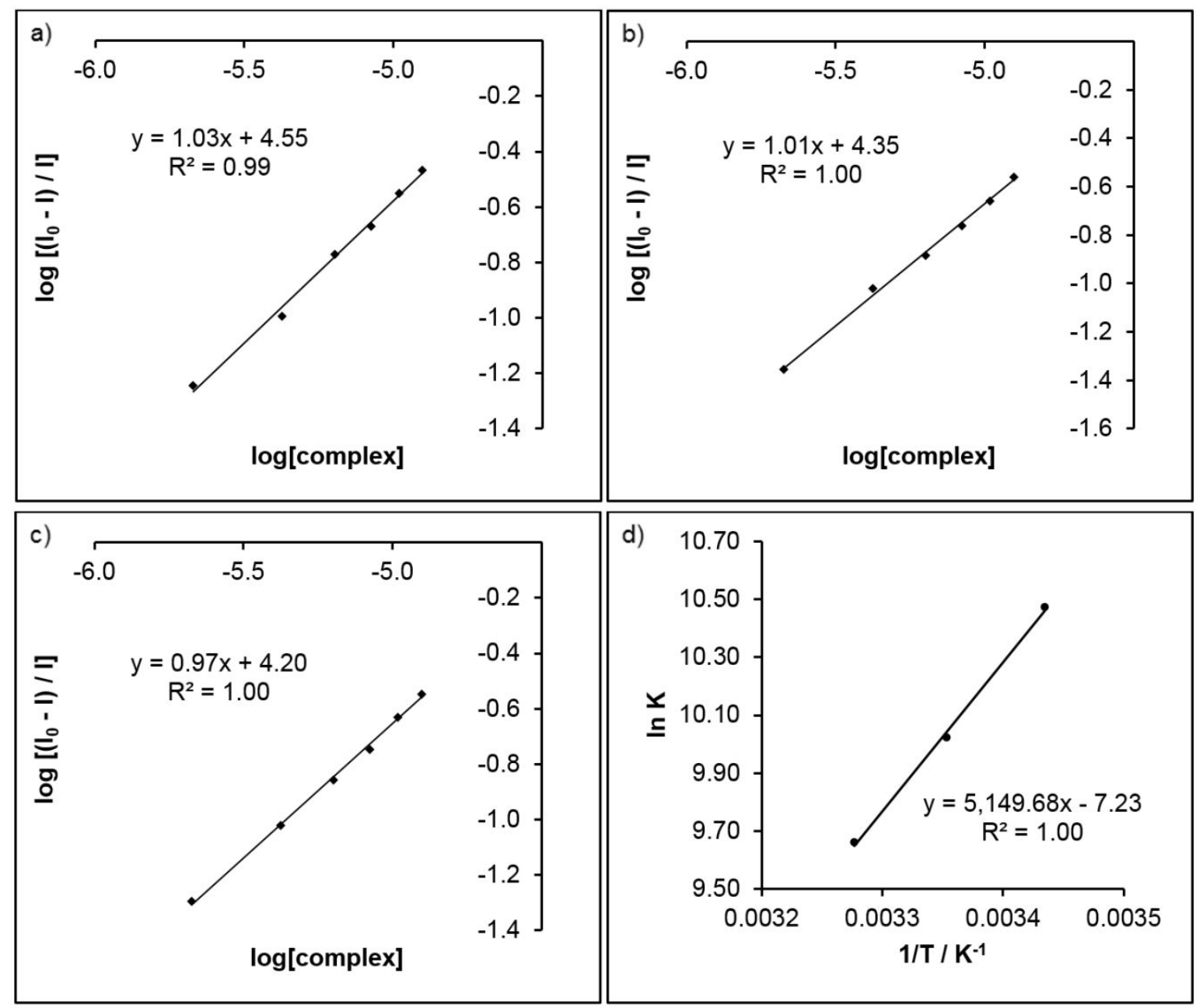

Figure S22. Graphical determination of the binding constant $\left(K_{b}\right)$ and number of binding sites $(n)$ of complex (3) to BSA at three temperatures: a) $291 \mathrm{~K}$, b) $298 \mathrm{~K}$, c) $305 \mathrm{~K}$ and d) van't Hoff plot. 

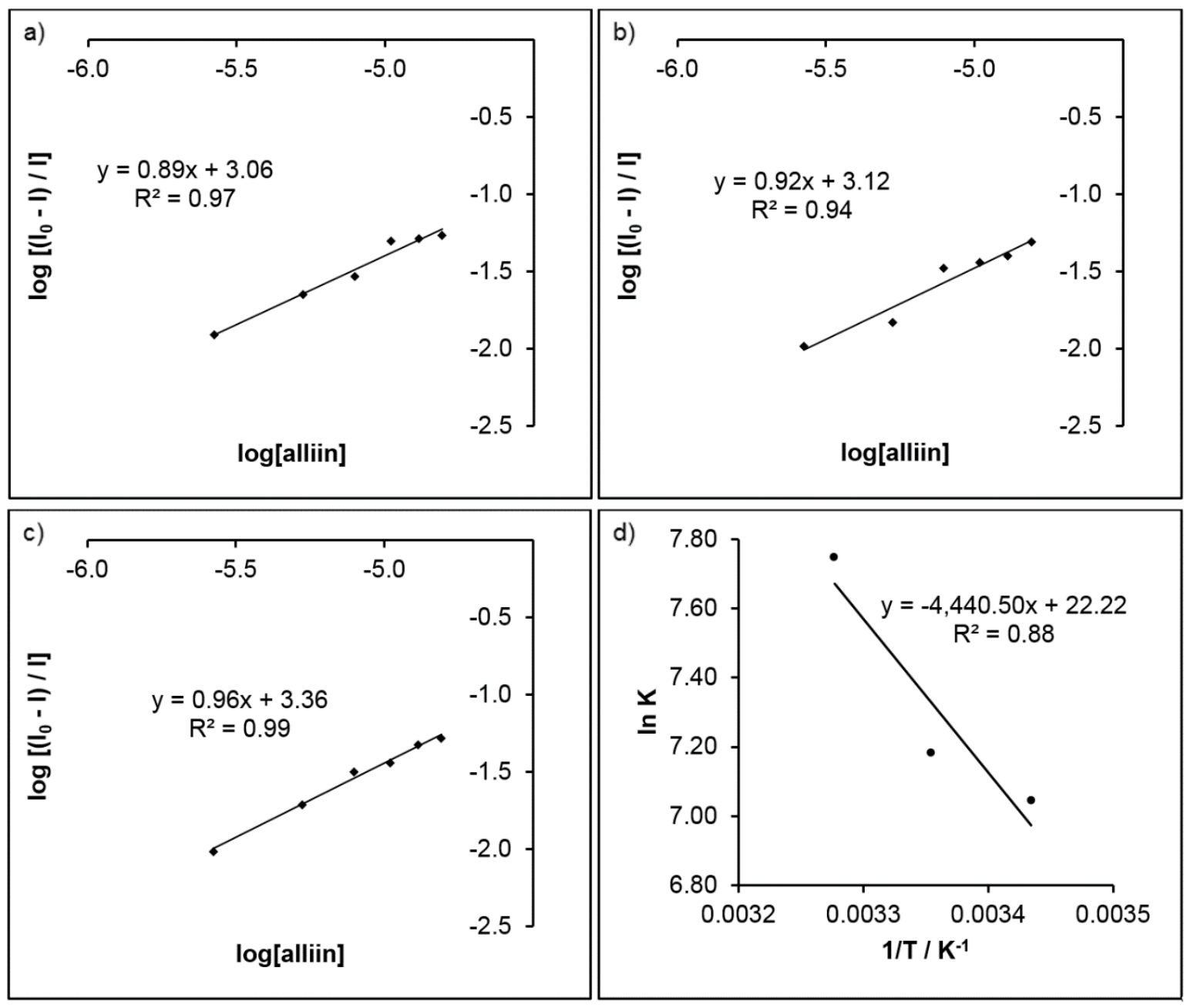

Figure S23. Graphical determination of the binding constant $\left(K_{b}\right)$ and number of binding sites $(n)$ of alliin to BSA at three temperatures: a) $291 \mathrm{~K}$, b) $298 \mathrm{~K}$, c) $305 \mathrm{~K}$ and d) van't Hoff plot. 

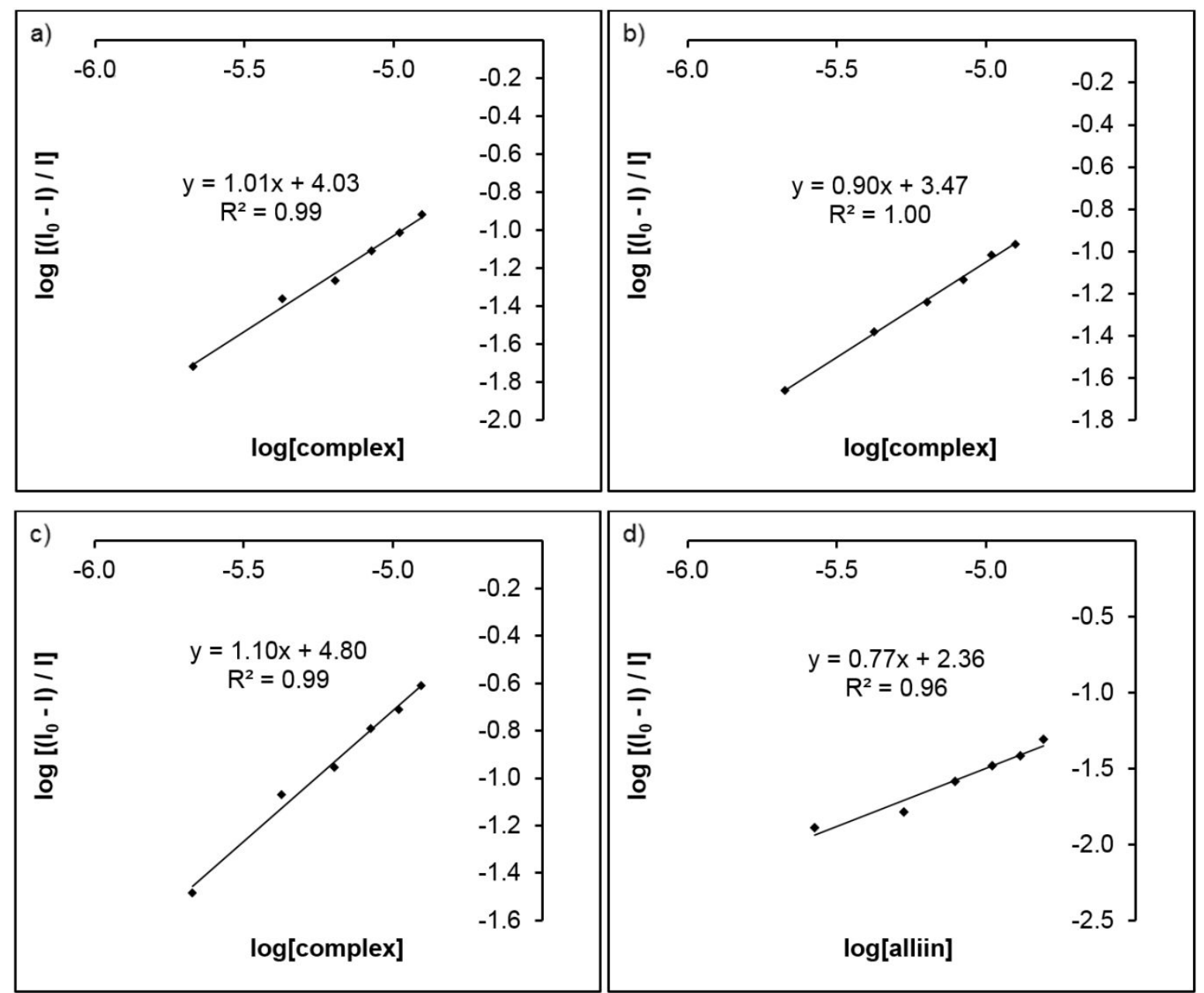

Figure S24. Graphical determination of the binding constant $\left(K_{b}\right)$ and number of binding sites $(n)$ of complexes (1) - (3) $(a-c)$ and alliin (d) with apotransferrin. 
Proliferation assays

The panel cell lines were inoculated onto a series of standard 96-well microtiter plates on day 0 , at 5000 cells per well according to the doubling times of specific cell line. Test agents were then added in five, 10-fold dilutions (0,01 to $100 \mu \mathrm{M})$ and incubated for further 72 hours. Working dilutions were freshly prepared on the day of testing in the growth medium. After 72 hours of incubation, the cell growth rate was evaluated by performing the MTT assay: experimentally determined absorbance values were transformed into a cell percentage growth (PG) using the formulas proposed by NIH. This method directly relies on control cells behaving normally at the day of assay because it compares the growth of treated cells with the growth of untreated cells in control wells on the same plate - the results are therefore a percentile difference from the calculated expected value.

The $\mathrm{IC}_{50}$ values for each compound were calculated from dose-response curves using linear regression analysis by fitting the mean test concentrations that give PG values above and below the reference value. If, however, all of the tested concentrations produce PGs exceeding the respective reference level of effect (e.g. PG value of 50) for a given cell line, the highest tested concentration is assigned as the default value (in the screening data report that default value is preceded by a ">" sign). Each test point was performed in quadruplicate in two individual experiments. The results were statistically analyzed (ANOVA, Tukey post-hoc test at $p<0.05$ ). Finally, the effects of the tested substances were evaluated by plotting the mean percentage growth for each cell type in comparison to control on dose response graphs.

Table S2. $I C_{50}$ values for complexes (1) - (3) and alliin.

\begin{tabular}{cccccc}
\hline \multirow{2}{*}{ Compound } & MCF-7 & CFPAC-1 & HeLa & SW620 & HFF-1 \\
\cline { 2 - 6 } & $>50$ & $\mathrm{IC}_{50} / \mu \mathrm{M}$ & \\
\hline$(\mathbf{1})$ & $>100$ & $>100$ & $>100$ & $>100$ & 0.74 \\
$(\mathbf{2})$ & $>100$ & $>100$ & $>100$ & $>100$ & 0.08 \\
$(\mathbf{3})$ & $>100$ & $>100$ & $33.82^{*}$ & $>100^{*}$ & $89^{*}$ \\
$\mathrm{HL}$ & $>100$ & $>100$ & $>100$ & $>100$ & 19.58 \\
\hline
\end{tabular}

*Unusual growth response curve. 